\title{
UTILIZAÇÃO DA FORMULAÇÃO LIVRE PARA DESENVOLVIMENTO DE UM ELEMENTO DE MEMBRANA COM LIBERDADES ROTACIONAIS.
}

Dissertação apresentada à Escola de Engenharia de São Carlos, da Universidade de São Paulo, como parte dos requisitos para a obtenção do Título de Mestre em Engenharia de Estruturas.

ORIENTADOR: Prof. Dr. Marcio Antonio Ramalho

São Carlos

1996 


\section{Peleteiro, Suzana Campana}

P435u Utilização da formulação livre para desenvolvimento de um elemento de membrana com liberdades rotacionais / Suzana Campana Peleteiro. -- São Carlos, 1996. 101p.

Dissertação (Mestrado) -- Escola de Engenharia de São CarlosUniversidade de São Paulo, 1996.

Orientador: Prof. Dr. Marcio Antonio Ramalho

1. Método dos elementos finitos - Membrana. I. Título. 
Aos meus pais,

Alcibei e Maria Ozilia

e irmãos,

Ubiratan e Guilherme. 


\section{AGRADECIMENTOS}

A todas as pessoas que direta ou indiretamente tornaram possível o desenvolvimento deste trabalho.

Em especial, ao meu orientador, Prof. Marcio Antonio Ramalho, pelo cuidadoso trabalho de orientação, pelo apoio e especialmente pela amizade demonstrada durante a elaboração desta pesquisa.

Ao Prof. Márcio Roberto Silva Corrêa pela colaboração, pelas excelentes sugestões, pelo incentivo e principalmente pela amizade.

As amigas, Tatiana Theophilo Silvany e Edja Laurindo da Silva, pela agradável convivência, pela amizade e apoio demonstrados durante o período de realização desta pesquisa.

Ao Conselho Nacional de Pesquisa Científica - CNPq, pela bolsa de estudos concedida.

A todos os amigos, colegas, professores e funcionários do Departamento de Estruturas da Escola de Engenharia de São Carlos - USP pela amizade e pelo convívio.

Acima de tudo, à DEUS, fonte e sentido de toda nossa vida. 


\section{LISTA DE SÍMBOLOS}

U $\quad$ - vetor do campo de deslocamentos

$\mathbf{N}_{\mathrm{r}} \quad$ - polinômio completo, até o grau que corresponde aos modos rígidos

$\mathbf{N}_{\mathrm{c}} \quad$ - polinômio completo, até o grau que corresponde aos modos de deformação constante

$\mathbf{N}_{\mathrm{S}} \quad$ - conjunto de funções de forma de alta ordem

$\mathbf{q}_{\mathrm{r}}, \mathbf{q}_{\mathrm{c}}, \mathbf{q}_{\mathrm{s}} \quad$ - parâmetros generalizados

G - matriz que relaciona os coeficientes associados com os deslocamentos nodais

- vetor dos deslocamentos nodais

H - inversa de G

K - matriz de rigidez do elemento nas coordenadas locais

$\mathbf{P}_{\mathrm{r}} \quad-$ forças associadas a $\mathrm{q}_{\mathrm{r}}$

$\mathbf{t}_{\mathrm{c}} \quad$ - forças nodais devido à um estado de deformação constante

$\mathbf{P}_{\mathrm{c}} \quad-$ forças associadas a $\mathbf{q}_{\mathrm{c}}$

$\sigma_{\mathrm{c}} \quad-$ vetor das componentes de tensão

L - matriz "amontoadora" (LUMPED)

C - matriz constitutiva

B - matriz dos modos de deformação

$\mathbf{U}_{\mathrm{p}} \quad$ - energia de deformação

$\varepsilon$

- vetor das componentes de deformação

$\mathrm{V}_{\mathrm{I}} \quad$ - volume

$F_{\mathrm{rc}} \quad-$ vetor de forças nodais

E

- módulo de elasticidade longitudinal 
A

$\mathbf{u}$

V

$\xi, \eta$

$\mathbf{U}_{\mathrm{b}}$

$\mathbf{U}_{\mathrm{s}}$

$\mathbf{p}_{\mathrm{c}}$

$\mathbf{D}_{\mathrm{m}}$

$\alpha, \beta$

f

d

$\mathbf{F}$

$\lambda$

$\mathrm{I}, \mathrm{m}, \mathrm{n}$

$\mathbf{R}$

$\mathbf{P}_{\text {I }}$

$\mathbf{P}_{\mathrm{n}}$

$\mathbf{p}_{1}$

$\mathbf{P}_{1}$
- módulo de elasticidade transversal

- coeficiente de Poisson

- área do elemento

- componente do campo de deslocamentos ao longo do eixo $\mathrm{x}$

- componente do campo de deslocamentos ao longo do eixo y

- coordenadas adimensionais

- parte do campo de deslocamentos $U$ referente aos modos básicos

- parte do campo de deslocamentos $U$ referente aos modos de alta ordem

- forças de membrana por unidade de comprimento

- matriz que relaciona as forças de membrana por unidade de comprimento com as deformações

- parâmetros livres

- vetor de forças nodais no sistema local de referência

- vetor de deslocamentos nodais no sistema local de referência vetor de forças nodais no sistema global de referência

matriz de transformação

cosenos diretores

matriz de rigidez nas coordenadas globais

carga distribuída na direção do lado l-J do elemento

carga distribuída na direção normal ao lado I-J do elemento

vetor de cargas nodais correspondente à força de superfície

- atuante na face do elemento, coordenadas locais

vetor de cargas nodais correspondente à força de superfície

- atuante na face do elemento, coordenadas globais 
vetor de cargas nodais correspondente ao peso próprio,

$\mathbf{P}_{2} \quad$ - coordenadas globais 


\section{RESUMO}

PELETEIRO, S.C. Utilização da formulação livre para desenvolvimento de um elemento de membrana com liberdades rotacionais. São Carlos, 1996.101p. Dissertação (Mestrado) - Escola de Engenharia de São Carlos, Universidade de São Paulo.

Neste trabalho aborda-se o desenvolvimento de um elemento finito de membrana com graus de liberdade rotacionais e sua implementação a um sistema computacional em elementos finitos. O trabalho é baseado na formulação livre de BERGAN \& NYGARD (1984) que produz um elemento simples e de bom desempenho. Aspectos fundamentais da formulação livre, do desenvolvimento do elemento e sua implementação ao sistema são apresentados. Resultados obtidos em alguns exemplos comprovam a eficiência do procedimento.

Palavras-chave: Elemento finito - membrana; Formulação livre; Graus de liberdade rotacionais. 


\begin{abstract}
PELETEIRO, S.C. Use of free formulation to the development of a membrane element with rotational degrees of freedom. São Carlos, 1996.101p. Dissertação (Mestrado) - Escola de Engenharia de São Carlos, Universidade de São Paulo.

In this work the formulation of a membrane finite element with rotational degrees of freedom and its implementation to a finite element computacional system is presented. The development is based on the free formulation of BERGAN \& NYGARD (1984) that produce a simple and efficient element. Fundamental aspects of the free formulation, of the element evaluation and its implementation to the system are shown. The results obtained in some examples indicate the accuracy of the procedure.
\end{abstract}

Keywords: Finite Element - membrane; Free Formulation; Rotational degrees of freedom. 


\section{CAPÍTULO I INTRODUÇÃO}

\subsection{GENERALIDADES}

Existe um grande número de estruturas de interesse prático para as quais se pode fazer uso das hipóteses da elasticidade bidimensional. A análise desses problemas ocupa um lugar de destaque nos primeiros desenvolvimentos do método dos elementos finitos. Com o decorrer do tempo, os elementos foram sendo aperfeiçoados, com o intuito de se melhorar cada vez mais a sua performance.

Muitos problemas na área da engenharia de estruturas envolvem os elementos estruturais de cascas e é notória a complexidade matemática de tais problemas nos casos reais, que quase sempre é representado por aproximações de problemas teóricos de solução matematicamente viável na mecânica do contínuo. Alguns exemplos de estruturas que envolvem este tipo de problema são: silos, tanques, túneis, vasos de pressão, cascos de embarcações, tubulações, chaminés, coberturas, reservatórios enterrados, abrigos subterrâneos, etc. Para a análise dessas estruturas pode-se fazer uso dos procedimentos do método dos elementos finitos implementados computacionalmente. Uma maneira bastante atraente para se analisar cascas é a utilização de dois elementos finitos planos, um de placa e um de membrana, que superpostos representem de maneira satisfatória o comportamento real da estrutura. 
Da necessidade de se modelar convenientemente o problema estrutural apresentado surgiu o interesse pelo elemento de membrana que incorpora, além das duas translações por nó em seu plano, uma rotação em torno do eixo perpendicular a esse plano. O elemento de membrana com liberdades rotacionais se apresenta extremamente atraente para a análise de cascas pelo método dos elementos finitos, acoplado a um elemento de placa. A introdução das rotações, e da rigidez correspondente, evita o problema de singularidade que surge quando se trabalha com elementos de casca coplanares e aproximadamente coplanares constituídas de um elemento de membrana que não possui os graus de liberdade relacionados.

\subsection{OBJETIVO}

O objetivo do presente trabalho é a viabilização da utilização prática de um novo elemento que possui graus de liberdade adicionais: rotações segundo eixos normais ao seu plano. Com esse trabalho pretende-se demonstrar que uma formulação invariante pode ser construída pelo uso da definição de rotações no meio contínuo, ao invés de se usar o conceito geométrico, mais intuitivo, para as rotações nas quinas.

No presente trabalho utiliza-se a formulação livre, sugerida pela primeira vez por BERGAN \& NYGARD (1984), que se mostra relativamente simples, pois a única imposição necessária nos modos de deslocamento é que eles devem conter os modos de deformação fundamentais: corpo rígido e deformação constante. Tais modos de deformação devem ser linearmente independentes entre si.

\subsection{HISTÓRICO}


Os primeiros modelos, para estado plano de tensão/deformação, desenvolvidos para o método dos elementos finitos, foram os elementos com translações livres nos nós. As primeiras experiências computacionais foram com elementos bilineares, elementos em que as funções de forma são o produto de dois polinômios lineares. Esses elementos são bastante simples, mas excessivamente rígidos para problemas em que os resultados são muito influenciados pelos esforços de flexão.

Na figura 1.1a tem-se um exemplo de elemento bilinear retangular. A figura 1.1b mostra o comportamento do elemento deformado sob a ação de um momento $\mathrm{M} 1$, supondo-se apenas translações nos nós, nota-se que não existe flexão dos lados dos elementos que permanecem retos. A figura 1.1c ilustra uma deformação mais coerente do elemento quando sob a ação de um momento M1. Como podemos observar no caso da figura 1.1b, o modelo não representa o comportamento de um elemento numa estrutura real. Para que os resultados obtidos por essa análise sejam mais verossímeis é preciso refinar muito a malha utilizada, até que o modelo possa representar de maneira satisfatória o comportamento da estrutura.

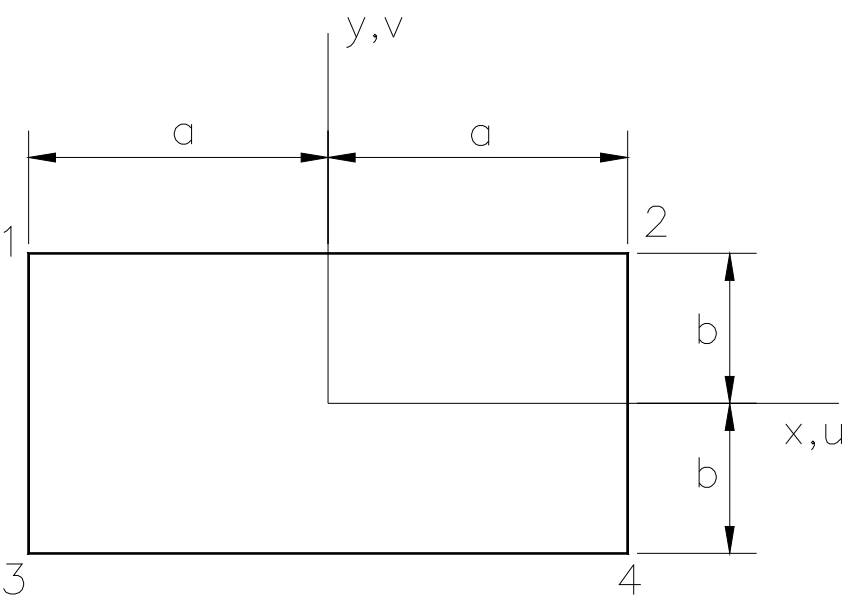

FIGURA 1.1a - Elemento Bilinear Retangular 


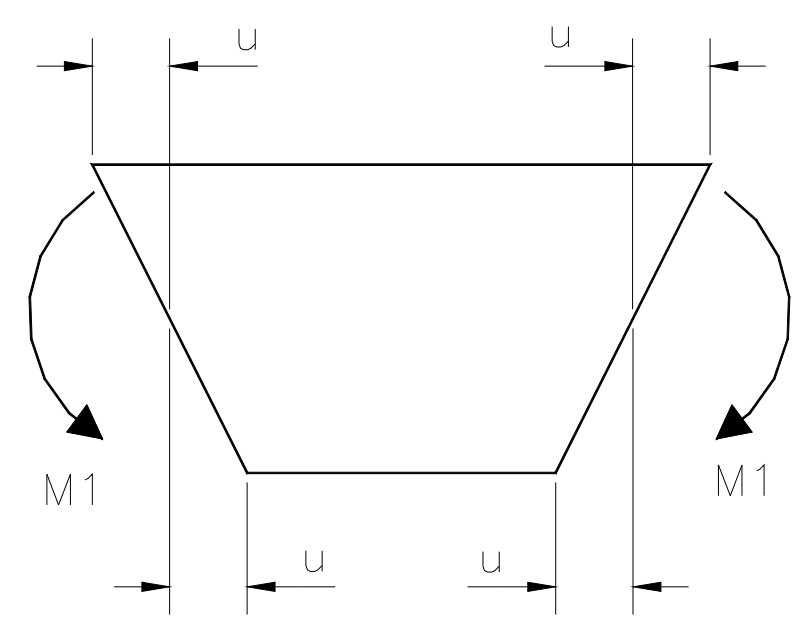

FIGURA 1.1b - Deformação do elemento sob a ação de um momento M1

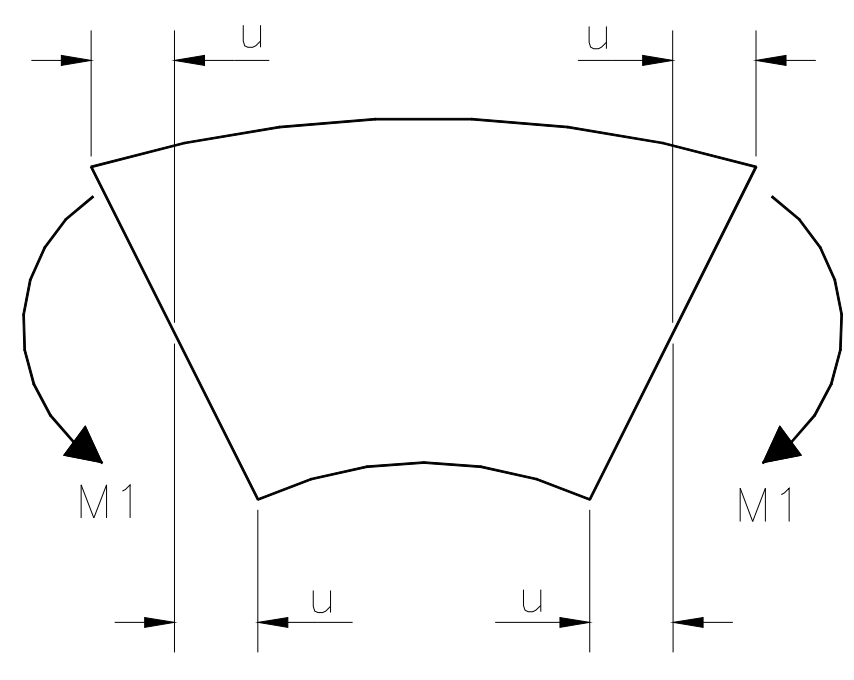

FIGURA 1.1c - Deformação mais verossímil do elemento devido a um momento M1

Entre os primeiros elementos desenvolvidos temos o triângulo linear, no qual utiliza-se uma aproximação linear para o campo de deslocamentos, e o retângulo bilinear que foram apresentados por TURNER et al (1956), e o quadrilátero geral bilinear apresentado por TAIG \& KERR (1964). Todos foram extensivamente usados para modelagem de estado plano de tensão/deformação e como componente de membrana na análise de estruturas de casca. 
O elemento triangular com aproximação quadrática para o campo de deslocamentos é reconhecido por produzir melhores resultados para os deslocamentos e tensões. A distribuição de tensões obtida através do seu uso é uma aproximação melhor do que a distribuição de tensões obtida com a utilização de elementos com aproximação linear para os deslocamentos. Entretanto esse melhor desempenho faz com que o número total de parâmetros se torne maior, já que estamos trabalhando com modos de deslocamento quadráticos ao invés de lineares. Com isso a implementação computacional se torna mais trabalhosa e o tempo de processamento aumenta.

Com o intuito de melhorar o desempenho desses elementos de membrana, diversos autores começaram a desenvolver formulações que pudessem modelar de maneira mais eficiente o estado plano de tensões. Uma das maneiras de se conseguir um melhor desempenho do elemento é a adição de graus de liberdade extras nos meios dos lados do elemento. Deslocamentos de alta ordem são relacionados às translações dos pontos médios dos nós. Atualmente os elementos mais populares desse tipo são os Lagrangianos com 8 e 9 pontos nodais.

Uma outra maneira de melhorar o desempenho de tais elementos é a inclusão das rotações em torno de eixos perpendiculares ao plano dos mesmos, intermediário aos elementos anteriores, tanto em número de graus de liberdade quanto em precisão. Este tipo de abordagem se apresenta bastante atraente. Muitas tentativas de se desenvolver elementos de membrana com liberdades rotacionais adicionais foram feitas, mas só obtiveram sucessos parciais. A formulação de elementos invariantes e convergentes para geometria arbitrária provou ser particularmente difícil. Esses fatos fizeram com que alguns autores desaconselhassem 0 desenvolvimento de tais elementos. 
WILLIAM (1969) derivou dois elementos quadrilaterais de membrana com 12 e 16 graus de liberdade. Em adição às 8 translações, o elemento com 12 graus de liberdade tem 4 rotações. A formulação usa a média das rotações do elemento e recai em funções de forma de viga associadas com as rotações dos extremos. Ambos os elementos são não-conformes, a compatibilidade interelemental não é satisfeita ao longo de todo o contorno dos elementos, mas prevalece apenas nos nós. Essa incompatibilidade tende a zero, na medida em que a rede é refinada.

Experiências indicam que o desempenho é variável, com bons resultados geralmente associados a malhas retangulares regulares. William, de fato, notou que a formulação do elemento não é invariante com respeito ao sistema de coordenadas de referência. Pode-se demonstrar que não existe uma relação única entre a rotação $\theta_{z}$ e os giros dos lados dos elementos adjacentes, descumprindo-se, portanto, os requisitos de continuidade $\mathrm{C}^{\circ}$.

Mais ou menos na mesma época, FELIPPA (1966) e CARR (1967) desenvolveram uma formulação para elemento triangular, iniciada com 20 graus de liberdade, 10 nós e expansão cúbica completa para triângulo em estado plano de tensões. Doze liberdades são colocadas nos pontos médios ao longo dos lados do elemento e expressos pelos 4 gradientes de deslocamento: $\partial u / \partial x, \partial u / \partial y, \partial v / \partial x$ e $\partial v / \partial y$, de cada canto. Um desenvolvimento similar para um triângulo de alta ordem foi documentado por BERGAN (1967). TOCHER \& HARTZ (1967) mostraram um hiperconforme triângulo em estado plano de tensões com derivadas de deslocamentos baseadas em funções de forma conformes $C^{1}$.

Esses elementos podem apresentar bons resultados na mão de especialistas, mas não são recomendados para programas de uso geral e prático. IRONS \& AHMAD (1981) concluíram que a implementação de rotações livres era inviável e seria um trabalho infrutífero. De fato, o 
elemento foi esquecido durante os anos 70, e em publicações mais recentes voltou a ser discutido, com alguns autores apresentando soluções para o problema.

Diversos autores sugerem modelar o estado plano de tensões utilizando-se elementos especiais em que se incorpora como terceira variável nodal um giro, $\theta_{z}$, no plano do elemento. O problema essencial desses elementos é que a definição de $\theta_{z}$ não é invariante com respeito ao sistema de coordenadas de referência, podendo-se demonstrar que não existe uma relação única entre $\theta_{z}$ e os giros dos lados dos elementos adjacentes, descumprindo-se, portanto, os requisitos de continuidade $\mathrm{C}^{0}$.

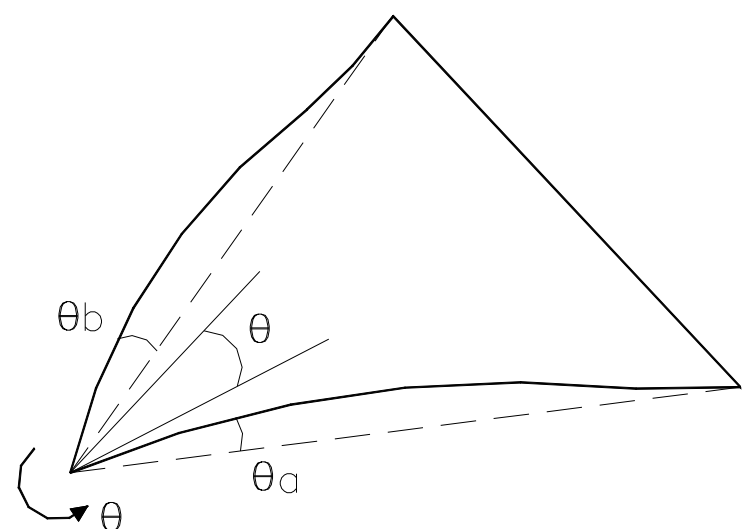

FIGURA 1.2 - Interpretação da rotação como média das rotações dos lados do elemento

Alguns pesquisadores que estudaram elementos de membrana com graus de liberdade rotacionais tradicionalmente consideraram as rotações como médias das rotações, $\theta \mathrm{a}$ e $\theta \mathrm{b}$, dos lados concorrentes ao vértice figura 1.2. No elemento simplificado discutido por WILLIAM (1969) e por ALMROTH \& BROGAN (1981) foi assumido que tanto $\theta$ a quanto $\theta b$ são iguais a rotação média $\theta$. Como essa hipótese elimina a possibilidade de distorções, uma versão alternativa foi proposta por WILLIAM (1969) na qual distorções por cisalhamento são introduzidas. Infelizmente isso destrói a invariância da formulação. 
Essas dificuldades de se relacionar as rotações dos nós com as rotações dos lados do elemento foram claramente ilustradas por IRONS \& AHMAD (1981). Mas essas dificuldades não impedem que se utilize a definição de rotação para meios contínuos:

$\theta_{z}=\frac{1}{2} \cdot\left(\frac{\partial \mathbf{v}}{\partial x}-\frac{\partial u}{\partial y}\right)$

que é independente com relação a adoção de $\mathrm{x}$ e y. A condição de invariância faz com que a condição $\theta=\theta_{z}$ possa ser introduzida mesmo se os elementos que se encontram em um nó forem referenciados a sistemas de coordenadas diferentes. Mas, é importante notar que $\theta_{z}$ não está diretamente relacionado com a rotação dos lados do elemento.

O primeiro elemento triangular com rotações livres que apresentou um bom desempenho foi desenvolvido por ALLMAN (1984). Allman apresentou uma alternativa simples para a formulação do elemento, baseada no princípio da mínima energia potencial, que combina as melhores propriedades dos elementos com aproximação linear e dos elementos com aproximação quadrática: deslocamentos quadráticos compatíveis com graus de liberdade apenas nos vértices dos triângulos. O elemento original de Allman apresentava alguns problemas, como "deficiência de posto da matriz" (rank deficiency), que foram corrigidos numa versão publicada em 1988. O elemento é não-conforme.

Em 1985 BERGAN \& FELIPPA desenvolveram um novo elemento, também não-conforme, mas partindo da formulação livre, sugerida pela primeira vez por BERGAN \& NYGARD (1984). A base da formulação é encontrar elementos que ao interagir com elementos adjacentes possam representar um campo de deslocamentos arbitrário de corpo rígido ou de deformação constante. 
A partir daí, o interesse por essa formulação cresceu muito e vários pesquisadores passaram a se dedicar ao estudo de novas maneiras de se desenvolver o elemento com liberdades rotacionais.

COOK (1987) desenvolveu um elemento triangular de membrana com liberdades rotacionais obtido a partir da formulação híbrida. A desvantagem desse elemento, e do elemento desenvolvido por ALLMAN (1984), é que pode-se ter um mecanismo no qual todas as rotações nodais da rede tenham o mesmo valor. Esse mecanismo pode ser evitado impondo-se uma rotação da rede igual a zero.

Em 1990, IBRAHIMBEGOVIC apresentou um elemento de membrana quadrilateral que possui, além das translações, rotações em seu plano. Uma aproximação não convencional é usada para o campo de deslocamentos combinado com uma aproximação independente das rotações. O elemento apresentou bons resultados tanto para redes de forma regular quanto para irregular. Ibrahimbegovic combinou o elemento com o elemento de placa DKQ desenvolvido por BATOZ \& TAHAR (1982) e obteve um performance muito boa para análise de cascas.

SZE et al (1992) apresentaram um elemento quadrilateral de membrana com liberdades rotacionais utilizando modos de tensão ortogonais. O elemento foi desenvolvido baseado na aproximação de ALLMAN (1984) e apresentou bons resultados quando comparado com outros elementos quadrilaterais já desenvolvidos.

CHEN (1992) publicou um trabalho no qual fez uma análise crítica da performance do elemento desenvolvido por Allman, quando combinado com um elemento de placa para análise de cascas. Chen utilizou uma integração reduzida uniforme no elemento para melhorar o seu desempenho e a comparou com o uso da integração convencional. 
HUGHES et al (1995) desenvolveram outros elementos de membrana com liberdades rotacionais, triangular e quadrilateral, introduzindo uma formulação variacional modificada para incorporar os campos de rotações independentes. Modos incompatíveis são incorporados na formulação para a obtenção de elementos finitos quadrilaterais com quatro nós bastante eficientes. Eles afirmam que um elemento de membrana padrão qualquer pode ser implementado com as liberdades rotacionais, utilizando-se a metodologia por eles apresentada. Para demonstrar são formulados uma família de elementos triangulares e quadrilaterais com modos incompatíveis.

Nesse trabalho optou-se pela utilização do elemento de membrana desenvolvido por BERGAN \& FELIPPA (1985), que por se basear na formulação livre se apresenta relativamente simples e produz resultados muito bons.

\subsection{ORGANIZAÇÃO DO TRABALHO}

O trabalho está organizado em sete capítulos. Cada capítulo trata de um assunto a ser abordado, de modo que as informações e formulações possam ser apresentadas de forma clara e organizada.

No primeiro capítulo apresenta-se um histórico sobre a evolução de elementos finitos para estado plano de tensão/deformação, com os principais desenvolvimentos e os resultados obtidos.

No segundo capítulo apresenta-se as noções básicas da formulação livre, em que foi baseado o elemento aqui utilizado. 
No terceiro capítulo faz-se um resumo da teoria da elasticidade para estado plano de tensão e se apresenta a formulação do elemento de membrana e a obtenção da sua matriz de rigidez.

O quarto capítulo é dedicado à implementação computacional do elemento a um sistema computacional de elementos finitos (LASER - 1990). Apresenta a sub-rotina desenvolvida, as características do sistema LASER e a maneira como foram compatibilizados.

No quinto capítulo são apresentados os resultados obtidos com 0 elemento desenvolvido para exemplos clássicos, comparados com resultados de outros elementos já conhecidos e de eficiência comprovada.

O sexto capítulo traz as conclusões gerais do trabalho, uma discussão sobre a sua eficiência e sugestões para o prosseguimento da pesquisa nessa área.

No sétimo capítulo têm-se as referências bibliográficas. 


\section{CAPÍTULO II \\ A FORMULAÇÃO}

\subsection{INTRODUÇÃO}

O método dos elementos finitos é um processo numérico para se resolver problemas de um meio contínuo. Os elementos podem ser formulados utilizando-se várias técnicas, como por exemplo: princípio dos trabalhos virtuais, energia potencial, energia potencial complementar, princípios variacionais, etc. Uma alternativa proposta por BERGAN \& NYGARD (1984) é a formulação livre. Essa formulação é baseada no teste do elemento individual proposto por BERGAN \& HANSSEN (1976). Uma vantagem significativa da formulação livre é que através do uso de funções não-conformes de deslocamento, se permite o desenvolvimento de uma nova família de elementos, com convergência garantida e implementação simples e eficiente.

A performance de um elemento finito depende, primeiramente, da função de deslocamento escolhida. Mas, independentemente das funções de forma adotadas, é necessário garantir a convergência dos resultados com um refinamento adequado da rede. Não se pode ter confiança em um elemento que apresente bons resultados para um problema em particular e para outros não. Para que o elemento apresente confiabilidade ele precisa ter a convergência garantida, à medida que a rede vai sendo refinada. Entretanto, se nada é conhecido a respeito das propriedades de convergência do elemento, os resultados obtidos não serão confiáveis. 
Para ter a convergência assegurada, o elemento precisa satisfazer as seguintes condições, com relação à função de deslocamentos:

A ) Não devem ocorrer deformações em um elemento quando o domínio discretizado estiver submetido a deslocamentos de corpo rígido.

B ) Se os deslocamentos nodais impostos forem compatíveis com um estado de deformações constantes, deve-se obter realmente o referido estado.

C ) As deformações resultantes nas faces de elementos adjacentes devem ser finitas. Esse critério impõe a continuidade de deslocamentos entre elementos. Se as deformações são definidas pelas primeiras derivadas, só precisa haver continuidade de deslocamentos. Se as deformações são definidas pelas derivadas segundas, as derivadas primeiras também precisam ser contínuas.

\subsection{NOÇÕES BÁSICAS - TESTE DO ELEMENTO INDIVIDUAL}

Devido à dificuldade de se obter funções de deslocamentos que sejam contínuas nas faces adjacentes dos elementos, IRONS et al (1965) propôs o patch-test. De acordo com Irons, o patch-test é um procedimento para verificar se o elemento, incluindo seus contornos, não produz ou perde energia durante um estado de deformação constante.

Quando estamos trabalhando com um elemento não-conforme, a descontinuidade dos deslocamentos nas faces entre elementos adjacentes pode causar o aparecimento de deformações infinitas nas mesmas. Apesar 
disso, no limite, quando o tamanho do elemento vai se reduzindo, a continuidade de deslocamento pode ser recuperada, e a formulação obtida tenderá para a solução correta. O patch-test é utilizado para testar essa continuidade e se mostra como uma ferramenta muito importante quando se trata do desenvolvimento de elementos finitos não-conformes. Uma das maneiras de se aplicar o patch-test é impor deslocamentos nodais correspondentes a um estado de deformação constante. Se o equilíbrio nodal for obtido sem que haja a necessidade de impor forças externas, e se o estado de deformação constante aplicado for obtido, isso implica que nenhum trabalho externo é perdido devido à descontinuidade entre elementos. Elementos não-conformes que satisfaçam ao patch-test irão convergir, e em alguns casos apresentam uma performance superior aos elementos conformes. A aplicação do patch-test envolve a análise de várias configurações para um mesmo elemento, podendo ser atendido para determinada configuração e para outra não.

Como a aplicação do patch-test se apresenta bastante trabalhosa, BERGAN \& HANSSEN (1976) e BERGAN (1980) propuseram uma nova maneira de se testar a convergência do elemento: o teste do elemento individual. Como o próprio nome já indica, o teste é aplicado em um único elemento. A grande vantagem desse teste é o fato de se poder utilizar seu conceito durante a formulação da matriz de rigidez do elemento. Dessa forma, uma das condições de convergência do elemento já fica automaticamente garantida pela própria formulação.

De acordo com BERGAN \& HANSSEN (1976) o conceito básico do teste é que o elemento, quando interagindo com seus vizinhos, deve ser capaz de reproduzir identicamente um estado arbitrário de corpo rígido e deformação constante. Essa exigência é uma consequência da condição limite de convergência, quando os elementos se tornam infinitesimais e a deformação de cada elemento aproxima-se de um valor constante. Durante 
tal estado, as forças entre elementos transferidas para os nós devem se cancelar aos pares, o que faz com que o patch-test esteja automaticamente atendido. $\mathrm{O}$ teste do elemento individual nada mais é do que um conjunto de equações lineares, para a matriz de rigidez do elemento, que representem as condições impostas.

O teste do elemento individual é a base da formulação livre desenvolvida por BERGAN \& NYGARD (1984). Também representa uma ferramenta muito importante no desenvolvimento de elementos finitos de alta performance. A formulação livre utiliza-se de modos de deslocamentos cujos únicos pré-requisitos são que eles precisam incluir os modos básicos de deformação (corpo rígido e deformação constante) e serem linearmente independentes, para permitir a determinação dos parâmetros generalizados em função dos parâmetros nodais. Uma grande vantagem da formulação livre é que sua utilização permite o uso de funções não-conformes para os deslocamentos e apresenta-se como uma alternativa bastante segura e eficiente no desenvolvimento de elementos de ótimo desempenho.

O campo de deslocamentos no domínio de um elemento pode ser aproximado por:

$\mathrm{U}=\mathrm{N}_{\mathrm{r}} \cdot \mathrm{q}_{\mathrm{r}}+\mathrm{N}_{\mathrm{c}} \cdot \mathrm{q}_{\mathrm{c}}+\mathrm{N}_{\mathrm{s}} \cdot \mathrm{q}_{\mathrm{s}}$

onde $\mathbf{N}_{\mathrm{r}}$ e $\mathbf{N}_{\mathrm{c}}$ representam um polinômio completo, até o grau que corresponde aos modos rígidos e de deformação constante, linearmente independentes, e $\mathbf{q}_{\mathrm{r}}$ e $\mathbf{q}_{\mathrm{c}}$ são os coeficientes associados (parâmetros generalizados). $\mathbf{N}_{s}$ representa um conjunto de funções de forma de alta ordem e $\mathbf{q}_{\mathrm{s}}$ são seus coeficientes associados. A relação entre esses coeficientes e os deslocamentos nodais do elemento, agrupados em um vetor $\mathbf{V}$, é dada pela transformação: 
$\mathbf{V}=\mathbf{G} \cdot \mathbf{q}=\mathbf{G}_{\mathbf{r}} \cdot \mathbf{q}_{\mathbf{r}}+\mathbf{G}_{\mathbf{c}} \cdot \mathbf{q}_{\mathbf{c}}+\mathbf{G}_{\mathbf{s}} \cdot \mathbf{q}_{\mathbf{s}}$

onde a matriz $\mathbf{G}$ é facilmente obtida particularizando-se a equação 2.1, através da substituição das coordenadas nodais. G é uma matriz quadrada nxn, onde n é o número de graus de liberdade do elemento.

O conjunto total dos modos precisa ser linearmente independente com respeito aos parâmetros nodais de deslocamento. Se esta condição for atendida, G é uma matriz não singular e a equação 2.2 pode ser invertida:

$\mathbf{q}=\left\{\begin{array}{l}\mathbf{q}_{\mathrm{rc}} \\ \mathbf{q}_{\mathrm{s}}\end{array}\right\}=\mathbf{G}^{-1} \cdot \mathrm{V}=\mathrm{H} \cdot \mathbf{V}=\left[\begin{array}{l}\mathrm{H}_{\mathrm{rc}} \\ \mathrm{H}_{\mathrm{s}}\end{array}\right] \cdot \mathrm{V}$

As sub-matrizes das equações 2.2 e 2.3 claramente satisfazem às seguintes condições:

$H_{\mathrm{rc}} \cdot \mathbf{G}_{\mathrm{rc}}=\mathbf{I}$

$\mathbf{H}_{\mathrm{s}} \cdot \mathbf{G}_{\mathrm{s}}=\mathbf{I}$

$\mathrm{H}_{\mathrm{rc}} \cdot \mathrm{G}_{\mathrm{s}}=\mathbf{0}$

$H_{s} \cdot G_{r c}=0$

A primeira parte do teste do elemento individual requer que a matriz de rigidez do elemento, $\mathbf{K}$, não produza forças nodais num estado de deslocamento de corpo rígido, logo é preciso que:

$\mathbf{K} \cdot \mathbf{G}_{\mathrm{r}} \cdot \mathbf{q}_{\mathrm{r}}=\mathbf{P}_{\mathrm{r}} \cdot \mathbf{q}_{\mathrm{r}}=\mathbf{0}$

onde $\mathbf{P}_{\mathrm{r}}$ são as forças generalizadas associadas a $\mathbf{q}_{\mathbf{r}}$. Desde que o valor de $\mathbf{q}_{\mathrm{r}}$ é qualquer, concluí-se que:

$\mathbf{K} \cdot \mathbf{G}_{\mathrm{r}}=\mathbf{P}_{\mathrm{r}}=\mathbf{0}$ 
Por outro lado, quando um estado arbitrário de deformação constante é imposto aparecem tensões no contorno do elemento, como mostra a figura 2.1. Essas tensões podem ser transferidas para os pontos nodais, onde teremos então forças concentradas $\mathbf{t}_{\mathrm{c}}$. As tensões são iguais e contrárias para dois elementos vizinhos. Fica claro que em um estado de deformação constante, se transformarmos as tensões ao longo dessa face em contribuições no vetor de forças nodais, estas se cancelarão aos pares. Com isso, o patch-test será atendido.

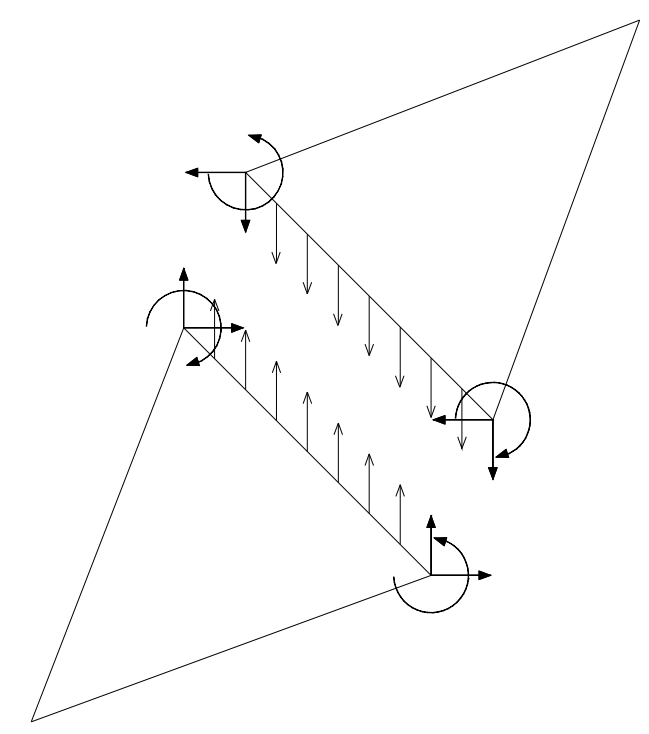

FIGURA 2.1 - Contribuição no vetor de forças nodais

Essa condição pode ser imposta através da seguinte equação:

$K \cdot G_{c} \cdot q_{c}=t_{c}=P_{c} \cdot q_{c}$

onde $\mathbf{P}_{\mathrm{c}}$ são as forças generalizadas correspondentes a $\mathbf{q}_{\mathrm{c}}$. Desde que essa equação deve ser satisfeita para qualquer valor de $\mathbf{q}_{\mathrm{c}}$, obtém-se:

$\mathbf{K} \cdot \mathbf{G}_{\mathrm{c}}=\mathbf{P}_{\mathrm{c}}$ 
As equações 2.6 e 2.8 representam o teste do elemento individual, e podem ser expressas em conjunto como:

$\mathbf{K} \cdot \mathbf{G}_{\mathrm{rc}}=\mathbf{P}_{\mathrm{rc}}$

Mostra-se ser possível representar as forças nodais do elemento, $\mathbf{t}_{\mathrm{c}}$, produzidas pelos modos de deformação constante da seguinte maneira:

$\mathbf{t}_{\mathrm{c}}=\mathrm{L} \cdot \sigma_{\mathrm{c}}$

onde $\sigma_{c}$ é formado pelas componentes de tensão constante. Supondo que as propriedades do material não variam ao longo do elemento, esse estado de tensão pode ser determinado utilizando-se a matriz constitutiva $\mathbf{C}$ e a matriz dos modos de deformação $\mathbf{B}_{c}$, correspondente aos modos $\mathbf{N}_{c}$, de acordo com a equação:

$\sigma_{\mathrm{c}}=\mathbf{C} \cdot \mathbf{B}_{\mathrm{c}} \cdot \mathbf{q}_{\mathrm{c}}$

Ressalta-se que $\mathbf{B}_{\mathrm{c}}$ é constante ao longo do elemento. Agora, comparando-se as equações 2.7, 2.10 e 2.11 fica claro que:

$\mathbf{P}_{\mathrm{c}}=\mathrm{L} \cdot \mathrm{C} \cdot \mathrm{B}_{\mathrm{c}}$

A matriz $\mathbf{L}$, que será melhor detalhada mais a frente, é chamada matriz de "amontoamento" (LUMPED), porque transfere o campo de tensões constantes $\sigma_{\mathrm{c}}$ para as forças nodais. Essa matriz representa um papel muito importante na formulação livre.

\subsection{FORMULAÇÃO PADRÃO VIA ENERGIA POTENCIAL}


$\mathrm{Na}$ aplicação do princípio da mínima energia potencial para 0 desenvolvimento de elementos finitos costuma-se garantir a continuidade entre elementos utilizando-se funções de forma conformes. Quando o operador diferencial que governa o problema é de ordem $2 \mathrm{~m}$, é necessário que as funções satisfaçam a continuidade interelemental de grau m-1 (IRONS \& AHMAD - 1980). Tais elementos, denominados conformes, atendem ao patch-test e a sua utilização produz resultados que convergem monotonicamente para a solução exata à medida que as discretizações vão sendo refinadas. Infelizmente, em muitos casos, é difícil garantir essa conformidade, ou então os elementos, quando conformes, se apresentam muito rígidos e quando utilizados em discretizações pouco refinadas não oferecem uma boa aproximação para o problema em análise. Mas, a experiência demonstra que alguns elementos baseados em funções nãoconformes satisfazem o patch-test e fornecem resultados muito bons e, em geral, melhores que os elementos conformes.

Apresenta-se a seguir a formulação baseada na energia potencial do ponto de vista do teste do elemento individual. A energia de deformação é dada pela integral estendida ao longo do seu volume:

$U_{p}=\frac{1}{2} \cdot \int_{V_{l}} \varepsilon^{\top} \cdot C \cdot \varepsilon \cdot d V_{I}$

onde C é a matriz constitutiva do material. Escrevendo-se as deformações em função dos parâmetros generalizados, pela aplicação de um operador diferencial no campo de deslocamentos, tem-se:

$\varepsilon=\Delta \mathbf{U}=\Delta \mathbf{N}_{\mathrm{rc}} \cdot \mathbf{q}_{\mathrm{rc}}+\Delta \mathbf{N}_{\mathrm{s}} \cdot \mathbf{q}_{\mathrm{s}}=\mathrm{B}_{\mathrm{rc}} \cdot \mathbf{q}_{\mathrm{rc}}+\mathrm{B}_{\mathrm{s}} \cdot \mathbf{q}_{\mathrm{s}}=\mathrm{B}_{\mathrm{q}} \cdot \mathbf{q}$

Logo, 
$U_{p}=\frac{1}{2} \cdot q^{\top} \cdot \int_{V_{l}} B_{q}^{\top} \cdot C \cdot B_{q} \cdot d V_{1} \cdot q=\frac{1}{2} \cdot q^{\top} \cdot K_{q} \cdot q$

Pode-se particionar a matriz de rigidez generalizada, de acordo com os modos rígidos e de deformação constante e os modos superiores, obtendo-se:

$\mathbf{K}_{\mathbf{q}}=\left[\begin{array}{cc}\mathbf{K}_{\text {qrc }} & \mathbf{K}_{\text {qrcs }} \\ \mathbf{K}^{\top}{ }_{\text {qrcs }} & \mathbf{K}_{\mathbf{q s}}\end{array}\right]$

onde:

$$
\begin{aligned}
& K_{\mathrm{qrc}}=\int_{\mathrm{V}_{\mathrm{l}}} \mathrm{B}_{\mathrm{rc}}^{\top} \cdot \mathrm{C} \cdot \mathrm{B}_{\mathrm{rc}} \cdot d \mathrm{~V}_{\mathrm{I}}=\mathrm{V}_{\mathrm{I}} \cdot \mathrm{B}_{\mathrm{rc}}^{\top} \cdot \mathrm{C} \cdot \mathrm{B}_{\mathrm{rc}} \\
& K_{\text {qrcs }}=\int_{V_{1}} B_{r c}^{\top} \cdot C \cdot B_{s} \cdot d V_{I} \\
& K_{q s}=\int_{V_{l}} B_{s}^{\top} \cdot C \cdot B_{s} \cdot d V_{1}
\end{aligned}
$$

Os modos de corpo rígido não produzem deformações e os coeficientes da matriz $\mathbf{K}_{\mathrm{q}}$ relacionados com esses modos se cancelam. Computacionalmente esse fato pode ser aproveitado separando-os dos modos de deformação constante e removendo-os das matrizes, exceto na inversão de G.

A energia de deformação também pode ser expressa por:

$$
\mathrm{U}_{\mathrm{p}}=\frac{1}{2} \cdot \mathrm{V}^{\top} \cdot \mathrm{K} \cdot \mathrm{V}
$$


Comparando-se as equações 2.15 com 2.3 a matriz de rigidez do elemento pode ser escrita como:

$\mathrm{K}=\mathrm{H}_{\mathrm{rc}}^{\top} \cdot \mathrm{K}_{\mathrm{qrc}} \cdot \mathrm{H}_{\mathrm{rc}}+\mathrm{H}_{\mathrm{rc}}^{\top} \cdot \mathrm{K}_{\mathrm{qrcs}} \cdot \mathrm{H}_{\mathrm{s}}+\mathrm{H}_{\mathrm{s}}^{\top} \cdot \mathrm{K}_{\mathrm{qrcs}}^{\top} \cdot \mathrm{H}_{\mathrm{rc}}+\mathrm{H}_{\mathrm{s}}^{\mathrm{T}} \cdot \mathrm{K}_{\mathrm{qs}} \cdot \mathrm{H}_{\mathrm{s}}$

Nesse ponto, é necessário verificar se a equação 2.19 satisfaz o teste do elemento individual, expresso pela equação 2.9. Torna-se necessário detalhar a sub-matriz $\mathbf{K}_{\text {qrc }}$, para isso aplica-se o PTV a um estado de deformação constante, logo:

$\delta \mathbf{q}_{\mathrm{rc}}^{\top} \cdot \mathrm{K}_{\mathrm{qrc}} \cdot \mathbf{q}_{\mathrm{rc}}=\delta \mathbf{G}_{\mathrm{rc}}^{\top} \cdot \mathbf{t}_{\mathrm{rc}}$

A partir das equações 2.2, 2.5 e 2.7 pode-se dar uma nova apresentação à equação 2.20, tem-se então:

$\delta \mathbf{q}_{\mathrm{rc}}^{\top} \cdot \mathbf{K}_{\mathrm{qrc}} \cdot \mathbf{q}_{\mathrm{rc}}=\delta \mathbf{q}_{\mathrm{rc}}^{\top} \cdot \mathbf{G}_{\mathrm{rc}}^{\top} \cdot \mathbf{P}_{\mathrm{rc}} \cdot \mathbf{q}_{\mathrm{rc}}$

E finalmente:

$\mathbf{K}_{\mathrm{qrc}}=\mathbf{G}_{\mathrm{rc}}^{\top} \cdot \mathbf{P}_{\mathrm{rc}}$

Multiplicando os dois termos da equação 2.19 por $\mathbf{G}_{\mathrm{rc}}$ tem-se:

$\mathrm{K} \cdot \mathrm{G}_{\mathrm{rc}}=\mathrm{H}_{\mathrm{rc}}^{\top} \cdot \mathrm{K}_{\mathrm{qrc}}+\mathbf{0}+\mathrm{H}_{\mathrm{s}}^{\top} \cdot \mathrm{K}_{\mathrm{qrcs}}^{\top}+\mathbf{0}$

Visto que $\mathbf{K}_{\mathrm{qrc}}=\mathbf{G}_{\mathrm{rc}}^{\mathbf{T}} \cdot \mathbf{P}_{\mathrm{rc}}$, então:

$K \cdot G_{r c}=H_{r c}^{T} \cdot G_{r c}^{T} \cdot P_{r c}+H_{s}^{T} \cdot K_{q r c s}^{T}$

Como $\mathbf{H}=\mathbf{G}^{-1}$, pode-se escrever que $\mathbf{H}_{\mathrm{rc}}^{\mathbf{T}} \cdot \mathbf{G}_{\mathrm{rc}}^{\mathbf{T}}=\mathbf{I}-\mathbf{H}_{\mathrm{s}}^{\mathbf{T}} \cdot \mathbf{G}_{\mathrm{s}}^{\mathbf{T}}$, logo: 
$K \cdot G_{r c}=\left(I-H_{s}^{\top} \cdot G_{s}^{\top}\right) \cdot P_{r c}+H_{s}^{\top} \cdot K_{q r c s}^{\top}$

Finalmente, tem-se:

$\mathbf{K} \cdot \mathbf{G}_{\mathrm{rc}}=\mathrm{P}_{\mathrm{rc}}+\mathbf{H}_{\mathrm{s}}^{\mathrm{T}} \cdot\left(\mathbf{K}_{\mathrm{qrcs}}^{\mathrm{T}}-\mathbf{G}_{\mathrm{s}}^{\mathrm{T}} \cdot \mathbf{P}_{\mathrm{rc}}\right)$

Para que a equação 2.9 seja satisfeita é necessário que a expressão entre parênteses em 2.26 se anule. Como não é fácil escolher modos superiores que respeitem essa condição, BERGAN \& NYGARD (1984) sugerem uma forma mais simples que consiste em se anular separadamente os dois termos da equação. Logo:

$$
\begin{aligned}
& \mathbf{G}_{\mathrm{s}}^{\mathrm{T}} \cdot \mathbf{P}_{\mathrm{rc}}=\mathbf{0} \\
& \mathbf{K}_{\mathrm{qrcs}}=\mathbf{0}
\end{aligned}
$$

A primeira condição traduz ortogonalidade em força e a segunda ortogonalidade em energia. Como os modos básicos (modos-rc) produzem $\mathbf{B}_{\mathrm{rc}}$ constante, para se anular $\mathbf{K}_{\text {qres }}$ basta que:

$$
\int_{V_{1}} B_{s} \cdot d V_{1}=0
$$

Um elemento finito derivado pelo princípio da mínima energia potencial, satisfaz os requisitos de convergência do teste do elemento individual desde que os modos básicos sejam completos, atendam as condições de ortogonalidade em força e energia e os modos básicos e superiores sejam linearmente independentes entre si. 
Considerando-se a hipótese de que a matriz de rigidez do elemento pode ser construída da seguinte maneira:

$\mathrm{K}=\mathrm{K}_{\mathrm{rc}}+\mathrm{K}_{\mathrm{s}}=\mathrm{P}_{\mathrm{rc}} \cdot \mathrm{H}_{\mathrm{rc}}+\mathrm{H}_{\mathrm{s}}^{\mathrm{T}} \cdot \mathrm{K}_{\mathrm{qs}} \cdot \mathrm{H}_{\mathrm{s}}$

$\mathbf{K}_{\mathrm{qs}}$ é a matriz generalizada dos modos superiores dada pela equação 2.17c. A razão para se adotar a expressão 2.29 se torna clara quando sujeitamos a matriz de rigidez, $\mathbf{K}$, ao teste do elemento individual:

$K \cdot G_{r c}=P_{r c} \cdot H_{r c} \cdot G_{r c}+H_{s}^{\top} \cdot K_{q s} \cdot H_{s} \cdot G_{r c}=P_{r c}$

Assim, fica claro que a equação 2.29 satisfaz os requisitos definidos pela equação 2.9 .

Aparentemente, a equação 2.29 não é simétrica. Para investigar esse ponto de maneira mais detalhada, coloca-se a matriz de rigidez do elemento em sua forma matricial, como na equação 2.16.

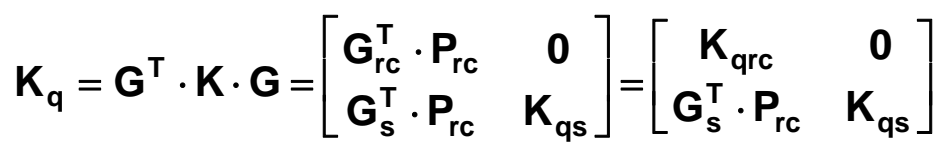

A forma escolhida para a matriz de rigidez $\mathbf{K}$ apresenta corretamente a energia e a rigidez referente aos modos básicos e superiores puros. Apesar disso, os termos que acoplam os dois modos não estão de acordo com a formulação da energia potencial em 2.17b. A matriz de rigidez não é simétrica. Essa formulação se torna inconsistente com relação à formulação via energia potencial, exceto quando os modos superiores apresentarem ortogonalidade em força.

\subsection{A FORMULAÇÃO LIVRE}


BERGAN \& NYGARD (1984) apresentaram uma formulação simples da matriz de rigidez que satisfaz implicitamente as equações do teste do elemento individual, equação 2.9, admitindo-se sempre que as funções assumidas podem ser não-conformes.

O campo de deslocamentos $\mathbf{U}$ de um elemento é expresso por um conjunto de modos rígidos e de deformação constante, modos-rc, e um conjunto de modos superiores, modos-s:

$\mathbf{U}=\mathbf{N}_{\mathrm{rc}} \cdot \mathbf{q}_{\mathrm{rc}}+\mathbf{N}_{\mathrm{s}} \cdot \mathbf{q}_{\mathrm{s}}$

O termo $\mathbf{N}_{\text {rc }}$ expressa um polinômio completo até o grau que corresponde aos modos rígidos e de deformação constante do problema dado e $\mathbf{q}_{\mathrm{rc}}$ são os coeficientes associados, ou parâmetros generalizados. O termo $\mathbf{N}_{\mathrm{s}}$ expressa um conjunto de funções de forma de alta ordem, ou modos superiores, e $\mathbf{q}_{\mathrm{s}}$ são os coeficientes associados, ou parâmetros generalizados.

O número total de coeficientes associados deve ser igual a $\mathrm{n}$, que é o número de graus de liberdade do elemento, componentes do vetor de deslocamentos nodais $\mathbf{V}$.

O cálculo das deformações a partir da equação 2.32 é obtido pela equação:

$\varepsilon=\Delta U=\Delta N_{r c} \cdot q_{r c}+\Delta N_{s} \cdot q_{s}=B_{r c} \cdot q_{r c}+B_{s} \cdot q_{s}$

onde $\Delta$ é um operador diferencial para o cálculo das deformações, e $\mathbf{B}_{\mathrm{rc}}$ e $\mathbf{B}_{\mathrm{s}}$ contêm as derivadas do campo de deslocamentos. 
A relação entre os parâmetros generalizados e os deslocamentos nodais $\mathbf{V}$ é facilmente estabelecida pela apropriada substituição das coordenadas nodais em $\mathbf{N}_{\mathrm{rc}}$ e $\mathbf{N}_{\mathrm{s}}$. E em alguns casos pode ser necessário derivar $\mathbf{N}_{\mathrm{rc}}$ e $\mathbf{N}_{\mathrm{s}}$, quando os parâmetros nodais incluem derivadas do campo de deslocamentos. Obtém-se, então:

$$
\mathbf{V}=\mathrm{V}_{\mathrm{rc}}+\mathrm{V}_{\mathrm{s}}=\mathbf{G}_{\mathrm{rc}} \cdot \mathbf{q}_{\mathrm{rc}}+\mathbf{G}_{\mathrm{s}} \cdot \mathbf{q}_{\mathrm{s}}=\mathbf{G} \cdot \mathbf{q}
$$

Escolhidos os modos superiores (modos-s) têm-se as funções de forma N. Substituindo a equação 2.3 na equação 2.32, obtém-se:

$$
\mathbf{U}=\mathrm{N}_{\mathrm{rc}} \cdot \mathrm{H}_{\mathrm{rc}} \cdot \mathbf{V}+\mathrm{N}_{\mathrm{s}} \cdot \mathrm{H}_{\mathrm{s}} \cdot \mathrm{V}=\left(\mathrm{N}_{\mathrm{rc}} \cdot \mathrm{H}_{\mathrm{rc}}+\mathrm{N}_{\mathrm{s}} \cdot \mathrm{H}_{\mathrm{s}}\right) \cdot \mathbf{V}=\mathbf{N} \cdot \mathbf{V}
$$

Logo,

$$
\mathrm{N}=\mathrm{N}_{\mathrm{rc}} \cdot \mathrm{H}_{\mathrm{rc}}+\mathrm{N}_{\mathrm{s}} \cdot \mathrm{H}_{\mathrm{s}}
$$

De acordo com o teste do elemento individual, as forças nodais $\mathbf{t}_{\mathrm{rc}}$, que podem ser encontradas por uma transferência consistente das tensões de superfície ao longo de um lado do elemento aos nós, precisam satisfazer a equação:

$$
t_{r c}=P_{r c} \cdot q_{r c}
$$

$\mathbf{P}_{\mathrm{rc}}$ representa as forças produzidas pelos parâmetros generalizados relacionados aos modos rígidos e de deformação constante. Essas forças dependem da matriz de deformação $\mathbf{B}_{\mathrm{rc}}$, da matriz constitutiva $\mathbf{C}$, de como as tensões são transferidas para os nós e da geometria do elemento. Assim, $\mathbf{P}_{\mathrm{rc}}$ pode ser escrita da forma:

$$
\mathrm{P}_{\mathrm{rc}}=\mathrm{L} \cdot \mathrm{C} \cdot \mathrm{B}_{\mathrm{rc}}
$$


onde $\mathbf{L}$ representa a matriz de transferência das tensões nas faces para os nós.

Obtida a matriz $\mathbf{K}$, as forças nodais $\mathbf{F}_{\mathrm{rc}}$ produzidas pela rigidez quando se considera um estado de deformação constante serão:

$F_{r c}=K \cdot V_{r c}=K \cdot G_{r c} \cdot q_{r c}$

O teste do elemento individual obriga que as forças $\mathbf{F}_{\mathrm{rc}}$ sejam iguais a $\mathbf{t}_{\mathrm{rc}}$, para qualquer valor de $\mathbf{q}_{\mathrm{rc}}$. Então:

$\mathbf{K} \cdot \mathbf{G}_{\mathrm{rc}}=\mathbf{P}_{\mathrm{rc}}$

Esta equação representa a restrição fundamental para que a matriz $\mathbf{K}$ satisfaça o teste do elemento individual.

O ponto mais importante para se conseguir que as condições de convergência sejam atendidas para um determinado elemento está na forma como se faz o acoplamento entre os modos básicos e os modos superiores na montagem da matriz de rigidez. No item 2.3 foi demonstrado que a simetria e a convergência podem ser obtidas pela imposição da ortogonalidade em força e em energia. Agora, modificando-se a equação 2.31, a matriz de rigidez generalizada, $\mathbf{K}_{\mathrm{q}}$, pode ser expressa como:

$K_{q}=\left[\begin{array}{cc}K_{q r c} & P_{r c}^{\top} \cdot G_{s} \\ G_{s}^{\top} \cdot P_{r c} & K_{q s}\end{array}\right]$

As sub-matrizes referentes aos modos básicos e superiores são determinadas da mesma forma que na formulação tradicional, enquanto as sub-matrizes que fazem o acoplamento dos modos superiores com os básicos foram substituídas. Considerando-se as equações 2.3 e 2.15 é fácil demonstrar que a matriz de rigidez do elemento correspondente será: 


$$
\begin{aligned}
& \mathbf{K}=\mathbf{H}^{\top} \cdot \mathbf{K}_{\mathrm{q}} \cdot \mathbf{H} \\
& \mathrm{K}=\mathrm{H}_{\mathrm{rc}}^{\top} \cdot \mathrm{K}_{\mathrm{qrc}} \cdot \mathbf{H}_{\mathrm{rc}}+\mathbf{H}_{\mathrm{rc}}^{\top} \cdot \mathbf{P r c}_{\mathrm{rc}}^{\top} \cdot \mathbf{G}_{\mathrm{s}} \cdot \mathbf{H}_{\mathrm{s}}+\mathbf{H}_{\mathrm{s}}^{\top} \cdot \mathbf{G}_{\mathrm{s}}^{\top} \cdot \mathbf{P}_{\mathrm{rc}} \cdot \mathbf{H}_{\mathrm{rc}}+\mathbf{H}_{\mathrm{s}}^{\top} \cdot \mathbf{K}_{\mathrm{qs}} \cdot \mathbf{H}_{\mathrm{s}}
\end{aligned}
$$

Essa matriz de rigidez precisa ser testada, em relação a convergência, de acordo com a equação 2.40. Assim obtém-se:

$$
\begin{aligned}
& K \cdot G_{r c}=H_{r c}^{\top} \cdot K_{q r c}+0+H_{s}^{\top} \cdot G_{s}^{\top} \cdot P_{r c}+0 \\
& K \cdot G_{r c}=\left(H_{r c}^{\top} \cdot G_{r c}^{\top}+H_{s}^{\top} \cdot G_{s}^{\top}\right) \cdot P_{r c}=P_{r c}
\end{aligned}
$$

Consequentemente, a modificação apresentada em 2.41 atende ao teste do elemento individual e ao patch-test.

O fato mais importante quando se analisa a equação 2.41 é verificar o porquê do nome formulação livre, no sentido de que não obriga que tenhamos ortogonalidade em força e em energia, ela é válida qualquer que sejam os modos superiores escolhidos.

A presente formulação torna extremamente simples a escolha dos modos superiores na equação 2.32; usualmente são escolhidos polinômios cujos termos são os polinômios de grau imediatamente superior aos modos de deformação constante. É fácil obter os deslocamentos nodais em função dos parâmetros generalizados, como mostrado em 2.34, mas é essencial que a matriz de rigidez seja formada utilizando-se a equação 2.43 .

Quanto às tensões, podem ser calculadas diretamente pela expressão:

$$
\sigma=\mathbf{C} \cdot \varepsilon=\mathrm{C} \cdot \mathrm{B}_{\mathbf{q}} \cdot \mathbf{q}=\mathbf{C} \cdot \mathrm{B}_{\mathbf{q}} \cdot \mathbf{H} \cdot \mathbf{V}
$$


Fica claro também que se pode economizar tempo de processamento fazendo-se a separação dos modos de corpo rígido dos modos de deformação constante em 2.11. A parte referente a deslocamentos de corpo rígido somente precisa ser considerada na inversão de $\mathbf{G}$, equação 2.3, e não tem influência em nenhuma equação relacionada com as deformações.

Como foi demonstrado na equação 2.43 , a matriz de rigidez, mostrada na equação 2.41, sempre satisfaz o teste do elemento individual e consequentemente o patch-test. Apesar disso, segundo BERGAN \& NYGARD (1984), testando-se uma grande variedade de funções superiores, verificou-se que a convergência não acontecia em alguns casos. Calculando-se os autovalores da matriz $\mathbf{K}$ foi verificada a existência de pelo menos um autovalor negativo nesses casos específicos. Numa situação de convergência normal, a influência dos modos superiores vai diminuindo, a medida que a rede vai sendo refinada. Isso não acontece quando aparece um ou mais autovalores negativos associados aos modos superiores.

Conclui-se que o teste do elemento individual e o patch-test não são condições suficientes para obter-se a convergência. É necessário certificarse de que não existem autovalores negativos na matriz $\mathbf{K}$. Isso fica claro pela análise da equação 2.41. Quando as funções dos modos superiores estiverem muito distantes da verificação da ortogonalidade a matriz de acoplamento passa a ter uma influência muito grande no cálculo da matriz de rigidez. Como os termos da matriz de acoplamento não são derivadas diretamente da energia de deformação não podemos garantir que $\mathbf{K}_{q}$, e consequentemente $\mathbf{K}$, seja positiva definida.

\subsection{ALTERAÇÕES NA FORMULAÇÃO PARA GARANTIR AUTOVALORES POSITIVOS}


A ocorrência de autovalores negativos fica evidente verificando-se que, na equação 2.41 , o termo $\mathbf{P}_{\mathrm{rc}}{ }^{\top} \mathbf{G}_{\mathrm{s}}$ pode tornar-se predominante em relação a $\mathbf{K}_{\text {qs. }}$. Isso pode ser contornado fazendo-se uma modificação em $\mathbf{K}_{\mathrm{qs}}$. Inicialmente, examina-se a matriz generalizada dos modos básicos:

$$
\begin{aligned}
& \mathrm{K}_{\mathrm{qrc}}=\mathrm{V}_{\mathrm{l}} \cdot \mathrm{B}_{\mathrm{rc}}^{\mathrm{T}} \cdot \mathrm{C} \cdot \mathrm{B}_{\mathrm{rc}}=\left(\mathrm{V}_{1} \cdot \mathbf{B}_{\mathrm{rc}}^{\mathrm{T}}\right) \cdot\left(\mathrm{C} \cdot \mathrm{B}_{\mathrm{rc}}\right) \\
& K_{\mathrm{qrc}}=\mathbf{G}_{\mathrm{rc}}^{\top} \cdot \mathbf{P}_{\mathrm{rc}}=\mathbf{G}_{\mathrm{rc}}^{\top} \cdot \mathbf{L} \cdot \mathbf{C} \cdot \mathbf{B}_{\mathrm{rc}}=\left(\mathbf{G}_{\mathrm{rc}}^{\top} \cdot \mathbf{L}\right) \cdot\left(\mathbf{C} \cdot \mathrm{B}_{\mathrm{rc}}\right)
\end{aligned}
$$

A matriz (C. B $_{\mathrm{rc}}$ ) da equação 2.46 possui a mesma dimensão da matriz constitutiva, porque $\mathbf{C}$ é positiva definida e $\mathbf{B}_{\mathrm{rc}}$ é de mesma dimensão que $\mathbf{C}$. Pode-se concluir que os primeiros termos das expressões 2.45 e 2.46 são iguais, logo:

$$
V_{1} \cdot B_{r c}^{\top}=G_{r c}^{\top} \cdot L
$$

Esta equação pode ser utilizada para verificar se a matriz "amontoadora", L, está correta. Usando-se 2.38 e 2.47 a matriz acopladora de 2.41 pode ser obtida por:

$$
P_{r c}^{\top} \cdot G_{s}=B_{r c}^{\top} \cdot C \cdot L^{\top} \cdot G_{s}=\frac{1}{V_{l}} \cdot G_{r c}^{\top} \cdot L \cdot C \cdot L^{\top} \cdot G_{s}
$$

Pode-se assegurar autovalores positivos na matriz $\mathbf{K}$ através da adição de um novo termo na formação da matriz $\mathbf{K}_{\mathrm{qs}}$, denominado de $\overline{\mathbf{K}}_{\mathrm{qs}}$, assim tem-se:

$$
\overline{\mathrm{K}}_{\mathrm{qs}}=\frac{1}{\mathrm{~V}_{\mathrm{I}}} \cdot \mathrm{G}_{\mathrm{s}}^{\mathrm{T}} \cdot \mathbf{L} \cdot \mathbf{C} \cdot \mathbf{L}^{\mathrm{T}} \cdot \mathbf{G}_{\mathrm{s}}
$$

A nova matriz generalizada fica: 


$$
\overline{\mathbf{K}}_{\mathrm{q}}=\left[\begin{array}{cc}
\mathbf{K}_{\mathrm{qrc}} & \mathbf{P}_{\mathrm{rc}}^{\mathrm{T}} \cdot \mathbf{G}_{\mathbf{s}} \\
\mathbf{G}_{\mathrm{s}}^{\mathrm{T}} \cdot \mathbf{P}_{\mathrm{rc}} & \mathbf{K}_{\mathbf{q s}}
\end{array}\right]
$$

Dessa forma, a matriz de rigidez do elemento pode ser obtida por:

$$
\mathrm{K}=\frac{1}{\mathrm{~V}_{\mathrm{I}}} \cdot \mathrm{L} \cdot \mathrm{C} \cdot \mathrm{L}^{\mathrm{T}}+\mathrm{H}_{\mathrm{s}}^{\mathrm{T}} \cdot \mathrm{K}_{\mathrm{qs}} \cdot \mathrm{H}_{\mathrm{s}}
$$

Fica claro que a matriz $\mathbf{K}$, da equação 2.51 , não apresenta autovalores negativos porque é formada por formas quadráticas de $\mathbf{C}$ e $\mathbf{K}_{\mathrm{qs}}$, que são ambas positivas definidas. A matriz $\mathbf{K}$ continua satisfazendo o teste do elemento individual:

$$
K \cdot G_{r c}=\frac{1}{V_{I}} \cdot L \cdot C \cdot L^{\top} \cdot G_{r c}+H_{s}^{\top} \cdot K_{q s} \cdot H_{s} \cdot G_{r c}
$$

Observando-se a equação $2.4 \mathrm{~d}$ tem-se:

$$
K \cdot G_{r c}=\frac{1}{V_{l}} \cdot L \cdot C \cdot\left(V_{l} \cdot B_{\text {qrc }}\right)+0
$$

E das equações 2.38 e 2.47 , obtém-se:

$$
\mathbf{K} \cdot \mathbf{G}_{\mathrm{rc}}=\mathbf{P}_{\mathrm{rc}}
$$

Em relação à formulação usual via energia potencial, a equação 2.45 apresenta uma expressão inalterada para a matriz referente aos modos básicos, enquanto a rigidez de acoplamento e dos modos superiores apresenta uma alteração com o objetivo de satisfazer à definição de 
autovalores positivos e ao teste de convergência. A nova matriz de rigidez pode ser expressa como:

$\mathrm{K}=\mathrm{K}_{\mathrm{b}}+\mathrm{K}_{\mathrm{s}}$

onde a matriz básica é dada por:

$K_{b}=\frac{1}{V_{l}} \cdot L \cdot C \cdot L^{\top}$

A matriz de rigidez é formada por uma parcela que depende apenas dos modos básicos, que se apresenta inalterável para elementos que tenham o mesmo arranjo de parâmetros nodais de deslocamento. A outra parcela é referente aos modos superiores e modifica-se com a alteração dos mesmos. Nota-se também que para a determinação da matriz de rigidez só interessa a sub-matriz $\mathbf{H}$, associada aos modos superiores $\mathbf{H}_{\mathbf{s}}$.

Os modos de alta ordem formam a matriz de rigidez de alta ordem:

$K_{s}=H_{s}^{\top} \cdot K_{q s} \cdot H_{s}$

Aqui, $\mathbf{H}_{\mathrm{s}}$ é a sub-matriz de $\mathbf{H}=\mathbf{G}^{-1}$ que relaciona $\mathbf{q}_{\mathrm{s}} \operatorname{com} \mathrm{o}$ vetor $\mathbf{V}$, e $\mathbf{K}_{\mathrm{qs}}$ é a matriz de rigidez generalizada para os modos de alta ordem:

$K_{q s}=\int_{V_{I}} B_{s}^{T} \cdot C \cdot B_{s} \cdot d V_{I}$ 
onde $\mathbf{B}_{\mathrm{s}}$ é a matriz de deformação para os modos de alta ordem. A matriz de rigidez formada pela soma das equações 2.56 e 2.57, automaticamente satisfaz às condições do teste do elemento individual.

A matriz de rigidez dos modos básicos, geralmente, é "rank deficiency", ou seja, apresenta deficiência de posto. Na formulação livre essa deficiência é corrigida pela adição da rigidez de alta ordem, baseada nos modos de deformação. A matriz básica $\mathbf{K}_{\mathrm{b}}$ é responsável pela convergência, e a matriz de alta ordem $\mathbf{K}_{\mathrm{s}}$ pela estabilidade e precisão. 


\section{CAPÍTULO III DESENVOLVIMENTO DO ELEMENTO}

\subsection{NOÇÕES DE ELASTICIDADE BIDIMENSIONAL}

Neste item apresenta-se um resumo da teoria da elasticidade bidimensional cujas noções são fundamentais para o desenvolvimento do elemento finito de membrana. Ressalta-se que todo o fundamento teórico apresentado foi baseado principalmente em VALLIAPPAN (1981), TIMOSHENKO \& GOODIER (1990) e VILLAÇA \& GARCIA (1996).

Importante frisar que são adotadas as seguintes hipóteses básicas:

a) O material é homogêneo, isto é, possui as mesmas propriedades em todos os seus pontos.

b) O material é isótropo, ou seja, em cada ponto as propriedades são as mesmas em todas as direções.

c) O material é elástico linear, o que significa que se admite a validade da lei de Hooke como relacionamento entre as tensões e as deformações.

d) As estruturas a serem analisadas estão submetidas a pequenos deslocamentos.

\subsubsection{Estado de Deformações}


A deformação em um ponto de um corpo é o resultado de um deslocamento relativo entre pontos vizinhos. Se não ocorre mudança de forma e dimensões do corpo, ou seja, se todos os pontos apenas transladam segundo um determinado eixo ou rotacionam em relação a um ponto, tem-se o chamado deslocamento de corpo rígido. Mas se a forma ou o tamanho do corpo sofrem alterações, então existe um estado de deformações não nulo.

A partir do campo de deslocamentos pode-se deduzir as deformações. Para o caso tridimensional, considera-se um elemento infinitesimal $d x$, dy e dz de um corpo elástico, figura 3.1, cujas faces são inicialmente normais aos eixos perpendiculares $x, y$ e $z$.

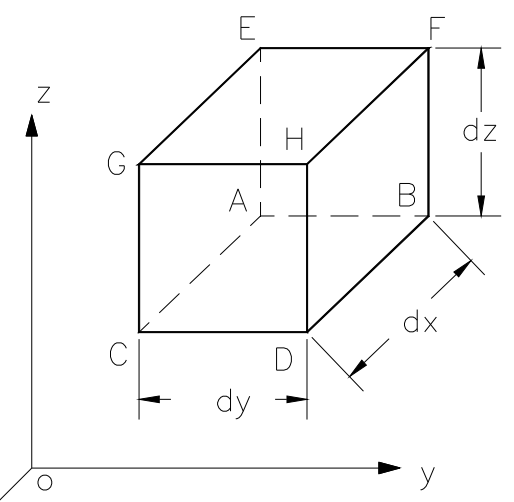

FIGURA 3.1 - Elemento infinitesimal de um corpo elástico

Assumindo-se que, sob a ação de um determinado carregamento, aparecem apenas tensões normais, então pode-se supor que a forma inicial paralelepipédica do corpo vai ser mantida, havendo modificações apenas nos comprimentos dos seus lados. Este estado de tensão produz apenas deformações normais denotadas por $\varepsilon_{x}, \varepsilon_{y}$ e $\varepsilon_{z}$. 
Considerando-se que o elemento também está sujeito a tensões de cisalhamento, então a forma paralelepipédica original sofrerá distorções. Este tipo de deformação pode ser medido pela mudança que ocorre no ângulo entre duas das faces do elemento. Essas distorções são denotadas por: $\gamma_{x y}, \gamma_{x z}, \gamma_{y x}, \gamma_{y z}, \gamma_{z x}$ e $\gamma_{z y}$, sendo os índices relativos aos eixos em cujo plano ocorre a mencionada distorção.

Assim, nove deformações, três deformações normais e seis distorções são necessárias para um perfeito conhecimento do estado tridimensional de deformações para um ponto. As três deformações normais produzem mudança de volume, sem que ocorra mudança de forma, e as seis deformações cisalhantes produzem apenas distorção, com manutenção do volume.

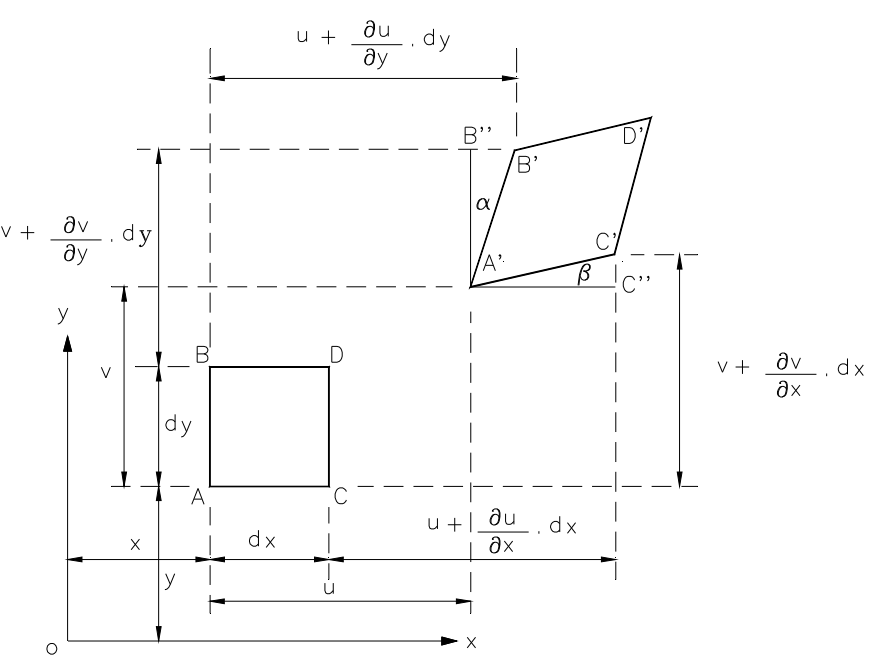

FIGURA 3.2 - Deformação do elemento no plano

Considerando-se agora o caso plano, analisa-se a face $A B C D$, projetada no plano xy, que após a deformação é representada por A'B'C'D', conforme mostra-se na figura 3.2. Nesse caso, as deformações que interessam são $\varepsilon_{x}, \varepsilon_{y}$ e $\gamma_{x y}$.

Observando-se a figura, pode-se escrever para a deformação $\varepsilon_{x}$ : 


$$
\begin{aligned}
& \varepsilon_{x}=\frac{A^{\prime} C^{\prime \prime}-A C}{A C} \\
& \varepsilon_{x}=\frac{(u+(\partial u / \partial x) d x+d x-u)-d x}{d x} \\
& \varepsilon_{x}=\frac{\partial u}{\partial x}
\end{aligned}
$$

Analogamente, pode-se mostrar que:

$$
\varepsilon_{\mathrm{y}}=\frac{\partial \mathbf{v}}{\partial \mathbf{y}}
$$

Para determinar a deformação angular, ou distorção, considera-se a rotação do lado $A C$ em relação $A$ :

$$
\begin{aligned}
& \tan \beta=\frac{C^{\prime} C^{\prime \prime}}{A C^{\prime}} \\
& \tan \beta=\frac{(v+(\partial v / \partial x) \cdot d x)-v}{(u+(\partial u / \partial x) \cdot d x+d x)-u} \\
& \tan \beta=\frac{(\partial v / \partial x)}{1+(\partial u / \partial x)}
\end{aligned}
$$

Considerando-se apenas deformações infinitesimais, então $\partial u / \partial x$ é muito pequeno se comparado com a unidade. Logo, pode-se aproximar: $\tan \beta=\frac{\partial v}{\partial x} \cong \beta$

Analogamente:

$$
\tan \alpha=\frac{\partial u}{\partial y} \cong \alpha
$$


Logo, a variação angular entre os lados $A B$ e $A C$ devido a deformação é:

$\gamma_{x y}=\alpha+\beta=\frac{\partial u}{\partial y}+\frac{\partial v}{\partial x}$

\subsubsection{Estado de Tensões}

Para um ponto de um sólido tridimensional, referenciado pelos eixos $\mathrm{x}, \mathrm{y}$ e $\mathrm{z}$, as componentes do estado de tensões podem ser apresentadas como na figura 3.3, onde são mostradas as tensões nas faces que se pode visualizar. Componentes de mesmo valor e sentido contrário existem nas faces opostas.

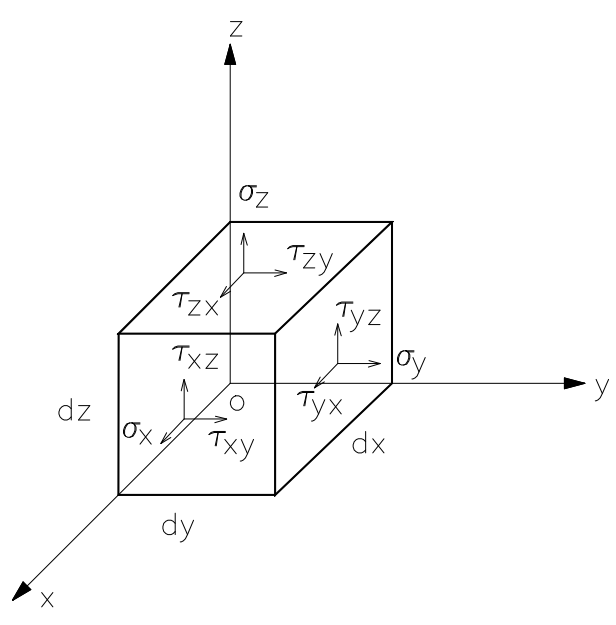

FIGURA 3.3 - Paralelepípedo infinitesimal sob um estado de tensão

Para o caso específico das membranas, estruturas planas com o carregamento aplicado exclusivamente no próprio plano da estrutura, tem-se o chamado estado plano de tensões. Então, considerando-se a estrutura desenvolvendo-se no plano $x y$, pode-se admitir que: 
$\sigma_{\mathrm{z}}=\tau_{\mathrm{zx}}=\tau_{\mathrm{zy}}=0$

Dessa forma, as componentes do estado de tensões podem ser escritas como:

$$
\begin{aligned}
& \sigma_{x}=\sigma_{x}(x, y) \\
& \sigma_{y}=\sigma_{y}(x, y) \\
& \sigma_{z}=0 \\
& \tau_{x y}=\tau_{x y}(x, y) \\
& \tau_{x z}=0 \\
& \tau_{y z}=0
\end{aligned}
$$

\subsubsection{Lei de Hooke Generalizada - Equações Constitutivas}

A relação entre as componentes de tensão e as componentes de deformação, para um determinado material, são conhecidas como equações constitutivas. No caso de materiais elásticos lineares essas equações constitutivas serão as equações conhecidas como lei de Hooke generalizada, ou simplesmente lei de Hooke:

$$
\begin{aligned}
& \varepsilon_{x}=\frac{1}{E} \cdot\left[\sigma_{x}-v \cdot\left(\sigma_{y}+\sigma_{z}\right)\right] \\
& \varepsilon_{y}=\frac{1}{E} \cdot\left[\sigma_{y}-v \cdot\left(\sigma_{x}+\sigma_{z}\right)\right] \\
& \varepsilon_{z}=\frac{1}{E} \cdot\left[\sigma_{z}-v \cdot\left(\sigma_{x}+\sigma_{y}\right)\right]
\end{aligned}
$$


$\gamma_{x y}=\frac{\tau_{x y}}{G}$

$\gamma_{\mathrm{xz}}=\frac{\tau_{\mathrm{xz}}}{\mathrm{G}}$

$\gamma_{\mathrm{yz}}=\frac{\tau_{\mathrm{yz}}}{\mathbf{G}}$

onde existe ainda uma relação suplementar entre os parâmetros elásticos que pode ser escrita como:

$\mathbf{G}=\frac{E}{2 \cdot(1+v)}$

Entretanto, para o já referido estado plano de tensões, as componentes da deformação, obtidas em função das componentes da tensão, podem ser escritas de forma simplificada:

$$
\begin{aligned}
& \varepsilon_{x}=\frac{1}{E} \cdot\left(\sigma_{x}-v \cdot \sigma_{y}\right) \\
& \varepsilon_{y}=\frac{1}{E} \cdot\left(\sigma_{y}-v \cdot \sigma_{x}\right) \\
& \varepsilon_{z}=-\frac{v}{E} \cdot\left(\sigma_{x}+\sigma_{y}\right) \\
& \gamma_{x y}=\frac{\tau_{x y}}{G}
\end{aligned}
$$


Assim, a matriz constitutiva $\mathbf{C}$, ou matriz de constantes elásticas, que permite calcular tensões em função das deformações, $\sigma=\mathbf{C} \varepsilon$, pode ser escrita como:

$C=\left[\begin{array}{ccc}C_{11} & C_{12} & 0 \\ C_{21} & C_{22} & 0 \\ 0 & 0 & C_{33}\end{array}\right]$

onde,

$$
\begin{aligned}
& C_{11}=C_{22}=\frac{E}{\left(1-v^{2}\right)} \\
& C_{12}=C_{21}=v \cdot C_{11} \\
& C_{33}=\frac{E}{2 \cdot(1+v)}=G
\end{aligned}
$$

\subsection{FORMULAÇÃO DO ELEMENTO}

Neste item apresenta-se a formulação da matriz de rigidez do elemento finito de membrana com liberdades rotacionais baseada na formulação livre, apresentada no capítulo II. Todo o desenvolvimento das matrizes e vetores relativos ao elemento será feito para o elemento triangular, o elemento quadrilateral será obtido pela união de quatro elementos triangulares utilizando-se a técnica da condensação estática. Ressalta-se que toda a formulação apresentada foi baseada no trabalho de BERGAN \& FELIPPA (1985). É importante frisar que todo o desenvolvimento foi feito considerando-se o elemento no plano, a 
implementação computacional e a consideração do elemento no espaço serão abordados no capítulo IV.

\subsubsection{Características do elemento}

As liberdades rotacionais são admitidas de acordo com a definição da mecânica do contínuo para rotações, dada pela equação:

$$
\theta_{z}=\frac{1}{2} \cdot\left(\frac{\partial v}{\partial x}-\frac{\partial u}{\partial y}\right)
$$

onde x e y são referidos aos eixos cartesianos no plano do elemento, e u e v são as componentes de deslocamento correspondentes. A rotação $\theta_{z}$ é invariante com respeito à escolha dos eixos de referência x e y.

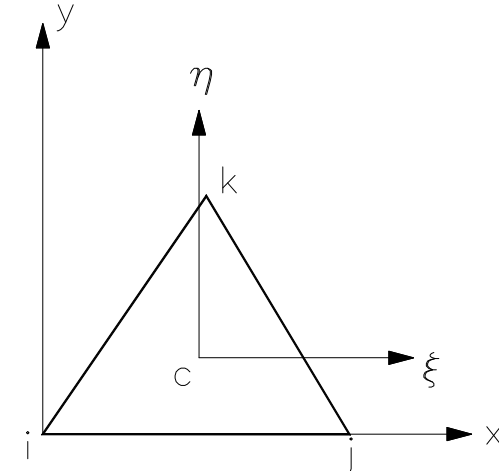

FIGURA 3.4 - Coordenadas locais do elemento triangular

A geometria de um elemento individual está ilustrada na figura 3.4. O triângulo é referido ao sistema cartesiano local $(x, y)$. Coordenadas adimensionais $(\xi, \eta)$ são definidas por: 


$$
\begin{gathered}
\xi=\frac{x-x_{c}}{\sqrt{A}}=\lambda \cdot\left(x-x_{c}\right) \\
\eta=\frac{y-y_{c}}{\sqrt{A}}=\lambda \cdot\left(y-y_{c}\right)
\end{gathered}
$$

onde, $x_{c}$ e $y_{c}$ são as coordenadas do centróide, A é a área do triângulo, dada pela equação:

$$
A=\frac{1}{2} \cdot\left(x_{j} y_{k}\right)
$$

Dessa forma, $\lambda=1 / \sqrt{\mathbf{A}}$ é um fator de escala com dimensões iguais ao inverso do comprimento. O uso de $\xi$ e $\eta$ elimina dependências dimensionais. Observa-se que:

$\frac{\partial \xi}{\partial \mathbf{x}}=\lambda, \quad \frac{\partial \xi}{\partial \mathbf{y}}=0, \quad \frac{\partial \eta}{\partial \mathbf{x}}=0, \quad \frac{\partial \eta}{\partial \mathbf{y}}=\lambda$,

e que:

$\xi_{i}+\xi_{j}+\xi_{k}=0, \quad \eta_{i}+\eta_{j}+\eta_{k}=0$

\subsubsection{Modos básicos de deslocamento}

O campo de deslocamentos $\mathbf{U}$ do elemento é definido pelas duas componentes $\mathbf{u}$ e v, ao longo dos eixos $x$ e y, respectivamente. O campo adotado é expresso como uma combinação linear de nove modos de deslocamento $\mathbf{N}_{\mathrm{i}}$ com amplitudes $\mathbf{q}_{\mathrm{i}}$, que podem ser expressos da forma:

$$
\mathbf{U}=\left\{\begin{array}{l}
\mathbf{u} \\
\mathbf{v}
\end{array}\right\}=\sum_{\mathrm{i}=1}^{9} \mathbf{N}_{\mathrm{i}} \cdot \mathbf{q}_{\mathrm{i}}=\mathbf{N} \cdot \mathbf{q}
$$


Em concordância com a formulação livre, o campo $\mathbf{U}$ deve ser decomposto em dois conjuntos $\mathbf{U}_{\mathrm{b}}$ e $\mathbf{U}_{\mathrm{s}}$, que são associados com os modos básicos e de alta ordem, respectivamente. Os modos básicos, para um elemento de membrana, são simplesmente três modos de corpo rígido e três modos de deformação constante. Utilizando-se as coordenadas $\xi$ e $\eta$ os modos básicos podem ser escritos da seguinte forma:

$$
\mathbf{U}_{b}=\mathbf{N}_{r} \cdot q_{r}+N_{c} \cdot q_{c}=\left[\begin{array}{ccc}
1 & 0 & -\eta \\
0 & 1 & \xi
\end{array}\right] \cdot q_{r}+\left[\begin{array}{lll}
\xi & 0 & \eta \\
0 & \eta & \xi
\end{array}\right] \cdot q_{c}
$$

Esses modos representam translações rígidas ao longo das direções $\mathrm{x}$ e y, uma rotação rígida em torno do eixo $\mathrm{z}$, as deformações uniformes $\varepsilon_{\mathrm{x}}=$ $\partial \mathrm{u} / \partial \mathrm{x}=$ const., $\varepsilon_{\mathrm{y}}=\partial \mathrm{v} / \partial \mathrm{y}=$ const. e a deformação cisalhante uniforme $\gamma_{\mathrm{xy}}=$ $\partial v / \partial x+\partial u / \partial y=$ const.

\subsubsection{Modos de alta ordem (ou modos superiores)}

Para um elemento com nove graus de liberdade, três modos de alta ordem são necessários. Considerando-se que as funções de forma para os modos básicos são lineares, a função mais apropriada para os modos de alta ordem são os polinômios quadráticos em termos de x e y, que produzem variação linear de tensões. Existe um total de seis funções para u e v e uma relação cuidadosa dos três modos precisa ser feita. BERGAN \& FELIPPA (1985) estudaram a seleção dos modos e sugerem os modos de flexão pura, como uma maneira efetiva de se conseguir uma boa performance do elemento.

O uso de coordenadas invariantes para modos de flexão pura requer um cuidadoso estudo da geometria do triângulo. Assumindo-se que os modos são escolhidos num sistema de coordenadas auxiliares rotacionados $\bar{x}$ e $\bar{y}$ (cujas versões adimensionais são $\bar{\xi}$ e $\bar{\eta}$ ) com origem no centróide 
do triângulo, figura 3.5, um modo de flexão pura no sistema $\bar{x}, \bar{y}$ pode ser definido de acordo com as seguintes equações:

$$
\bar{u}=\bar{\xi} \cdot \bar{\eta}, \quad \bar{v}=-\frac{1}{2} \cdot \bar{\xi}^{2}
$$

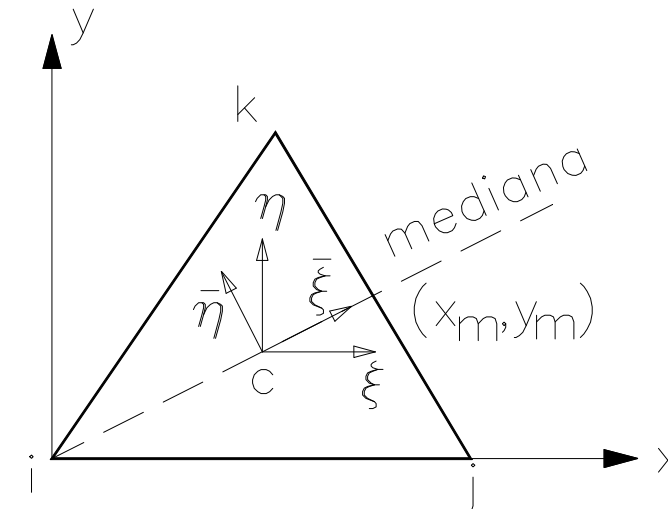

FIGURA 3.5 - Sistema de coordenadas auxiliares

Ressalta-se que a deformação cisalhante no sistema auxiliar é nula:

$$
\bar{\gamma}_{x y}=\frac{\partial \overline{\mathbf{u}}}{\partial \bar{y}}+\frac{\partial \overline{\mathbf{v}}}{\partial \bar{x}}=0
$$

Sendo $\varphi$ o ângulo entre os eixos $\xi$ e $\bar{\xi}$, o sistema pode ser rotacionado através da equação:

$$
\left\{\begin{array}{c}
\bar{\xi} \\
\bar{\eta}
\end{array}\right\}=\left[\begin{array}{cc}
\cos \varphi & \operatorname{sen} \varphi \\
-\operatorname{sen} \varphi & \cos \varphi
\end{array}\right] \cdot\left\{\begin{array}{c}
\xi \\
\eta
\end{array}\right\}
$$

A relação entre os modos de flexão pura no sistema auxiliar, equação 3.21, e as coordenadas locais adimensionais, é dada por: 


$$
\left\{\begin{array}{c}
- \\
\bar{u} \\
\bar{v}
\end{array}\right\}=\left[\begin{array}{ccc}
-\operatorname{sen} \varphi \cos \varphi & \cos ^{2} \varphi-\operatorname{sen}^{2} \varphi & \operatorname{sen} \varphi \cos \varphi \\
-\frac{1}{2} \cos ^{2} \varphi & -\operatorname{sen} \varphi \cos \varphi & -\frac{1}{2} \operatorname{sen}^{2} \varphi
\end{array}\right] \cdot\left\{\begin{array}{c}
\xi^{2} \\
\xi \eta \\
\eta^{2}
\end{array}\right\}
$$

A transformação entre componentes de deslocamentos locais e os deslocamentos referentes aos eixos auxiliares pode ser obtida pela seguinte equação:

$$
\left\{\begin{array}{l}
\mathbf{u} \\
\mathbf{v}
\end{array}\right\}=\left[\begin{array}{cc}
\cos \varphi & -\operatorname{sen} \varphi \\
\operatorname{sen} \varphi & \cos \varphi
\end{array}\right] \cdot\left\{\begin{array}{c}
- \\
\mathbf{u} \\
\bar{v}
\end{array}\right\}
$$

Substituindo-se a equação 3.25 na equação 3.24 temos os modos da equação 3.21, expressos diretamente no sistema local, que podem definidos da forma:

$$
\left\{\begin{array}{l}
u \\
v
\end{array}\right\}=\left[\begin{array}{ccc}
-\frac{1}{2} \operatorname{sen} \varphi \cos ^{2} \varphi & \cos ^{3} \varphi & \frac{1}{2} \operatorname{sen}^{3} \varphi+\operatorname{sen} \varphi \cos ^{2} \varphi \\
-\operatorname{sen}^{2} \varphi \cos \varphi-\frac{1}{2} \cos ^{3} \varphi & -\operatorname{sen}^{3} \varphi & \frac{1}{2} \operatorname{sen}^{2} \varphi \cos \varphi
\end{array}\right] \cdot\left\{\begin{array}{l}
\xi^{2} \\
\xi \eta \\
\eta^{2}
\end{array}\right\}
$$

Para que se tenham três modos de alta ordem do tipo da equação 3.21, é necessário que sejam selecionados três valores de $\varphi: \varphi_{1}, \varphi_{2}$ e $\varphi_{3}$, que devem ser intrinsicamente relacionados com a geometria do triângulo, figura 3.5. As direções dos três lados do elemento fornecem a escolha mais óbvia, mas nos leva a uma matriz G singular. Uma outra opção seria adotar as direções das três medianas do triângulo como eixo local auxiliar $\overline{\mathrm{x}}$, essa escolha fornece um conjunto de modos independentes.

Os três modos de alta ordem podem ser expressos, de forma expandida como: 
$U_{s}=N_{s} \cdot q_{s}=N_{s 1} \cdot q_{7}+N_{s 2} \cdot q_{8}+N_{s 3} \cdot q_{9}$

Em concordância com a equação 3.26, um modo típico pode ser expresso da seguinte maneira:

$\mathbf{N}_{s i}=\left\{\begin{array}{l}\mathbf{u}_{s i} \\ \mathbf{v}_{s i}\end{array}\right\}=\left[\begin{array}{lll}\mathbf{a}_{1 i} & \mathbf{a}_{2 i} & \mathbf{a}_{3 i} \\ \mathbf{b}_{1 \mathrm{i}} & \mathbf{b}_{2 i} & \mathbf{b}_{3 i}\end{array}\right] \cdot\left\{\begin{array}{c}\xi^{2} \\ \xi \eta \\ \eta^{2}\end{array}\right\} \quad, \quad i=1,2,3$

onde:

$a_{1 i}=-\frac{1}{2}\left(s_{i} \cdot c_{i}^{2}\right), \quad a_{2 i}=c_{i}^{3}, \quad a_{3 i}=\frac{1}{2}\left(s_{i}^{3}\right)+s_{i} \cdot c_{i}^{2}$,

$b_{1 i}=-s_{i}^{2} \cdot c_{i}-\frac{1}{2}\left(c_{i}^{3}\right), \quad b_{2 i}=-s_{i}^{3}, \quad b_{3 i}=\frac{1}{2}\left(s_{i}^{2} \cdot c_{i}\right)$,

$s_{i}=\operatorname{sen} \varphi_{i}=\frac{\left(\eta_{m}-\eta_{i}\right)}{\mu_{i}}=-\frac{3}{2} \cdot \frac{\eta_{i}}{\mu_{i}}$,

$\mathbf{c}_{i}=\cos \varphi_{i}=\frac{\left(\xi_{m}-\xi_{i}\right)}{\mu_{i}}=-\frac{3}{2} \cdot \frac{\xi_{i}}{\mu_{i}}$

Onde o índice $\mathrm{m}$ indica o ponto médio entre j e k. Aqui $\xi_{\mathrm{m}}, \eta_{\mathrm{m}}$ e $\mu_{\mathrm{i}}$ são as coordenadas adimensionais desse ponto, definidas pelas seguintes equações:

$$
\begin{aligned}
& \xi_{m}=\frac{1}{2} \cdot\left(\xi_{j}+\xi_{k}\right), \quad \eta_{m}=\frac{1}{2} \cdot\left(\eta_{j}+\eta_{k}\right), \\
& \mu_{i}=\sqrt{\left(\xi_{m}-\xi_{i}\right)^{2}+\left(\eta_{m}-\eta_{i}\right)^{2}}=\frac{3}{2} \cdot \sqrt{\xi_{i}^{2}+\eta_{i}^{2}}
\end{aligned}
$$

onde i, j e k denotam a permutação cíclica entre 1,2 e 3; por exemplo i = 2, j $=3, k=1$. 


\subsubsection{Equações de membrana}

Os graus de liberdade do elemento de membrana triangular escritos de forma vetorial são:

$$
\mathbf{V}^{\top}=\left[\begin{array}{lllllllll}
u_{1} & v_{1} & \theta_{1} & u_{2} & v_{2} & \theta_{2} & u_{3} & v_{3} & \theta_{3}
\end{array}\right]
$$

A relação entre os deslocamentos nodais, equação 3.32, e os parâmetros generalizados q são obtidos através da matriz $\mathbf{G}$ fazendo-se a apropriada substituição das coordenadas nodais nas funções de forma. $\mathbf{G}_{\mathrm{rc}}$ é uma sub-matriz (9X6) correspondente aos modos básicos e de deformação constante e $\mathbf{G}_{\mathrm{s}}$ é uma sub-matriz (9X3) correspondente aos modos de alta ordem.

$$
\mathbf{G}_{r c}=\left[\begin{array}{cccccc}
1 & 0 & -\eta_{i} & \xi_{i} & 0 & \eta_{i} \\
0 & 1 & \xi_{i} & 0 & \eta_{i} & \xi_{i} \\
0 & 0 & \lambda & 0 & 0 & 0 \\
1 & 0 & -\eta_{j} & \xi_{j} & 0 & \eta_{j} \\
0 & 1 & \xi_{j} & 0 & \eta_{j} & \xi_{j} \\
0 & 0 & \lambda & 0 & 0 & 0 \\
1 & 0 & -\eta_{k} & \xi_{k} & 0 & \eta_{k} \\
0 & 1 & \xi_{k} & 0 & \eta_{k} & \xi_{k} \\
0 & 0 & \lambda & 0 & 0 & 0
\end{array}\right]
$$

Particionando-se a sub-matriz $\mathbf{G}_{\mathrm{s}}$, obtém-se:

$$
\mathbf{G}_{\mathrm{s}}=\left[\begin{array}{lll}
\mathbf{G}_{\mathrm{s} 11} & \mathbf{G}_{\mathrm{s} 12} & \mathbf{G}_{\mathrm{s} 13} \\
\mathbf{G}_{\mathrm{s} 21} & \mathbf{G}_{\mathrm{s} 22} & \mathbf{G}_{\mathrm{s} 23} \\
\mathbf{G}_{\mathrm{s} 31} & \mathbf{G}_{\mathrm{s} 32} & \mathbf{G}_{\mathrm{s} 33}
\end{array}\right]
$$

onde: 
$\mathbf{G}_{s i j}=\left[\begin{array}{c}\mathbf{a}_{1 j} \cdot \xi_{i}^{2}+\mathbf{a}_{2 j} \cdot \xi_{i} \cdot \eta_{i}+\mathbf{a}_{3 j} \cdot \eta_{i}^{2} \\ \mathbf{b}_{1 j} \cdot \xi_{i}^{2}+\mathbf{b}_{2 j} \cdot \xi_{i} \cdot \eta_{i}+b_{3 j} \cdot \eta_{i}^{2} \\ -\lambda \cdot\left(\mathbf{c}_{j} \cdot \xi_{i}+s_{j} \cdot \eta_{i}\right)\end{array}\right]$

As deformações de membrana são encontradas pela apropriada diferenciação dos modos de deslocamento assumidos, assim tem-se:

$\varepsilon=\left\{\begin{array}{l}\varepsilon_{\mathrm{xx}} \\ \varepsilon_{\mathrm{yy}} \\ \gamma_{\mathrm{xy}}\end{array}\right\}=\left[\begin{array}{cc}\partial / \partial \mathbf{x} & 0 \\ 0 & \partial / \partial \mathbf{y} \\ \partial / \partial \mathrm{y} & \partial / \partial \mathrm{x}\end{array}\right] \cdot \mathbf{U}=\Delta \mathbf{N} \cdot \mathbf{q}=\mathbf{B}_{\mathrm{rc}} \cdot \mathbf{q}_{\mathrm{rc}}+\mathbf{B}_{\mathrm{s}} \cdot \mathbf{q}_{\mathrm{s}}$

onde $\Delta$ é o operador diferencial para deformações de membrana. Aplicando o operador na equação 3.20, obtém-se:

$\mathrm{B}_{\mathrm{rc}}=\Delta \mathrm{N}_{\mathrm{rc}}=\lambda \cdot\left[\begin{array}{llllll}0 & 0 & 0 & 1 & 0 & 0 \\ 0 & 0 & 0 & 0 & 1 & 0 \\ 0 & 0 & 0 & 0 & 0 & 2\end{array}\right]$

Fazendo-se o mesmo para os modos de alta ordem, obtém-se:

$B_{s}=\Delta N_{s}=\lambda \cdot\left[\begin{array}{ccc}2 a_{11} \xi+a_{21} \eta & 2 a_{12} \xi+a_{22} \eta & 2 a_{13} \xi+a_{23} \eta \\ b_{21} \xi+2 b_{31} \eta & b_{22} \xi+2 b_{32} \eta & b_{23} \xi+2 b_{33} \eta \\ -4 b_{31} \xi-4 a_{11} \eta & -4 b_{32} \xi-4 a_{12} \eta & -4 b_{33} \xi-4 a_{13} \eta\end{array}\right]$

As forças de membrana por unidade de comprimento, p, são relacionadas com as deformações através da matriz $\mathbf{D}_{\mathbf{m}}$ :

$$
\mathbf{p}=\left\{\begin{array}{l}
\mathbf{p}_{\mathrm{xx}} \\
\mathbf{p}_{\mathrm{yy}} \\
\mathbf{p}_{\mathrm{xy}}
\end{array}\right\}=\left[\begin{array}{lll}
\mathbf{D}_{11} & \mathbf{D}_{12} & \mathbf{D}_{13} \\
\mathbf{D}_{21} & \mathbf{D}_{22} & \mathbf{D}_{23} \\
\mathbf{D}_{31} & \mathbf{D}_{32} & \mathbf{D}_{33}
\end{array}\right] \cdot\left\{\begin{array}{l}
\varepsilon_{\mathrm{xx}} \\
\varepsilon_{\mathrm{yy}} \\
\gamma_{\mathrm{xy}}
\end{array}\right\}=\mathbf{D}_{\mathrm{m}} \cdot \varepsilon
$$


onde $\mathbf{D}_{\mathrm{m}}$ é a matriz que relaciona as forças de membrana por unidade de comprimento com as deformações. É essencialmente a matriz constitutiva da elasticidade, C, integrada ao longo da espessura do elemento. Esta integração reduz o volume $V_{\text {I }}$ para $A$, a área do elemento.

Os coeficientes da matriz $\mathbf{D}_{\mathrm{m}}$, da equação 3.39 , são admitidos como constantes ao longo de todo o elemento. Para um elemento de espessura t, material com módulo de elasticidade transversal E e coeficiente de Poisson $v$, a matriz $\mathbf{D}_{\mathrm{m}}$ pode ser expressa como:

$$
D_{m}=\frac{1}{1-v^{2}} \cdot\left[\begin{array}{ccc}
1 & v & 0 \\
v & 1 & 0 \\
0 & 0 & \frac{(1-v)}{2}
\end{array}\right]
$$

\subsubsection{Matriz "amontoadora"}

A matriz "amontoadora" $\mathbf{L}$, definida no capítulo II através da equação 2.10, para o caso geral de um elemento tridimensional, expressa a relação entre as forças nodais $\mathbf{t}_{\mathrm{c}}$ e um estado de deformação constante $\sigma_{\mathrm{c}}$. Similarmente, para o presente caso:

$t_{c}=L \cdot p_{c}$

onde $\mathbf{t}_{\mathrm{c}}$ são as forças nodais consistentes com as liberdades nodais, equação 3.32, e $\mathbf{p}_{\mathrm{c}}$ são as forças de membrana por unidade de comprimento, constantes ao longo do elemento. As forças de membrana, referidas ao sistema local de coordenadas, em um ponto que pertence a um lado do elemento podem ser determinadas utilizando-se as relações de transformação de coordenadas. Dessa forma, obtêm-se as equações: 


$$
\begin{aligned}
& \bar{p}_{x x}=p_{x x} \cdot \cos ^{2} \psi+p_{y y} \cdot \operatorname{sen}^{2} \psi+2 \cdot p_{x y} \cdot \operatorname{sen} \psi \cdot \cos \psi \\
& \bar{p}_{x y}=-p_{x x} \cdot \operatorname{sen} \psi \cdot \cos \psi+p_{y y} \cdot \operatorname{sen} \psi \cdot \cos \psi+p_{x y} \cdot\left(\cos ^{2} \psi-\operatorname{sen}^{2} \psi\right)
\end{aligned}
$$

Nas quais $\psi$ define a orientação do lado do elemento, conforme figura 3.6.
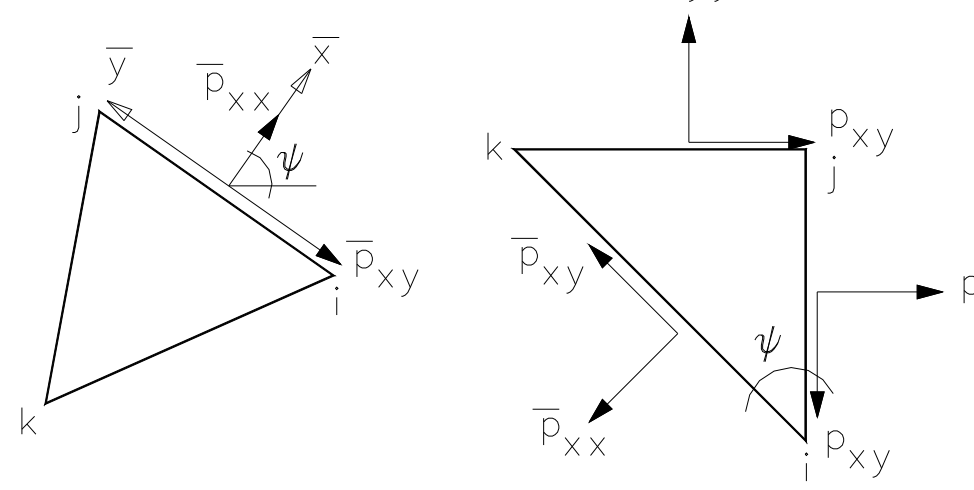

FIGURA 3.6 - Forças de membrana no lado do elemento

Em um estado arbitrário de deformação constante, quando a matriz constitutiva C não se altera no domínio do elemento, as forças calculadas em todos os pontos desse domínio, incluindo os seus lados, se mantêm inalterados.

Os deslocamentos ao longo do lado i-j, considerando-se o sistema de coordenadas locais $(\bar{x}, \bar{y})$, são dados pela transformação: 


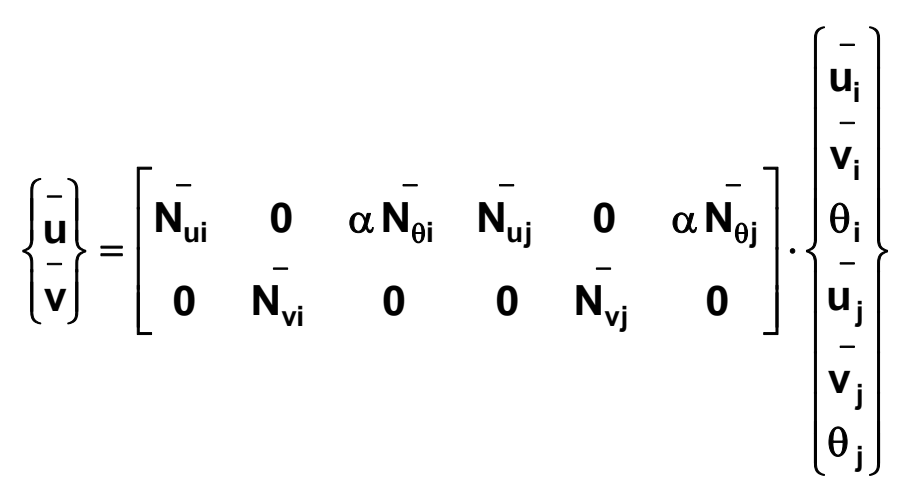

$\overline{\mathbf{N}}_{\mathrm{ui}}, \quad \overline{\mathbf{N}}_{\mathrm{uj}}, \quad \overline{\mathbf{N}}_{\theta \mathrm{i}}$ e $\quad \overline{\mathbf{N}}_{\theta \mathrm{j}}$ são funções de interpolação típicas de viga que definem o deslocamento $\bar{u}$ em termos dos deslocamentos nodais nos nós $\mathrm{i}$ e j. Similarmente, $\overline{\mathbf{N}}_{\mathrm{vi}}$ e $\overline{\mathbf{N}}_{\mathrm{vj}}$ são funções de interpolação lineares para a componente tangencial $\overline{\mathrm{v}}$.

Pode-se observar que um fator de escala $\alpha$ foi introduzido nas funções de forma, com o intuito de relacionar os deslocamentos normais do contorno do elemento com as rotações. Não existe uma relação única entre as rotações dos lados do elemento e as rotações definidas pela mecânica do contínuo, equação 3.14. O fator $\alpha$ funciona como um parâmetro de ligação entre os dois conceitos de rotação. A determinação das forças concentradas nos nós pode ser feita mediante aplicação do PTV e obtém-se:

$$
\begin{aligned}
t_{u j} & =\frac{l_{i j}}{2} \cdot\left(p_{x x} \cdot \cos \psi+p_{x y} \cdot \operatorname{sen} \psi\right)=\frac{1}{2}\left(y_{j i} \cdot p_{x x}+x_{i j} \cdot p_{x y}\right) \\
t_{v j} & =\frac{l_{i j}}{2} \cdot\left(p_{y y} \cdot \operatorname{sen} \psi+p_{x y} \cdot \cos \psi\right)=\frac{1}{2}\left(x_{i j} \cdot p_{y y}+y_{j i} \cdot p_{x y}\right) \\
t_{\theta j} & =\alpha \frac{I_{i j}^{2}}{12} \cdot\left(p_{x x} \cdot \cos ^{2} \psi+p_{y y} \cdot \operatorname{sen}^{2} \psi+2 \cdot p_{x y} \cdot \operatorname{sen} \psi \cdot \cos \psi\right) \\
& =\frac{\alpha}{12} \cdot\left(y_{j i}^{2} \cdot p_{x x}+x_{i j}^{2} \cdot p_{y y}+2 \cdot x_{i j} \cdot y_{j i} \cdot p_{x y}\right)
\end{aligned}
$$

onde $x_{i j}=x_{i}-x_{j}, y_{j i}=y_{j}-y_{i}, l_{i j}$ é o comprimento do lado do elemento. 
A contribuição do lado j-k para o nó j é obtida seguindo-se um procedimento similar, e a soma das duas contribuições fornece a força total no nó j. As forças transferidas aos dois outros nós são obtidas pela simples permutação de índices. A matriz "amontoadora", L, pode ser escrita da seguinte forma:

$$
L=\left\{\begin{array}{l}
L_{i} \\
L_{j} \\
L_{k}
\end{array}\right\}
$$

onde:

$$
L_{j}=\frac{1}{2} \cdot\left[\begin{array}{ccc}
y_{k i} & 0 & x_{i k} \\
0 & x_{i k} & y_{k i} \\
\frac{\alpha}{6}\left(y_{j i}^{2}-y_{k j}^{2}\right) & \frac{\alpha}{6}\left(x_{i j}^{2}-x_{j k}^{2}\right) & \frac{\alpha}{3}\left(x_{i j} \cdot y_{j i}-x_{j k} \cdot y_{k j}\right)
\end{array}\right]
$$

Se $\alpha=0$, tem-se a matriz "amontoadora" para o triângulo com deformação constante (CST). Para esse elemento as forças nodais são relacionadas apenas com translações.

\subsubsection{Matriz generalizada de alta ordem}

Para um elemento bidimensional, a matriz generalizada de alta ordem que aparece na equação 2.50 é:

$$
K_{q s}=\int_{A} B_{s}^{T} \cdot D_{m} \cdot B_{s} \cdot d A
$$


A matriz $\mathbf{B}_{\mathrm{s}}$ contém apenas funções lineares e é dada pela equação 3.38. Pode-se denominar a i-ésima coluna de $\boldsymbol{B}_{\mathrm{s}}$ de:

$B_{s i}=\xi \cdot B_{\xi i}+\eta \cdot B_{\eta i}$

onde $\mathbf{B}_{\xi}$ e $\mathbf{B}_{\eta}$ são os coeficientes de $\mathbf{B}_{s}$ associados com $\xi$ e $\eta$, respectivamente.

Assumindo-se que a matriz $\mathbf{D}_{\mathrm{m}}$ é constante ao longo de todo o elemento, os (i,j)-ésimos termos da matriz $\mathbf{K}_{\mathrm{qs}}$ podem ser expressos por:

$$
\begin{aligned}
\mathbf{K}_{\mathrm{qs}}(\mathbf{i}, \mathbf{j})= & \mathbf{J}_{\xi \xi} \mathbf{B}_{\xi \mathrm{j}}^{\top} \mathbf{D}_{\mathbf{m}} \mathbf{B}_{\xi j}+\mathbf{J}_{\xi \eta}\left(\mathbf{B}_{\xi \mathrm{i}}^{\top} \mathbf{D}_{\mathbf{m}} \mathbf{B}_{\eta \mathbf{j}}+\mathbf{B}_{\eta \mathbf{i}}^{\top} \mathbf{D}_{\mathbf{m}} \mathbf{B}_{\xi j}\right) \\
& +\mathbf{J}_{\eta \eta} \mathbf{B}_{\eta \mathrm{i}}^{\top} \mathbf{D}_{\mathbf{m}} \mathbf{B}_{\eta \mathbf{j}}
\end{aligned}
$$

Onde $\mathrm{J}_{\xi \xi}, \mathrm{J}_{\xi \eta}$ e $\mathrm{J}_{\eta \eta}$ são os momentos de inércia de área, dados pelas integrais:

$$
\begin{aligned}
& \mathbf{J}_{\xi \xi}=\int_{A} \xi^{2} \cdot d A=-\frac{A}{6} \cdot\left(\xi_{i} \xi_{j}+\xi_{j} \xi_{k}+\xi_{k} \xi_{i}\right) \\
& \mathbf{J}_{\xi \eta}=\int_{A} \xi \eta \cdot d A=\frac{A}{12} \cdot\left(\xi_{i} \eta_{i}+\xi_{j} \eta_{j}+\xi_{k} \eta_{k}\right) \\
& \mathbf{J}_{\eta \eta}=\int_{A} \eta^{2} \cdot d A=-\frac{A}{6} \cdot\left(\eta_{i} \eta_{j}+\eta_{j} \eta_{k}+\eta_{k} \eta_{i}\right)
\end{aligned}
$$

\subsubsection{A matriz de rigidez}

Em concordância com a formulação livre, a matriz de rigidez do elemento é formada pela superposição da matriz referente aos modos básicos com a matriz referente aos modos de alta ordem: 
$\mathrm{K}=\mathrm{K}_{\mathrm{b}}+\mathrm{K}_{\mathrm{s}}$

A matriz dos modos básicos, dada pela equação 2.48 , para o caso bidimensional fica:

$K_{b}=\frac{1}{A} \cdot L \cdot D_{m} \cdot L^{\top}$

A matriz dos modos de alta ordem, dada pela equação 2.49, para 0 presente caso fica:

$K_{s}=H_{s}^{\top} \cdot K_{q s} \cdot H_{s}$

Como já foi mencionado, a matriz de alta ordem pode ser multiplicada por um valor escalar positivo qualquer $\beta$, logo a matriz de rigidez total do elemento é dada por:

$\mathrm{K}=\mathrm{K}_{\mathrm{b}}+\beta \cdot \mathrm{K}_{\mathrm{s}}$

que satisfaz ao patch-test e ao requisito de ser positiva definida para convergência.

\subsubsection{Os parâmetros livres}

No item 3.2.5 um parâmetro $\alpha \geq 0$ foi introduzido na formulação da matriz "amontoadora", L. Esse parâmetro aparece como um fator de escala nas funções de forma, multiplicando os termos relacionados com os graus de liberdade rotacionais. O valor de $\alpha$ afeta a matriz dos modos básicos e 0 cálculo das deformações. 
Um segundo parâmetro, $\beta \geq 0$, pode ser introduzido multiplicando-se a matriz dos modos de alta ordem. Logo a matriz de rigidez da estrutura pode ser expressa da forma:

$\mathrm{K}=\mathrm{K}_{\mathrm{b}}+\beta \cdot \mathrm{K}_{\mathrm{s}}$

Justifica-se a utilização desses parâmetros porque a matriz de rigidez produzida pela formulação livre satisfaz o teste do elemento individual para qualquer matriz de rigidez que possua o "rank" (posto da matriz) apropriado. Consequentemente, a matriz $\mathbf{K}_{\mathrm{s}}$ pode ser multiplicada por um coeficiente positivo qualquer, sem que seja destruída a propriedade fundamental de convergência.

Os valores de $\alpha$ e $\beta$ foram estudados por BERGAN \& FELIPPA (1985) com o intuito de se aperfeiçoar as propriedades da rigidez do elemento. Chegou-se a conclusão de que um valor ótimo de $\alpha$ estaria entre 1 e 2 . Recomenda-se utilizar um valor médio de $\alpha=1.5$ para casos gerais.

O parâmetro $\beta$ para a matriz de alta ordem pode ser utilizado para ajustar a matriz de rigidez total, $\mathbf{K}$, e com isso otimizar a convergência. A determinação de um valor ótimo para $\beta$ por técnicas de equilíbrio de energia é discutida por BERGAN \& FELIPPA (1985). Como resultado das pesquisas, esses autores recomendam o valor $\beta=0.5$ combinado com o fator de rotação $\alpha=1.5$, para uso geral e prático.

\subsubsection{Determinação das deformações e tensões}

Desde que os deslocamentos são conhecidos, as deformações podem ser obtidas através da equação: 


$$
\varepsilon=\varepsilon_{c}+\varepsilon_{s}=B_{r c} \cdot q_{r c}+\sqrt{\beta} \cdot B_{s} \cdot q_{s}=\left(B_{r c} \cdot H_{r c}+\sqrt{\beta} \cdot B_{s} \cdot H_{s}\right) \cdot v
$$

Nota-se que a parte de corpo rígido de $\mathbf{B}_{\mathrm{rc}}$ é nula, e que $\varepsilon_{\mathrm{s}}$ desaparece no centróide de elemento $(\xi=\eta=0)$. Alternativamente, $\varepsilon_{c}$ pode ser obtida através da matriz "amontoadora", L:

$$
\varepsilon_{c}=\frac{1}{A} \cdot L \cdot V
$$

O uso de $\sqrt{\beta}$ na equação 3.56 torna consistente em energia a relação deformação/deslocamento com a matriz de alta ordem.

As deformações $\varepsilon_{\mathrm{s}}$, que são associadas aos modos de alta ordem, variam linearmente ao longo do elemento. Seus valores nos vértices do elemento podem ser obtidos através da substituição apropriada das coordenadas nodais em $\mathbf{B}_{\mathrm{s}}$.

Uma vez obtidas as deformações, as correspondentes tensões são facilmente obtidas através da equação:

$\sigma=\mathbf{C} \cdot \varepsilon$

\subsubsection{Formação do elemento quadrilateral}

No presente trabalho o elemento quadrilateral é formado pela composição de quatro elementos triangulares, com posterior condensação estática dos parâmetros internos, figura 3.7. 


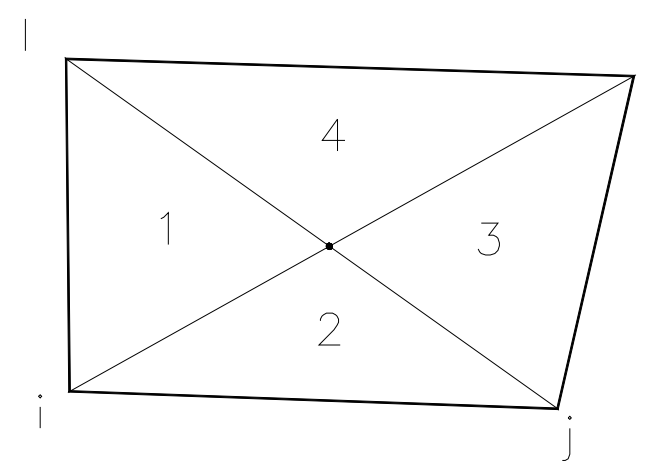

FIGURA 3.7 - Quadrilátero formado por quatro triângulos

A técnica da condensação estática é aplicada para reduzir o número de graus de liberdade, eliminando-se os graus de liberdade internos quando se faz a montagem da matriz de rigidez do elemento.

A matriz de rigidez $\mathbf{K}$ do quadrilátero relaciona-se com 0 vetor de deslocamentos $\mathbf{V}$ e o vetor de cargas $\mathbf{F}$, através da equação:

$\mathbf{K} \cdot \mathbf{V}=\mathbf{F}$

Particionando-se o vetor de deslocamentos nodais $\mathbf{V}$ em $\mathbf{v}_{\mathrm{i}}$ e $\mathbf{v}_{\mathrm{e}}$, onde $\mathbf{v}_{\mathrm{i}}$ são os deslocamentos nodais relacionados aos nós internos do elemento, à serem eliminados e $\mathbf{v}_{\mathrm{e}}$ são os deslocamentos relacionados aos nós externos, figura 3.8 .

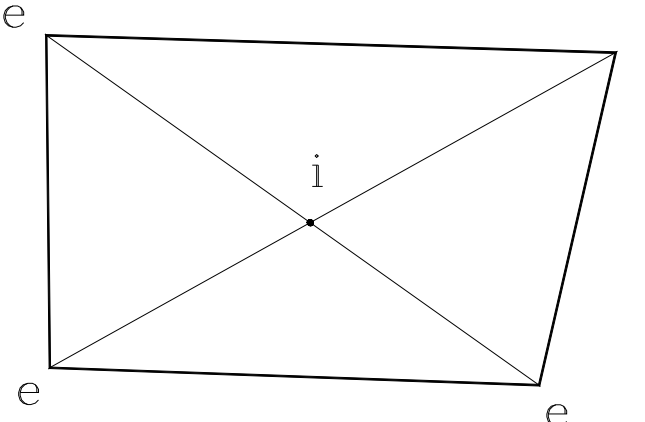

FIGURA 3.8 - Nós internos e externos do elemento quadrilateral 
Separando-se os parâmetros localizados nos vértices do quadrilátero dos parâmetros internos, as equações de equilíbrio podem ser escritas como:

$$
\left[\begin{array}{ll}
K_{i i} & K_{i e} \\
K_{e i} & K_{e e}
\end{array}\right] \cdot\left\{\begin{array}{c}
v_{i} \\
v_{e}
\end{array}\right\}=\left\{\begin{array}{c}
F_{i} \\
F_{e}
\end{array}\right\}
$$

Da expressão 3.60 tem-se:

$$
\begin{aligned}
& F_{i}=K_{i i} \cdot v_{i}+K_{i e} \cdot v_{e} \\
& F_{e}=K_{e i} \cdot v_{i}+K_{e e} \cdot v_{e}
\end{aligned}
$$

A solução das equações associadas a $\mathbf{v}_{\mathrm{i}}$ fica da forma:

$$
v_{i}=K_{i i}^{-1} \cdot\left(F_{i}-K_{i i} \cdot v_{e}\right)
$$

Levando-se esse resultado à equação 3.61b, tem-se:

$$
\overline{\mathrm{K}}_{\mathrm{ee}} \cdot \mathbf{v}_{\mathrm{e}}=\overline{\mathrm{F}}_{\mathrm{e}}
$$

onde:

$$
\begin{aligned}
& \overline{\mathrm{K}}_{\mathrm{ee}}=\mathrm{K}_{\mathrm{ee}}-\mathrm{K}_{\mathrm{ei}} \cdot \mathrm{K}_{\mathrm{ii}}^{-1} \cdot \mathrm{K}_{\mathrm{ie}} \\
& \overline{\mathrm{F}}_{\mathrm{e}}=\mathrm{F}_{\mathrm{e}}-\mathrm{K}_{\mathrm{ei}} \cdot \mathrm{K}_{\mathrm{ii}}^{-1} \cdot \mathrm{F}_{\mathrm{i}}
\end{aligned}
$$


$\overline{\mathbf{K}}_{\text {ee }}$ é a matriz de rigidez reduzida e $\overline{\mathbf{F}}_{\mathrm{e}}$ o vetor de forças alterado, correspondentes aos graus de liberdade externos, com a inclusão dos efeitos das liberações realizadas nos graus de liberdade internos. 


\section{CAPÍTULO IV}

A IMPLEMENTAÇÃO

\subsection{INTRODUÇÃO}

Neste capítulo procura-se esclarecer a implementação computacional e a maneira como foi feita a compatibilização da rotina desenvolvida e o sistema LASER, RAMALHO (1990). O objetivo do presente capítulo é apresentar as características gerais do sistema LASER e da rotina. Para um estudo mais aprofundado do sistema LASER é necessário que se recorra à referência citada.

\subsection{O SISTEMA LASER}

O sistema LASER, Linguagem para Análise de Sistemas Estruturais Reticulados, desenvolvido por RAMALHO (1990) é um conjunto de rotinas voltadas para as diversas etapas envolvidas em uma análise estrutural de grande porte. Trata-se de um sistema computacional para análise elástica linear de grandes estruturas em microcomputadores. Para a discretização da estrutura o sistema possui elementos que permitem a simulação adequada das mais diversas peças estruturais. Estão disponíveis os seguintes elementos: treliça, barra, membrana, sólido, placa, casca, contorno e sapata rígida. Todos esses elementos são compatíveis entre si, podendo ser utilizados simultaneamente e constituindo um sistema computacional único.

O sistema foi estruturado em forma de módulos prevendo-se as futuras modificações que poderia sofrer para um constante aprimoramento ao longo do tempo. Dessa forma para que se faça uma implementação, em 
um determinado elemento, não é necessário que se conheça toda a estrutura do programa. Basta que se faça as modificações na rotina referente ao elemento que se pretende aperfeiçoar ou alterar. No presente trabalho, programou-se um novo elemento na rotina referente ao elemento de membrana, trocando-se o elemento existente por um outro, de melhor performance.

Cada tipo de elemento disponível para uso no programa LS tem seu próprio conjunto de código. Portanto seus recursos e potencialidade são muitas vezes bastante diferentes, existindo, entretanto determinadas características gerais que podem ser encontradas em todos esses tipos. Neste item comenta-se algumas dessas características comuns, deixandose características particulares ao novo elemento de membrana para os próximos itens.

Tratando-se de um programa baseado no processo dos deslocamentos, é fundamental que ao final das rotinas relativas aos elementos tenham sido calculados a matriz de rigidez e o vetor de cargas nodais. Esses dois conjuntos de dados serão utilizados na montagem do sistema global de equações. Considerando-se que a rotina que realiza a montagem do sistema de equações é única e trabalha com todos os tipos de elementos, é importante que tanto a matriz como o vetor seja construído em relação ao sistema global de referência. Assim sendo, para levar essas contribuições ao sistema de equações globais, basta saber em que graus de liberdade deve-se contribuir com cada rigidez. No esquema adotado pelo programa isso se dá através de um vetor onde esses graus de liberdade terão seus números armazenados. As tensões e/ou esforços para os elementos são obtidos pela simples multiplicação de uma matriz que relaciona essas grandezas a serem calculadas com os deslocamentos nodais obtidos no processamento e posterior adição de eventuais tensões e/ou esforços iniciais. Para esse procedimento é necessário que as rotinas dos elementos construam a matriz que relaciona tensões e/ou esforços com 
os deslocamentos e o vetor de tensões e/ou esforços iniciais. A saída dos valores calculados é realizada pela própria rotina de comando de cada tipo de elemento, através da formatação conveniente.

\subsection{A ROTINA DESENVOLVIDA}

\subsubsection{Caracterização do elemento}

O elemento de membrana é utilizado para a análise de estado plano de tensão. É definido por três ou quatro pontos nodais (conforme seja triangular ou quadrilateral) e pode ser colocado em qualquer posição do espaço definido pelo sistema de referência global da estrutura, conforme a figura 4.1.

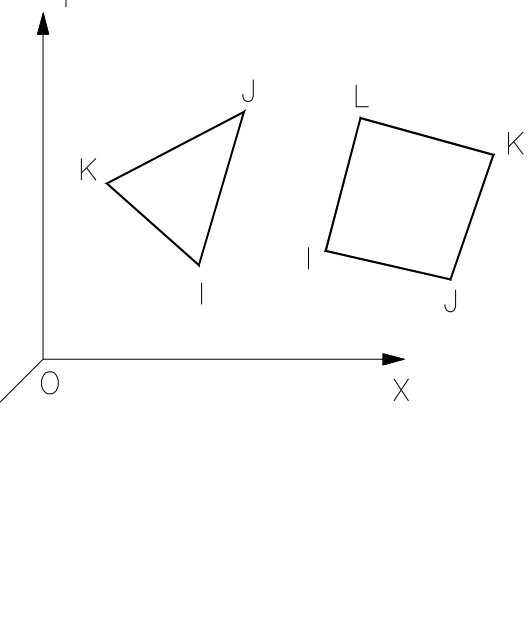

FIGURA 4.1 - Elementos de membrana de três e quatro nós

O elemento possui seis graus de liberdade por nó, três translações e três rotações de um ponto no espaço. O sistema de referência local é composto por dois eixos normais, $x$ e y. Esses eixos locais são definidos pela numeração dos nós do elemento, seja ele triangular ou quadrilateral. $O$ 
eixo local x está colocado sobre o lado I-J, com direção positiva definida de "I" para "J". Já o eixo local y é normal a x conforme se mostra na figura 4.2.
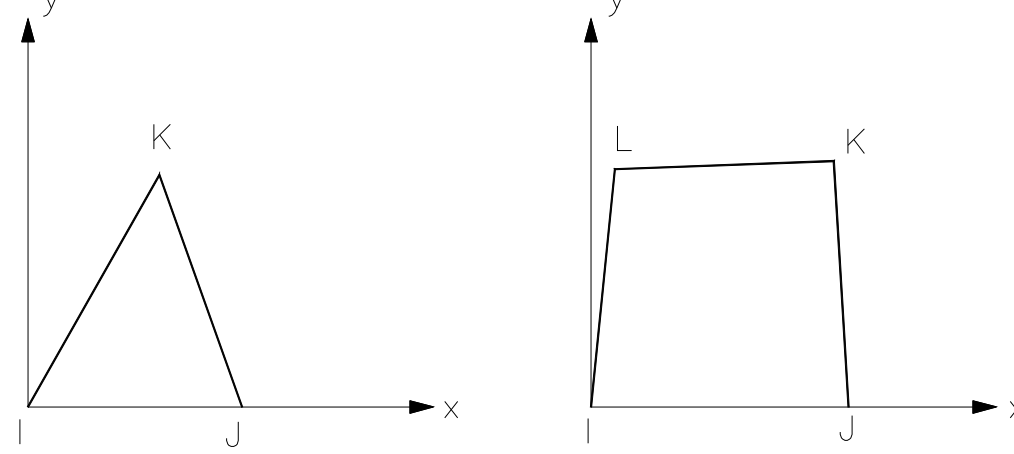

FIGURA 4.2 - Sistemas locais de referência

O elemento permite apenas a consideração de material isotrópico e os parâmetros a serem fornecidos são: o módulo de elasticidade longitudinal E, o coeficiente de Poisson v e o módulo de elasticidade transversal G.

É interessante mencionar que o elemento em questão pode degenerar no elemento CST (Constant Strain Triangle). Caso o usuário deseje trabalhar com o elemento CST é necessário informar ao programa para que as liberdades rotacionais sejam desconsideradas, caso contrário o programa vai trabalhar com esses graus de liberdade.

Por apresentar rigidez apenas no seu próprio plano, o elemento também só resiste a carregamentos contidos nesse plano. É possível a definição de carregamento distribuído constante, na direção normal e na própria direção do lado I-J de cada elemento. É admitido o cálculo automático de peso próprio, através de frações atuantes segundo os eixos globais da estrutura.

A utilização do elemento aqui analisado é bastante ampla, incluindose nessa relação todos os casos de estruturas bidimendionais carregadas 
exclusivamente no seu próprio plano, por exemplo, vigas paredes e chapas diversas.

\subsubsection{Coordenadas globais e locais}

As coordenadas do elemento segundo um sistema local são apresentadas na figura 4.3 .

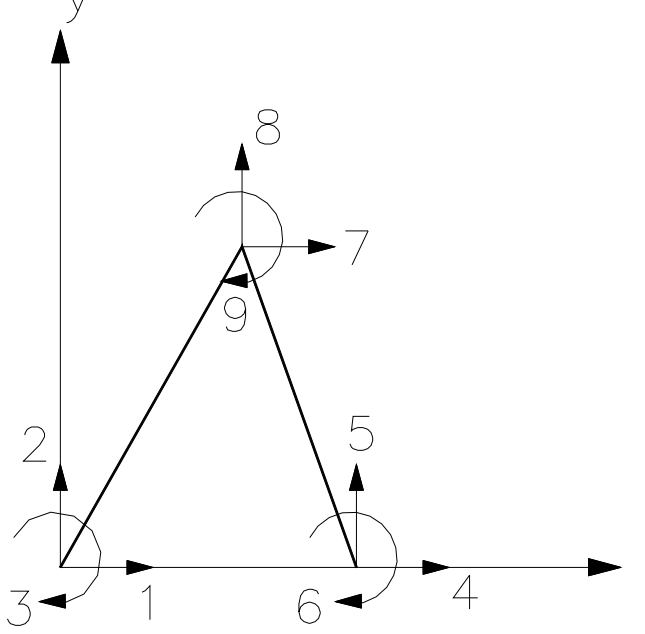

FIGURA 4.3 - Coordenadas locais

Nessas coordenadas podem ser definidos os vetores de forças e deslocamentos locais $\mathbf{f}$ e $\mathbf{d}$ :

$$
f=\left\{\begin{array}{c}
f_{1} \\
f_{2} \\
\cdot \\
\cdot \\
f_{9}
\end{array}\right\}
$$

$$
d=\left\{\begin{array}{c}
d_{1} \\
d_{2} \\
\cdot \\
\cdot \\
d_{9}
\end{array}\right\}
$$


Quanto às coordenadas globais, ou seja, forças e deslocamentos segundo o sistema de referência global da estrutura, a situação é apresentada na figura 4.4, para o primeiro nó do elemento.

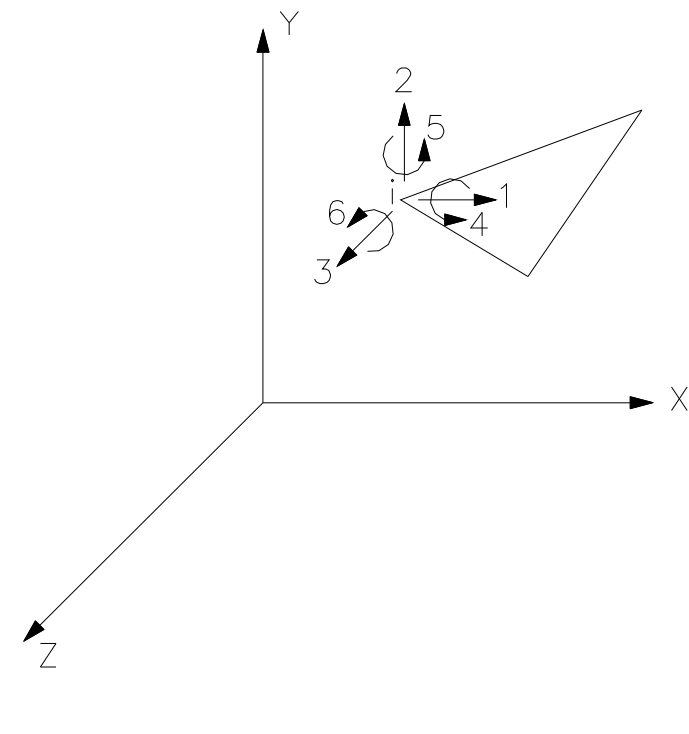

FIGURA 4.4 - Coordenadas globais

Observando-se a referida figura, percebe-se que os vetores de forças e deslocamentos terão agora seis parâmetros por nó e podem ser escritos da seguinte forma:
$F=\left\{\begin{array}{c}F_{1} \\ F_{2} \\ \cdot \\ \cdot \\ F_{18}\end{array}\right\}$
$D=\left\{\begin{array}{c}D_{1} \\ D_{2} \\ \cdot \\ \cdot \\ D_{18}\end{array}\right\}$

A relação entre esforços e deslocamentos locais e globais pode ser definida através de uma matriz de transformação $\lambda$, de nove linhas e dezoito colunas, segundo as relações que se seguem: 
$\mathbf{f}=\lambda \cdot \mathbf{F}$

$\mathbf{d}=\lambda \cdot \mathbf{D}$

A referida matriz $\lambda$ é calculada pelos cossenos diretores dos eixos locais em relação aos eixos globais $X, Y$ e Z . A figura 4.5 mostra a situação do elemento no espaço e a figura 4.6 detalha esses cossenos e esclarece a nomenclatura adotada.

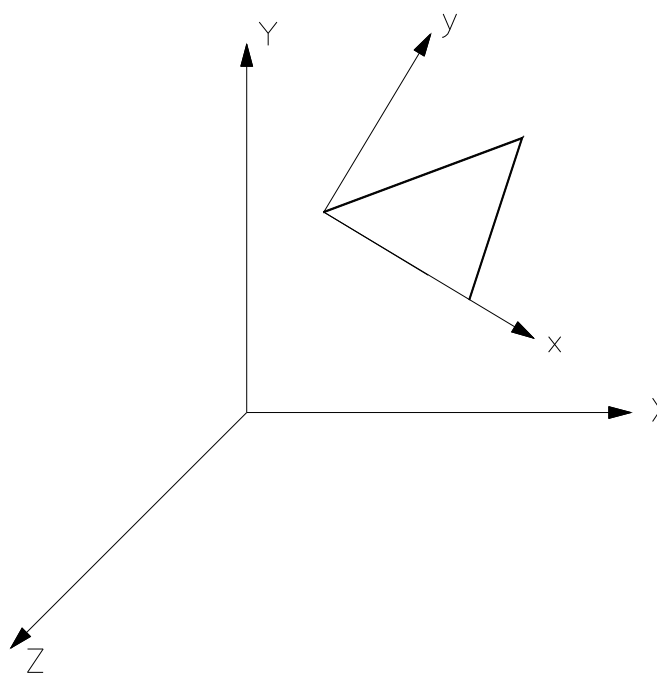

FIGURA 4.5 - Sistema local e global 


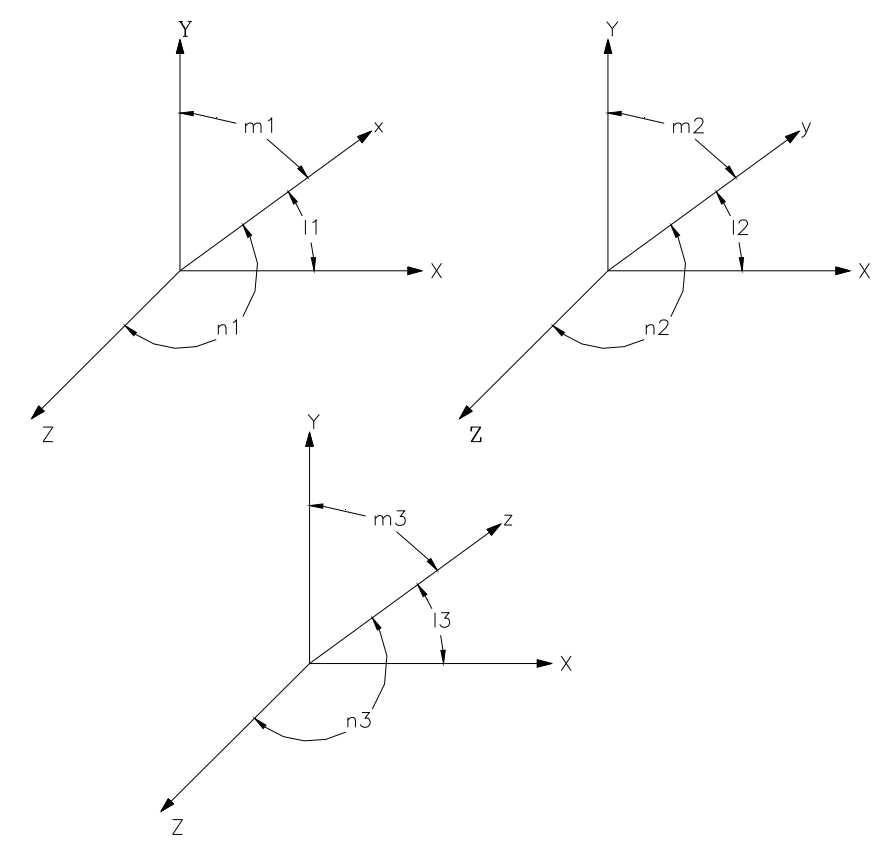

FIGURA 4.6 - Cossenos diretores dos eixos locais

Desse modo, a matriz $\lambda$ pode ser expressa da forma:

$$
\lambda=\left[\begin{array}{ccc}
\lambda_{0} & 0 & 0 \\
0 & \lambda_{0} & 0 \\
0 & 0 & \lambda_{0}
\end{array}\right]
$$

onde,

$$
\lambda_{0}=\left[\begin{array}{cccccc}
\mathrm{l}_{1} & \mathrm{~m}_{1} & \mathrm{n}_{1} & 0 & 0 & 0 \\
\mathrm{l}_{2} & \mathrm{~m}_{2} & \mathrm{n}_{2} & 0 & 0 & 0 \\
0 & 0 & 0 & \mathrm{l}_{3} & \mathrm{~m}_{3} & \mathrm{n}_{3}
\end{array}\right] \quad \text { e } \quad 0=\left[\begin{array}{llllll}
0 & 0 & 0 & 0 & 0 & 0 \\
0 & 0 & 0 & 0 & 0 & 0 \\
0 & 0 & 0 & 0 & 0 & 0
\end{array}\right]
$$

\subsubsection{Matriz de rigidez nas coordenadas globais}

A matriz de rigidez nas coordenadas locais, $\mathbf{K}$, é a matriz que relaciona as forças e deslocamentos nessas coordenadas, segundo a equação: 
$\mathbf{f}=\mathbf{K} \cdot \mathbf{d}$

A matriz $\mathbf{K}$ foi formulada no capítulo III e agora é necessário obter-se a matriz de rigidez no sistema global de coordenadas. Para tanto se utiliza a matriz de rotação da equação 4.4. Desse modo, pode-se colocar o elemento em qualquer posição do espaço, o que o torna compatível com o sistema LASER. Utilizando-se às equações 4.3 e 4.5, tem-se:

$\lambda \cdot \mathbf{F}=\mathbf{K} \cdot \lambda \cdot \mathbf{D}$

No presente caso, a matriz $\lambda$ é uma matriz de rotação. Portanto sua inversa é igual à transposta. Logo pode-se escrever:

$\mathbf{F}=\lambda^{\top} \cdot \mathbf{K} \cdot \lambda \cdot \mathbf{D}$

Ou seja, a matriz de rigidez do elemento em relação aos eixos de referência globais resulta:

$\mathbf{R}=\lambda^{\top} \cdot \mathbf{K} \cdot \lambda$

\subsubsection{Matriz da relação tensão/deslocamento}

Considere-se a relação entre as tensões e as deformações dada pela equação:

$\sigma=\mathbf{C} \cdot \boldsymbol{\varepsilon}$

A matriz C, matriz constitutiva do elemento tem a seguinte forma: 
$C=\left[\begin{array}{ccc}\frac{E}{1-v^{2}} & \frac{E \cdot v}{1-v^{2}} & 0 \\ \frac{E \cdot v}{1-v^{2}} & \frac{E}{1-v^{2}} & 0 \\ 0 & 0 & G\end{array}\right]$

As deformações são obtidas a partir dos deslocamentos d e da matriz $\mathbf{B}$, que relaciona deformações com deslocamentos, ou seja:

$\varepsilon=\mathrm{B} \cdot \mathrm{d}$

As componentes do vetor $\varepsilon$, deformações do elemento em função do sistema de referência local, podem ser escritas como:

$$
\begin{aligned}
& \varepsilon_{x}=\frac{\partial u}{\partial x} \\
& \varepsilon_{y}=\frac{\partial v}{\partial y} \\
& \gamma_{x y}=\frac{\partial u}{\partial y}+\frac{\partial v}{\partial x}
\end{aligned}
$$

A matriz que relaciona as tensões com os deslocamentos é montada em função dos pontos do elemento nos quais os resultados serão apresentados. Considerando-se as equações 4.3 e 4.9, obtém-se:

$$
\sigma=\mathbf{C} \cdot \mathbf{B} \cdot \lambda \cdot \mathbf{D}
$$

Imaginando-se que as tensões sejam calculadas num ponto determinado para as direções i e j, tem-se:

$$
\sigma_{\mathrm{ij}}=\mathbf{C} \cdot \mathbf{B}_{\mathrm{ij}} \cdot \lambda \cdot \mathbf{D}
$$


No caso da rotina desenvolvida as tensões serão apresentadas no centróide e nos vértices do elemento. A matriz da relação, denominada TD, pode ser escrita da forma:

$\mathrm{TD}=\mathrm{C} \cdot \mathrm{B}_{\mathrm{ij}} \cdot \lambda$

\subsubsection{Vetor de cargas}

São permitidos dois tipos de carregamento sobre o elemento: forças de superfície atuantes na face I-J e peso próprio. Os vetores de carga, para cada carregamento, são portanto formados considerando-se esses dois efeitos.

Quanto ao carregamento sobre a face, somente podem ser definidos valores constantes, na direção normal e na sua própria direção, cujos sentidos positivos são mostrados na figura 4.7 .

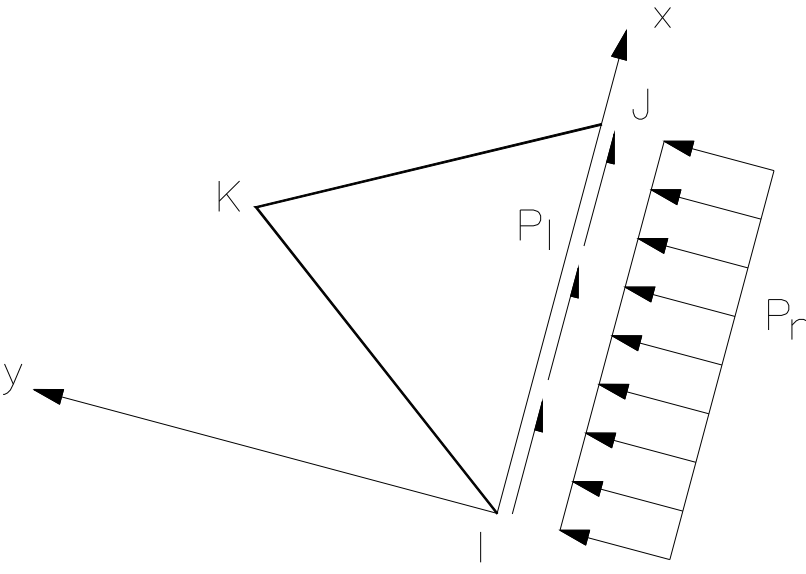

FIGURA 4.7 - Forças de superfície sobre a face I-J

Em função das coordenadas locais, o vetor de cargas devido às tensões pode ser encontrado pela equação: 
$p_{1}=L \cdot P$

O vetor de cargas nodais $\mathbf{p}_{1}$ em coordenadas locais, correspondente às forças de superfície atuantes na face do elemento, é dada pela equação:

$$
p_{1}=\left\{\begin{array}{l}
p_{i u} \\
p_{i v} \\
p_{i \theta} \\
p_{j u} \\
p_{j v} \\
p_{j \theta}
\end{array}\right\}=\left\{\begin{array}{c}
\frac{1}{2} \cdot x_{i j} \cdot p_{I} \\
\frac{1}{2} \cdot x_{i j} \cdot p_{n} \\
\frac{1}{12} \cdot x_{i j}^{2} \cdot p_{n} \\
\frac{1}{2} \cdot x_{i j} \cdot p_{I} \\
\frac{1}{2} \cdot x_{i j} \cdot p_{n} \\
-\frac{1}{12} \cdot x_{i j}^{2} \cdot p_{n}
\end{array}\right\}
$$

onde $x_{i j}=x j-x i, p_{n}$ é a carga distribuída normal ao lado l-J e $p_{\mathrm{l}}$ é a carga linearmente distribuída ao longo do lado I-J, figura 4.7.

Para se calcular o vetor de cargas $\mathbf{P}_{1}$, em relação às coordenadas globais, basta fazer:

$$
P_{1}=\lambda^{\top} \cdot p_{1}
$$

O peso próprio não será calculado como carga consistente, mas simplesmente colocado segundo as direções globais de acordo com frações definidas pelo usuário. Desse modo, é necessário o cálculo do volume (área $x$ espessura) associado a cada um dos nós.

Assim, o vetor de contribuição do peso próprio $\mathbf{P}_{2}$, já em coordenadas globais resulta: 
$\mathbf{P}_{2}=\gamma \cdot\left\{\begin{array}{l}\mathbf{p}_{2 \mathrm{i}} \\ \mathbf{p}_{2 \mathrm{j}} \\ \mathbf{p}_{2 \mathrm{k}}\end{array}\right\}$

onde:

$p_{2 i}=\left\{\begin{array}{c}v_{i} \cdot a_{x} \\ V_{i} \cdot a_{y} \\ v_{i} \cdot a_{z} \\ 0 \\ 0 \\ 0\end{array}\right\}$

onde $a_{x}, a_{y}$ e $a_{z}$ são as frações do peso próprio a serem consideradas segundo os eixos $x, y$ e $z$.

Portanto, para o vetor de cargas do elemento obtém-se:

$$
P E=P_{1}+P_{2}
$$




\section{CAPÍTULO V \\ EXEMPLOS}

\subsection{INTRODUÇÃO}

Nesse capítulo apresentam-se alguns exemplos da utilização do elemento desenvolvido com a finalidade de verificar o seu desempenho e compará-lo com outros elementos já existentes e de eficiência comprovada. Para isso, procurou-se testar o elemento com exemplos clássicos e que apresentassem da melhor forma possível o desempenho do mesmo.

\subsection{EXEMPLO 1}

Esse primeiro exemplo trata de uma viga em balanço com uma carga parabolicamente distribuída ao longo da extremidade livre, figura 5.1. O problema foi proposto por BERGAN \& FELIPPA (1985) com a intenção de se verificar o desempenho do elemento quando sujeito a um carregamento predominante de flexão.

A viga, mostrada na figura 5.1, está sob a ação de uma carga total $P$, possui módulo de elasticidade longitudinal $E=30.000$ e coeficiente de Poisson $v=1 / 4$. A rede típica utilizada nas discretizações da estrutura está ilustrada na figura 5.2. As redes são constituídas de dois triângulos retângulos, para o caso do elemento triangular, ou de um quadrado, para o caso do elemento quadrilateral. As redes são definidas na tabela 5.1 por $\left(\mathrm{N}_{\mathrm{x}}\right.$ $x N_{y}$ ), onde $N_{x}$ é o número de subdivisões na direção $x$ e $N_{y}$ é o número de 
subdivisões na direção y. As condições de contorno são representadas pelo impedimento das duas translações, nas direções $x$ e y, nos nós localizados na seção $x=0$. As rotações nodais são livres.

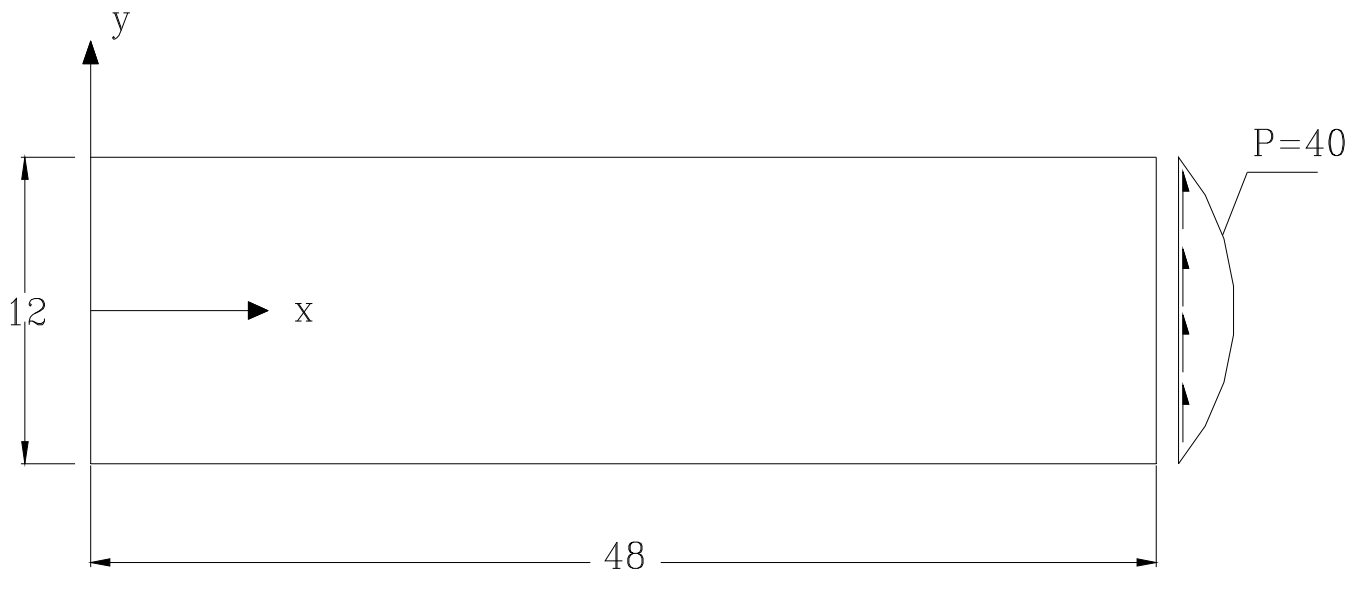

FIGURA 5.1 - Viga em balanço

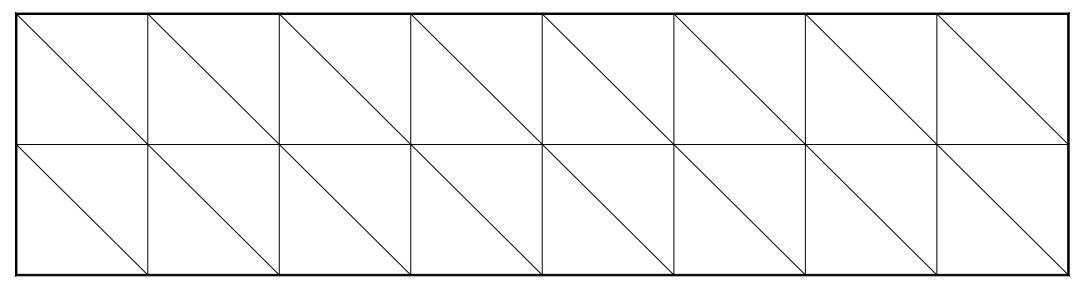

FIGURA 5.2 - Rede típica para elemento triangular (8x2)

$\mathrm{Na}$ tabela 5.1 apresentam-se os resultados obtidos para 4 discretizações diferentes da viga. Para efeito de comparação apresentam-se os resultados obtidos com os elementos: CST, PE (elemento apresentado por BERGAN \& FELIPPA(1985), desenvolvido pela formulação tradicional via energia potencial utilizando-se as mesmas funções de forma adotadas no presente trabalho), o elemento isoparamétrico implementado por RAMALHO (1990) no sistema LASER e o elemento desenvolvido no presente trabalho, variando-se os valores dos parâmetros livres.

TABELA 5.1 - Deslocamento da viga utilizando-se elementos triangulares. 


\begin{tabular}{|l|c|c|c|c|}
\hline ELEMENTO & $\begin{array}{c}1 \\
(4 \times 1)\end{array}$ & $\begin{array}{c}2 \\
(8 \times 2)\end{array}$ & $\begin{array}{c}3 \\
(16 \times 4)\end{array}$ & $\begin{array}{c}4 \\
(32 \times 8)\end{array}$ \\
\hline CST & 0.09095 & 0.19657 & 0.29411 & 0.33778 \\
\hline PE & 0.21421 & 0.31893 & 0.36284 & 0.37654 \\
\hline FF-1 $(\alpha=1.5, \beta=0.5)$ & 0.34498 & 0.35435 & 0.35529 & 0.35567 \\
\hline FF-2 $(\alpha=1.5, \beta=1.0)$ & 0.26776 & 0.32779 & 0.34745 & 0.35313 \\
\hline FF-3 $(\alpha=1.0, \beta=1.0)$ & 0.18812 & 0.28282 & 0.32249 & 0.34899 \\
\hline ISOPARAMÉTRICO & 0.14024 & 0.28467 & 0.39360 & 0.43995 \\
\hline VALOR TEÓRICO & \multicolumn{4}{|c|}{0.35583} \\
\hline
\end{tabular}

Utilizando-se a rede discretizada em triângulos chega-se a conclusão que o elemento desenvolvido apresenta uma boa performance. Quando comparado com o CST nota-se que apesar desse também convergir, exige uma rede mais refinada para apresentar resultados satisfatórios. O elemento PE não converge, os resultados são razoáveis para redes pouco refinadas, mas à medida em a rede vai sendo refinada o elemento diverge. De acordo com BERGAN \& FELIPPA (1985) esse efeito acontece devido à perda de energia dos elementos não-conformes que não satisfazem ao patch-test. Comparando-se os resultados obtidos com as três opções da formulação livre percebe-se que o ajuste dos parâmetros livres acelera a convergência dos resultados.

$\mathrm{Na}$ figura 5.3 apresenta-se o gráfico de convergência dos elementos CST, PE e da formulação livre utilizando-se os valores recomendados dos parâmetros livres. O gráfico ilustra com maior clareza a convergência dos resultados obtidos. Na figura 5.4 compara-se os resultados obtidos com a variação dos parâmetros livres. 


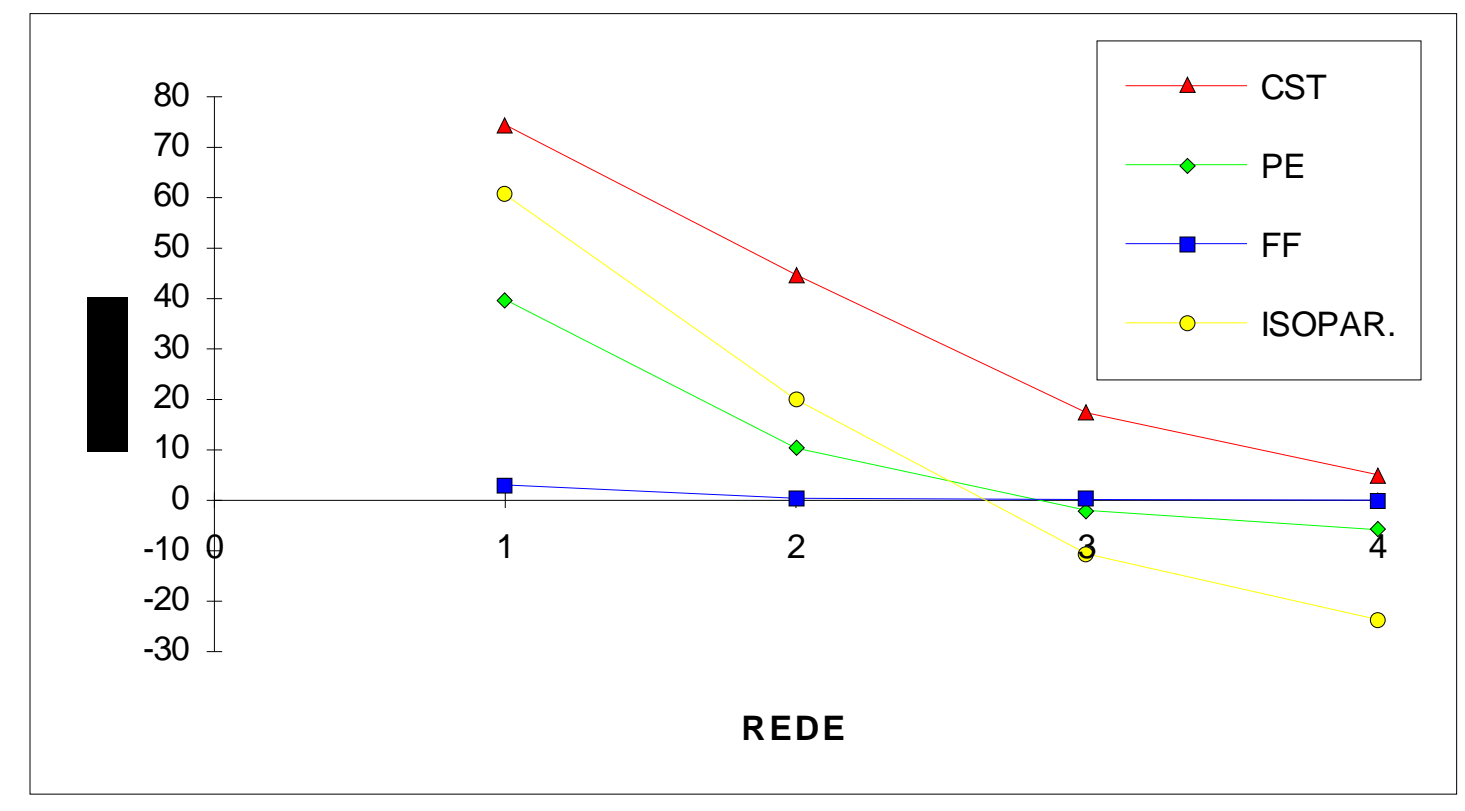

FIGURA 5.3 - Gráfico de convergência dos deslocamentos

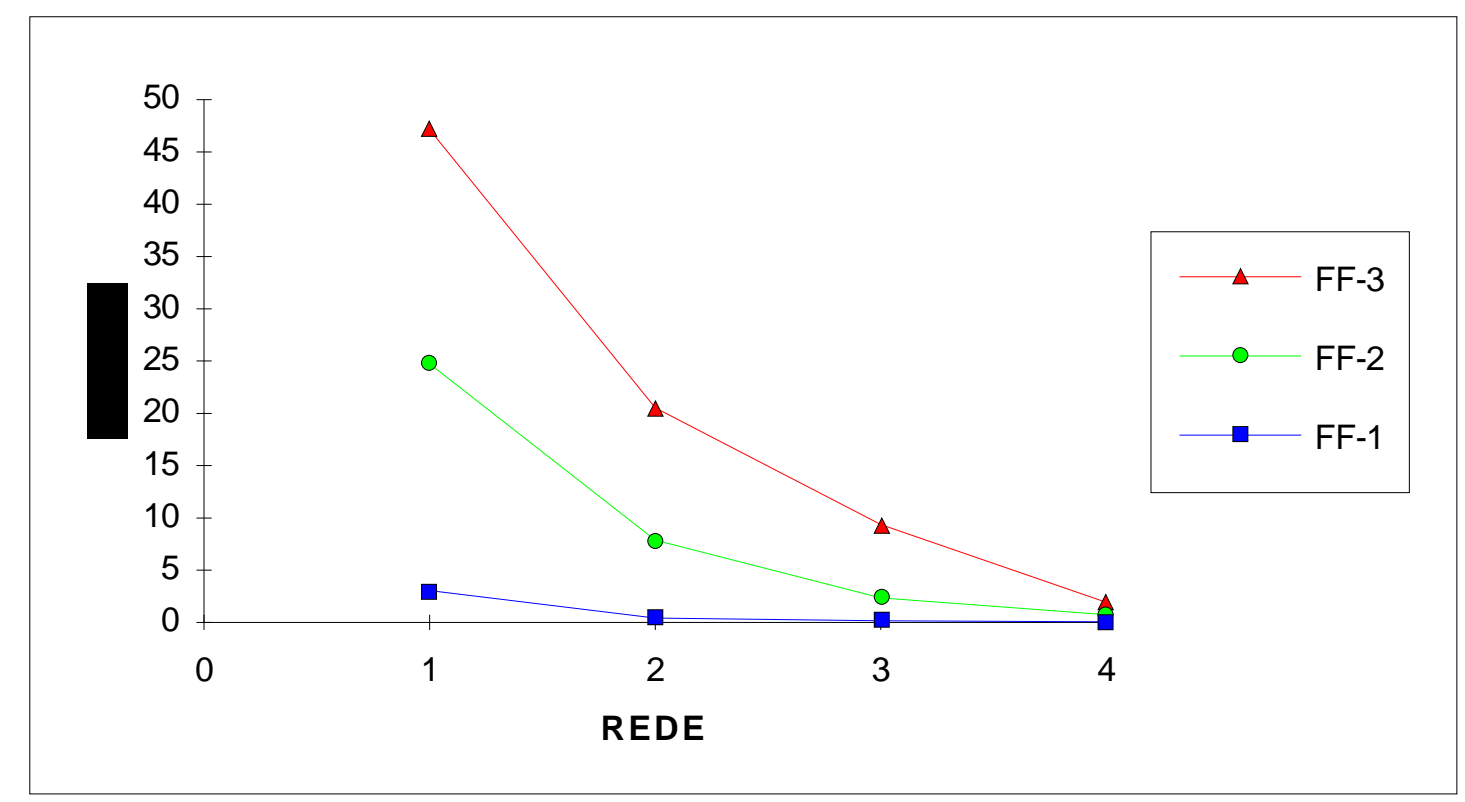

FIGURA 5.4 - Gráfico de convergência dos deslocamentos

TABELA 5.2 - Deslocamento da viga utilizando-se elementos quadrilaterais. 


\begin{tabular}{|l|c|c|c|c|}
\hline \multicolumn{5}{|c|}{ DESLOCAMENTO NO PONTO C } \\
\hline ELEMENTO & $\begin{array}{c}1 \\
(4 \times 1)\end{array}$ & $\begin{array}{c}2 \\
(8 \times 2)\end{array}$ & $\begin{array}{c}3 \\
(16 \times 4)\end{array}$ & $\begin{array}{c}4 \\
(32 \times 8)\end{array}$ \\
\hline CST & 0.20583 & 0.29842 & 0.33875 & 0.35112 \\
\hline FF-1 $(\alpha=1.5, \beta=0.5)$ & 0.29874 & 0.35292 & 0.35657 & 0.35536 \\
\hline FF-2 $(\alpha=1.5, \beta=1.0)$ & 0.25229 & 0.33192 & 0.35027 & 0.35502 \\
\hline FF-3 $(\alpha=1.0, \beta=1.0)$ & 0.24516 & 0.32476 & 0.34750 & 0.35422 \\
\hline ISOPARAMÉTRICO & 0.34933 & 0.35181 & 0.35438 & 0.35618 \\
\hline VALOR TEÓRICO & \multicolumn{5}{|c|}{0.35583} \\
\hline
\end{tabular}

Utilizando-se o elemento quadrilateral nota-se que a convergência do elemento CST e do elemento isoparamétrico melhora se comparado com o triangular. Já a performance do elemento desenvolvido pela formulação livre apresenta melhores resultados para o elemento triangular.

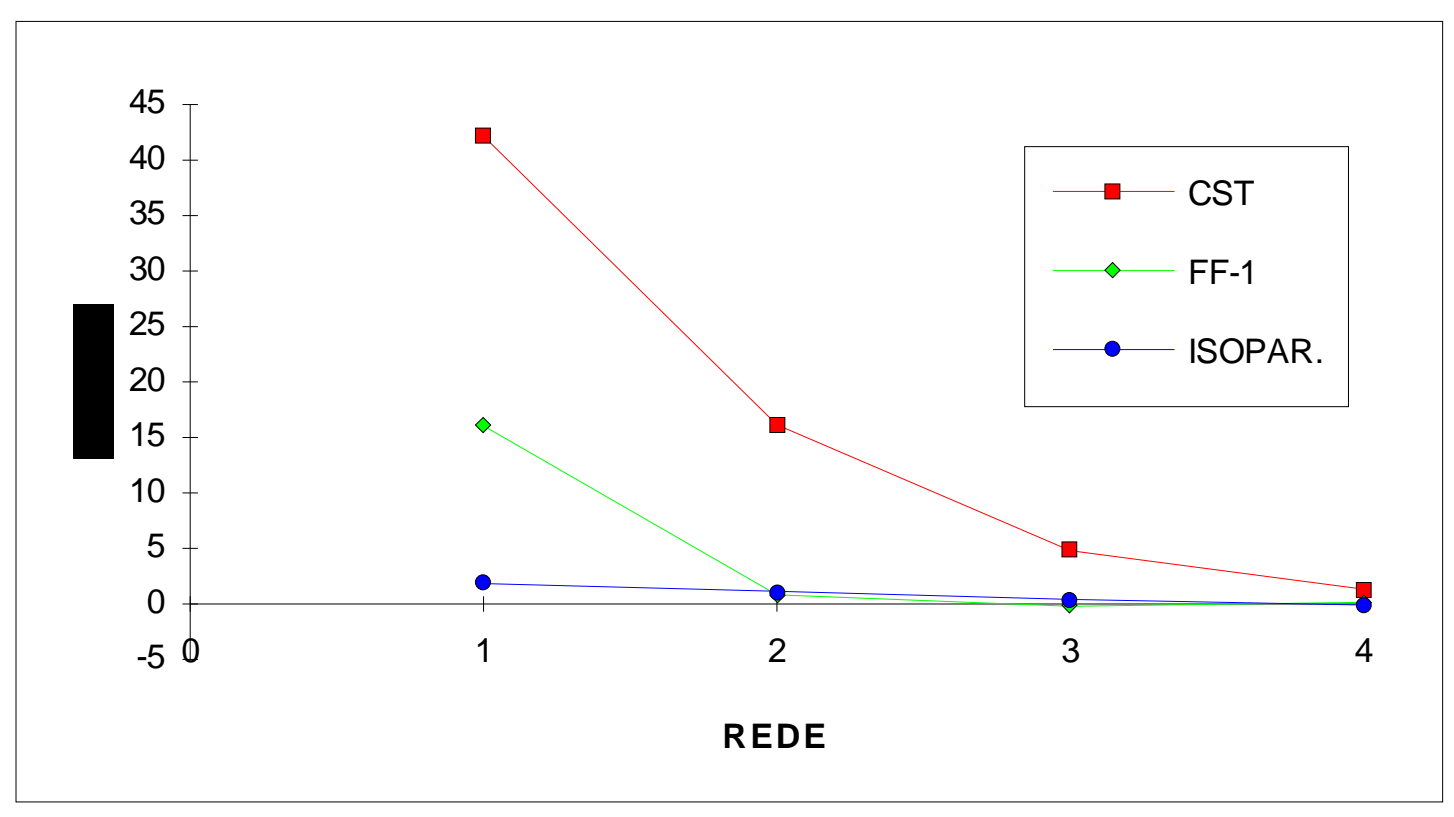

FIGURA 5.5 - Gráfico de convergência dos deslocamentos 


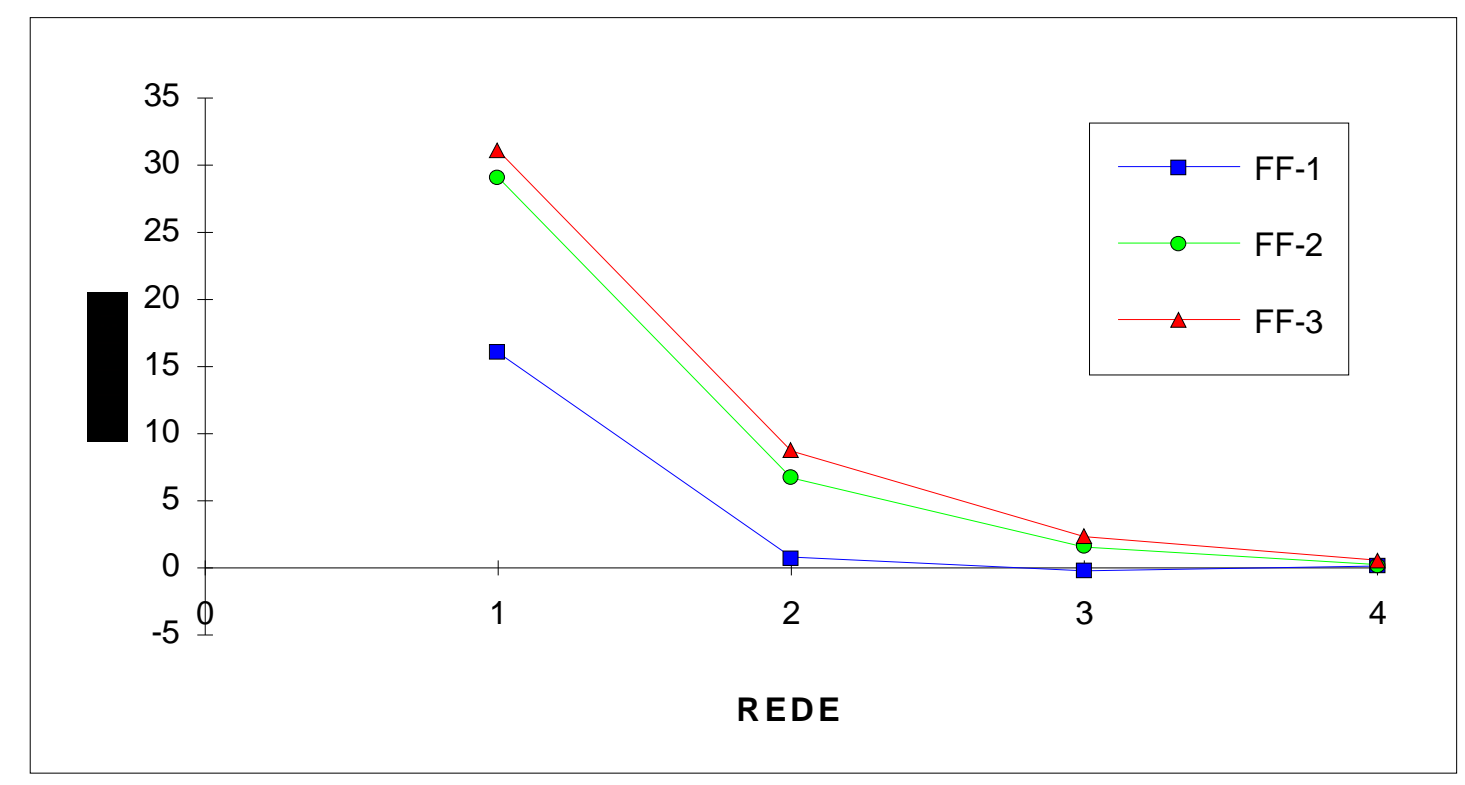

FIGURA 5.6 - Gráfico de convergência dos deslocamentos

$\mathrm{Na}$ tabela 5.3 mostra-se os valores das componentes de tensão obtidos para a discretização de $(4 \times 16)$ na seção da viga referente à $x=12.0$.

TABELA 5.3 - Tensões na viga considerando-se a rede de (4×16).

\begin{tabular}{|l|c|c|c|c|c|}
\hline TENSÃO & Coord. $X$ & Coord. $Y$ & Teoria & CST & FF \\
\hline$\sigma_{x}$ & 12.0 & 6.0 & -60.00 & -41.10 & -54.56 \\
\hline$\sigma_{x}$ & 12.0 & 3.0 & -30.00 & -25.08 & -30.09 \\
\hline$\sigma_{x}$ & 12.0 & 0.0 & 0.00 & -0.41 & -0.15 \\
\hline$\sigma_{x}$ & 12.0 & -3.0 & 30.00 & 24.38 & 29.75 \\
\hline$\sigma_{x}$ & 12.0 & -6.0 & 60.00 & 41.87 & 55.56 \\
\hline$\tau_{x y}$ & 12.0 & 6.0 & 0.00 & 0.47 & 3.04 \\
\hline$\tau_{x y}$ & 12.0 & 3.0 & 3.75 & 3.20 & 3.55 \\
\hline$\tau_{x y}$ & 12.0 & 0.0 & 5.00 & 4.31 & 4.91 \\
\hline$\tau_{x y}$ & 12.0 & -3.0 & 3.75 & 3.34 & 3.61 \\
\hline$\tau_{x y}$ & 12.0 & -6.0 & 0.00 & 3.91 & 0.15 \\
\hline
\end{tabular}


Nota-se que para as tensões normais, $\sigma_{x}$, os resultados obtidos com a formulação livre são melhores que os resultados obtidos com o elemento CST, apesar de se apresentarem subestimados em relação aos valores teóricos. Observa-se que para as tensões de cisalhamento, $\tau_{\mathrm{xy}}$, os valores obtidos nos nós extremos apresentam resíduos. Isto se deve à rede adotada. Como esta não apresenta simetria, os resultados obtidos para as tensões não são simétricos. Esta rede foi escolhida para manter a coerência nas comparações feitas com o trabalho de BERGAN \& FELIPPA (1984). Se adotarmos uma rede simétrica, figura 5.7 , os resultados melhoram significativamente como pode ser visto na tabela 5.4.

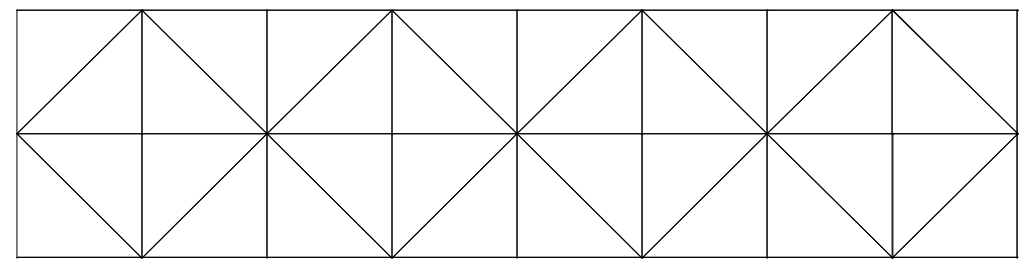

FIGURA 5.7 - Rede simétrica para elemento triangular $(8 \times 2)$

TABELA 5.4 - Tensões na viga considerando-se a rede simétrica de (4×16).

\begin{tabular}{|c|c|c|c|c|}
\hline TENSÃO & Coord. $X$ & Coord. Y & Teoria & FF \\
\hline$\sigma_{x}$ & 12.0 & 6.0 & -60.00 & -60.38 \\
\hline$\sigma_{x}$ & 12.0 & 3.0 & -30.00 & -29.88 \\
\hline$\sigma_{x}$ & 12.0 & 0.0 & 0.00 & 0.00 \\
\hline$\sigma_{x}$ & 12.0 & -3.0 & 30.00 & 29.88 \\
\hline$\sigma_{x}$ & 12.0 & -6.0 & 60.00 & 60.38 \\
\hline$\tau_{x y}$ & 12.0 & 6.0 & 0.00 & 1.84 \\
\hline$\tau_{x y}$ & 12.0 & 3.0 & 3.75 & 3.62 \\
\hline$\tau_{x y}$ & 12.0 & 0.0 & 5.00 & 4.92 \\
\hline$\tau_{x y}$ & 12.0 & -3.0 & 3.75 & 3.62 \\
\hline$\tau_{x y}$ & 12.0 & -6.0 & 0.00 & 1.84 \\
\hline $5.3 x$
\end{tabular}

5.3. EXEMPLO 2 
Considera-se, neste exemplo, o problema proposto por COOK (1974), ilustrado na figura 5.8. O exemplo foi elaborado como um teste para elementos de membrana. A solução analítica não é conhecida. Para efeito de comparação adota-se o resultado obtido por BERGAN \& FELIPPA (1985) com uma rede de (32 x 32). A notação utilizada para as diferentes discretizações é a mesma do exemplo 1, ou seja, $\left(N_{x} \times N_{y}\right)$, onde $N_{x}$ é o número de subdivisões na direção $x$ e $N_{y}$ é o número de subdivisões na direção y. As restrições impostas são o impedimento das duas translações nos nós correspondentes à seção $\mathrm{x}=0$.

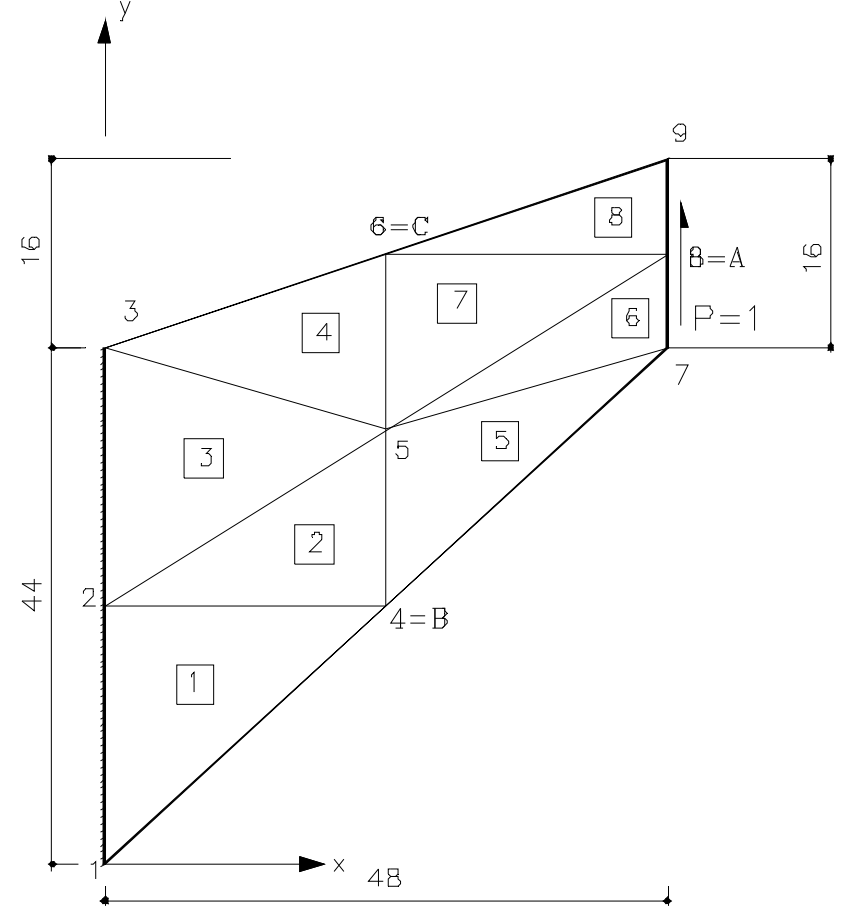

FIGURA 5.8 - Rede típica para elemento triangular (2×2)

$\mathrm{Na}$ tabela 5.5 apresentam-se os resultados obtidos para 0 deslocamento do ponto $A$, utilizando-se o elemento desenvolvido no presente trabalho. Para efeito de comparação apresentam-se os valores obtidos por CHEN (1992), utilizando-se o elemento formulado por ALLMAN (1984). O elemento original, desenvolvido por Allman, possui três graus de 
liberdade por nó, duas translações e uma rotação, e foi desenvolvido pela formulação padrão via energia potencial. O elemento foi formulado adotando-se um campo de deslocamento com aproximação cúbica. Em seu trabalho, Chen analisa os resultados obtidos com o elemento do Allman desenvolvido com integração normal, designado por $(n=6)$, e utiliza uma integração normal reduzida para aperfeiçoar o elemento, esse elemento melhorado é designado por $(n=4)$.

TABELA 5.5 - Deslocamento da viga no ponto A.

\begin{tabular}{|l|c|c|c|c|}
\hline \multicolumn{5}{|c|}{ DESLOCAMENTO NO PONTO A } \\
\hline ELEMENTO & $\begin{array}{c}1 \\
(2 \times 2)\end{array}$ & $\begin{array}{c}2 \\
(4 \times 4)\end{array}$ & $\begin{array}{c}3 \\
(8 \times 8)\end{array}$ & $\begin{array}{c}4 \\
(16 \times 16)\end{array}$ \\
\hline CST & 11.99 & 18.28 & 22.02 & 23.41 \\
\hline FF $(\alpha=1.5, \beta=0.5)$ & 20.37 & 22.42 & 23.41 & 23.79 \\
\hline ALLMAN $(n=6)$ & 18.58 & 21.78 & & \\
\hline ALLMAN $(n=4)$ & 21.78 & 22.65 & & \\
\hline VALOR ESPERADO & \multicolumn{5}{|c|}{23.91} \\
\hline
\end{tabular}

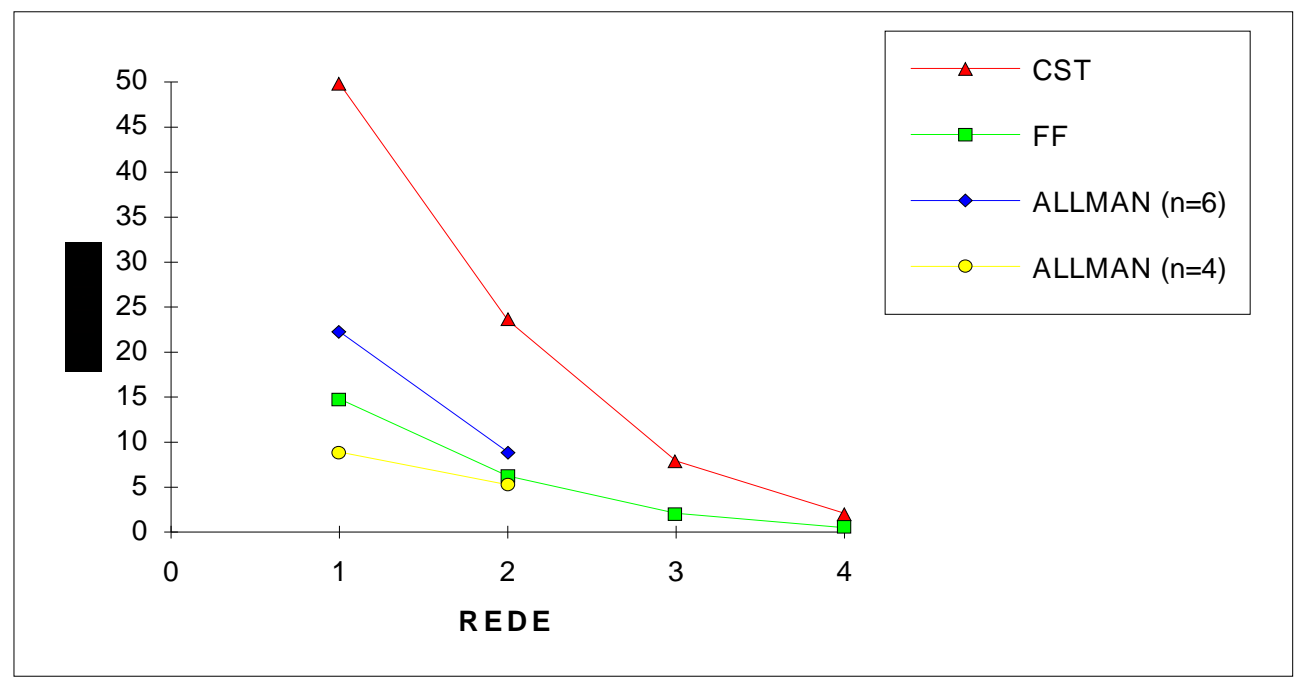

FIGURA 5.9 - Gráfico de convergência dos deslocamentos 
Nota-se que a convergência do elemento baseado na formulação livre é bem superior à convergência do elemento CST. Comparando-se os resultados obtidos com o elemento do Allman desenvolvido com a integração normal $(n=6)$ com os resultados obtidos utilizando-se a formulação livre, nota-se que essa última apresenta resultados melhores. Para o elemento desenvolvido com a integração normal reduzida $(n=4)$, os resultados obtidos são melhores que os obtidos com a formulação livre.

TABELA 5.6 - Tensão máxima no ponto B.

\begin{tabular}{|l|c|c|c|c|}
\hline \multicolumn{5}{|c|}{ TENSÃO MÁXIMA NO PONTO B } \\
\hline ELEMENTO & $\begin{array}{c}1 \\
(2 \times 2)\end{array}$ & $\begin{array}{c}2 \\
(4 \times 4)\end{array}$ & $\begin{array}{c}3 \\
(8 \times 8)\end{array}$ & \begin{tabular}{c}
$(16 \times 16)$ \\
\hline CST
\end{tabular} \\
\hline FF $(\alpha=1.5, \beta=0.5)$ & 0.0792 & 0.1508 & 0.2000 & 0.2217 \\
\hline ALLMAN $(n=6)$ & 0.1048 & 0.1747 & & 0.2347 \\
\hline ALLMAN $(n=4)$ & 0.1182 & 0.1792 & & \\
\hline VALOR ESPERADO & \multicolumn{5}{|c|}{0.2359} \\
\hline
\end{tabular}

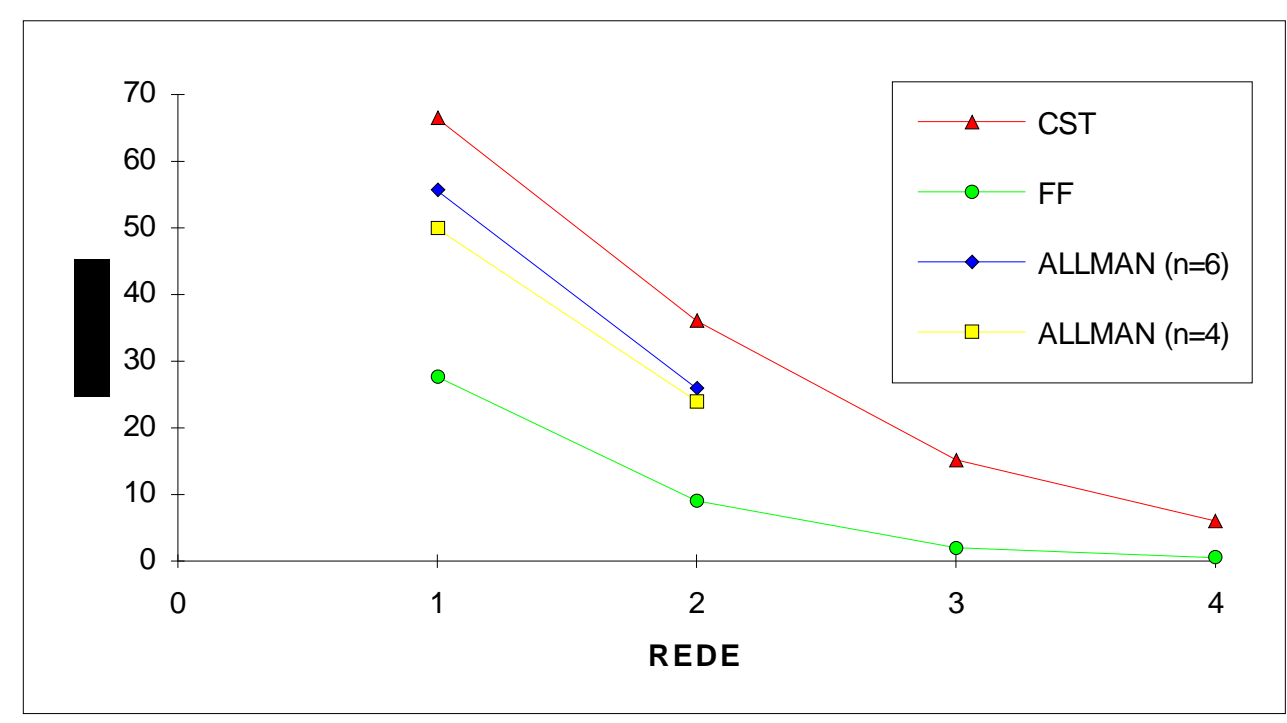

FIGURA 5.10 - Gráfico de convergência da tensão máxima no ponto $B$ TABELA 5.7 - Tensão mínima no ponto C. 


\begin{tabular}{|l|c|c|c|c|}
\hline \multicolumn{5}{|c|}{ TENSÃO MÍNIMA NO PONTO C } \\
\hline ELEMENTO & $\begin{array}{c}1 \\
(2 \times 2)\end{array}$ & $\begin{array}{c}2 \\
(4 \times 4)\end{array}$ & $\begin{array}{c}3 \\
(8 \times 8)\end{array}$ & $\begin{array}{c}4 \\
(16 \times 16)\end{array}$ \\
\hline CST & -0.0464 & -0.1064 & -0.1579 & -0.1847 \\
\hline FF $(\alpha=1.5, \beta=0.5)$ & -0.1856 & -0.1726 & -0.1903 & -0.1981 \\
\hline ALLMAN $(n=6)$ & -0.1098 & -0.1484 & & \\
\hline ALLMAN $(n=4)$ & -0.1341 & -0.1578 & & \\
\hline VALOR ESPERADO & \multicolumn{5}{|c|}{-0.2012} \\
\hline
\end{tabular}

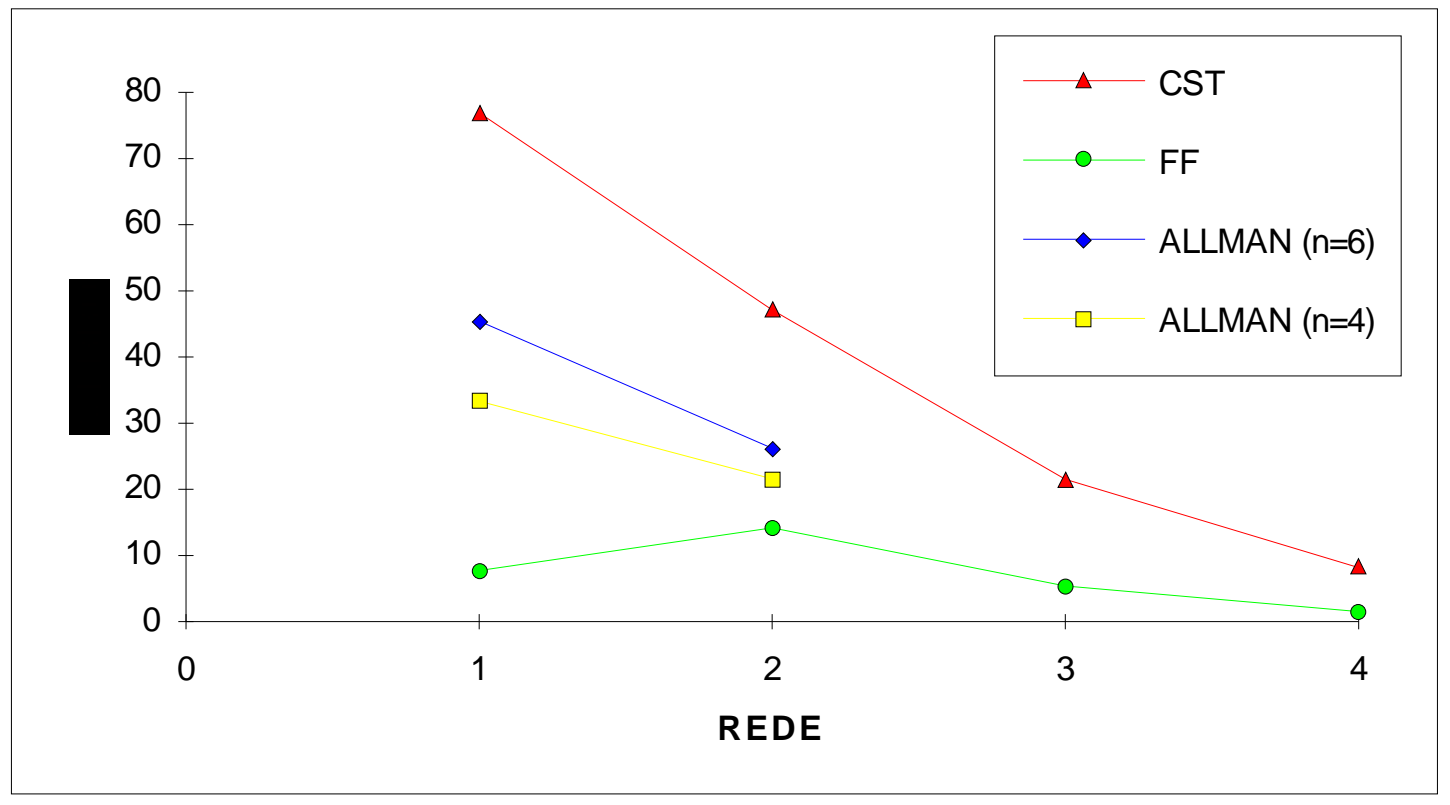

FIGURA 5.11 - Gráfico de convergência da tensão mínima no ponto C

Para os valores das tensões percebe-se que a convergência do elemento desenvolvido através da formulação livre apresenta-se superior tanto ao CST quanto ao elemento desenvolvido por Allman e ao elemento aperfeiçoado por Chen. Analisando-se a figura 5.11 verifica-se que a convergência do elemento desenvolvido com a formulação livre não ocorre de forma monotônica. Esse fato é uma característica da formulação de elementos não conformes, que garante a convergência dos resultados, mas não garante que a convergência ocorra de forma monotônica. Entretanto, 
mesmo com essa característica, os resultados obtidos com o elemento desenvolvido convergem de maneira mais rápida e são melhores que os resultados obtidos com os outros elementos utilizados para as comparações.

\subsection{EXEMPLO 3}

A figura 5.12 mostra a planta de um núcleo de elevador de seção transversal delgada aberta. A estrutura é de concreto armado, com paredes de espessura constante de $25 \mathrm{~cm}$. O edifício possui 15 andares de 4,00 m de pé-direito cada um. O módulo de elasticidade longitudinal $E$, é de 14.486.600 kN/m² e o módulo de elasticidade transversal G, é de 6.036 .700 $\mathrm{kN} / \mathrm{m}^{2}$.

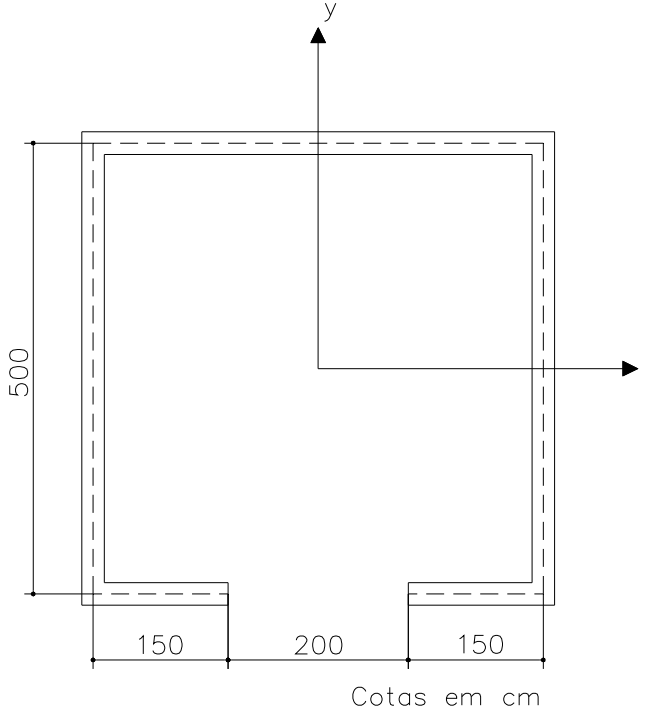

FIGURA 5.12 - Planta do núcleo do elevador

O carregamento aplicado, conforme figura 5.13, consiste de duas cargas concentradas aplicadas no topo da estrutura, as cargas são aplicadas distribuídas nos nós. No primeiro caso aplica-se uma ação horizontal $\mathrm{H}=600 \mathrm{kN}$ no sentido do eixo $\mathrm{y}$, no segundo caso aplica-se a mesma ação no sentido do eixo x. Em ambos os casos aplica-se uma carga 
vertical V $=30.000 \mathrm{kN}$. O núcleo é suposto rigidamente engastado na sua base.

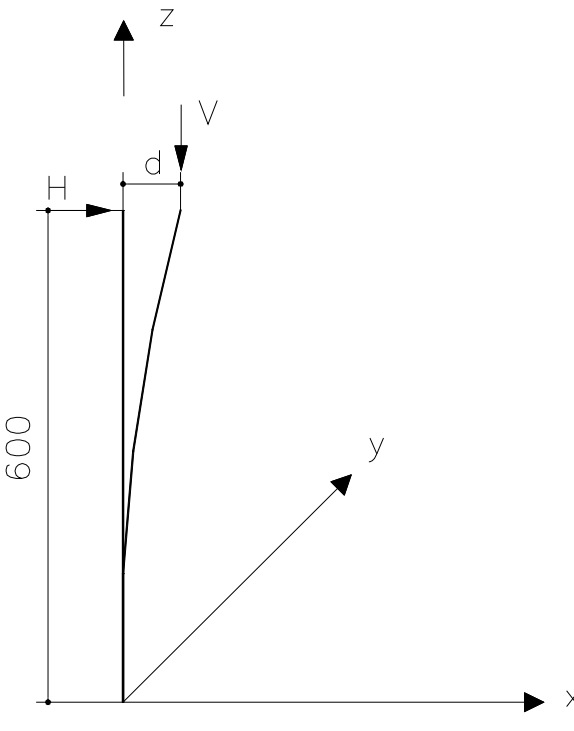

FIGURA 5.13- Carregamentos aplicados ao núcleo

Este exemplo, apresentado por MORI (1992), possui solução analítica. A finalidade da sua apresentação é demonstrar o bom funcionamento do elemento em planos diferentes no espaço.

O deslocamento teórico do topo do núcleo, a flecha calculada na extremidade livre, pode ser obtido através da equação:

$$
d=\frac{P \cdot L^{3}}{3 \cdot E \cdot I}
$$

onde,

$\mathrm{d}=$ deslocamento na direção da ação aplicada

$\mathrm{P}=$ ação horizontal

$\mathrm{L}=$ comprimento (altura)

$E=$ módulo de elasticidade transversal

$\mathrm{I}$ = momento de inércia da seção 
$\mathrm{Na}$ figura 5.14 ilustra-se a discretização utilizada. Os resultados analíticos e os obtidos com o elemento desenvolvido são apresentados na tabela 5.8.

TABELA 5.8- Deslocamento no topo da estrutura

\begin{tabular}{|c|c|c|c|}
\hline \multicolumn{3}{|c|}{ Deslocamento no topo da estrutura (d) em metros } \\
\hline \multicolumn{2}{|c|}{ CASO 1 } & \multicolumn{2}{|c|}{ CASO 2} \\
$(\mathrm{H}$ - Direção do eixo y $)$ & (H - Direção do eixo $x)$ \\
\hline ANALÍTICO & FF & ANALÍTICO & FF \\
\hline 0.171767 & 0.171499 & 0.144293 & 0.148309 \\
\hline
\end{tabular}

Através da análise dos resultados nota-se que os valores obtidos com o programa estão bem próximos dos resultados analíticos. Este exemplo não só confirma os bons resultados obtidos com o uso do elemento, mas também comprova que a sua implementação ao sistema LASER foi bem sucedida. Fica claro que a obtenção da matriz de rigidez no sistema local e a sua posterior rotação para o sistema de referência global funciona perfeitamente. Com este exemplo garante-se que o programa tem condições de analisar uma estrutura independentemente da posição em que ela se encontra no espaço. 


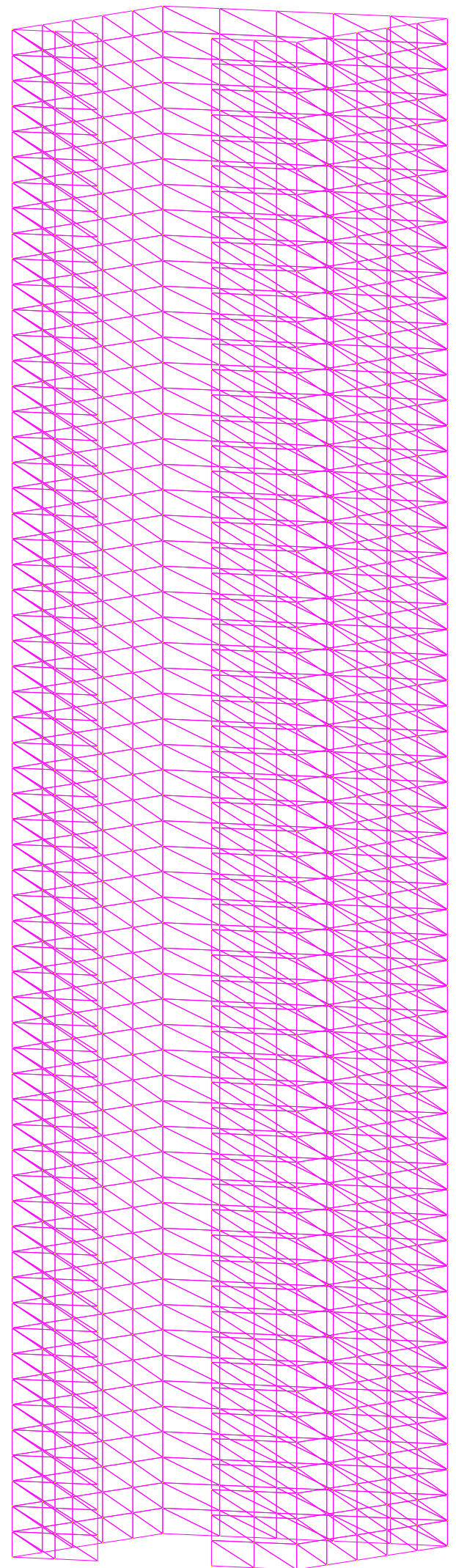

FIGURA 5.14 - Discretização do núcleo 


\subsection{EXEMPLO 4}

Neste exemplo pretende-se avaliar o desempenho da ligação de elementos de barra ao elemento de membrana desenvolvido. A análise será feita avaliando-se o deslocamento no topo de duas paredes, quando submetidas a uma ação horizontal. Avalia-se o deslocamento das paredes isoladas e compara-se com o deslocamento obtido quando se supõe a ligação por lintéis. No caso das paredes ligadas fazem-se duas discretizações: a primeira utilizando-se os elementos de barra para discretizar os lintéis e a segunda exclusivamente com a utilização dos elementos de membrana.

As paredes, cuja situação em planta é apresentada na figura 5.15, são supostas de concreto armado, com espessura constante de $20 \mathrm{~cm}$, módulo de elasticidade longitudinal $E=2.000 .000 \mathrm{kN} / \mathrm{m}^{2}$ e módulo de elasticidade transversal $G=800.000 \mathrm{kN} / \mathrm{m}^{2}$. A estrutura tem um total de 12 $\mathrm{m}$ de altura e os lintéis, quando existentes, são dispostos a cada $3 \mathrm{~m}$.

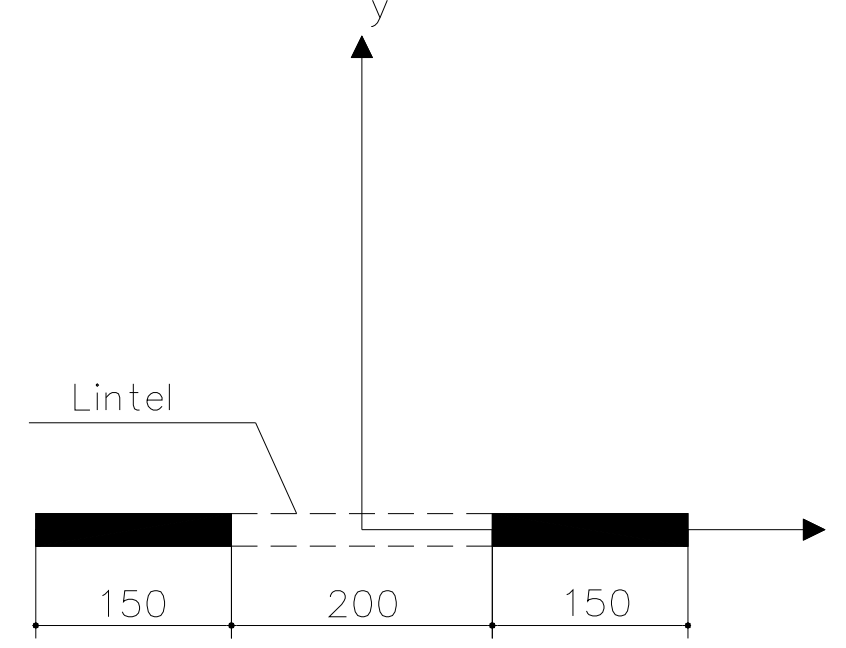

FIGURA 5.15 - Planta das paredes 
Para as paredes isoladas, a vista frontal e a discretização adotada estão ilustradas na figura 5.16. O carregamento é aplicado segundo a direção $x$, no topo da estrutura, e consiste de duas cargas concentradas de $30 \mathrm{kN}$ aplicadas uma em cada parede.

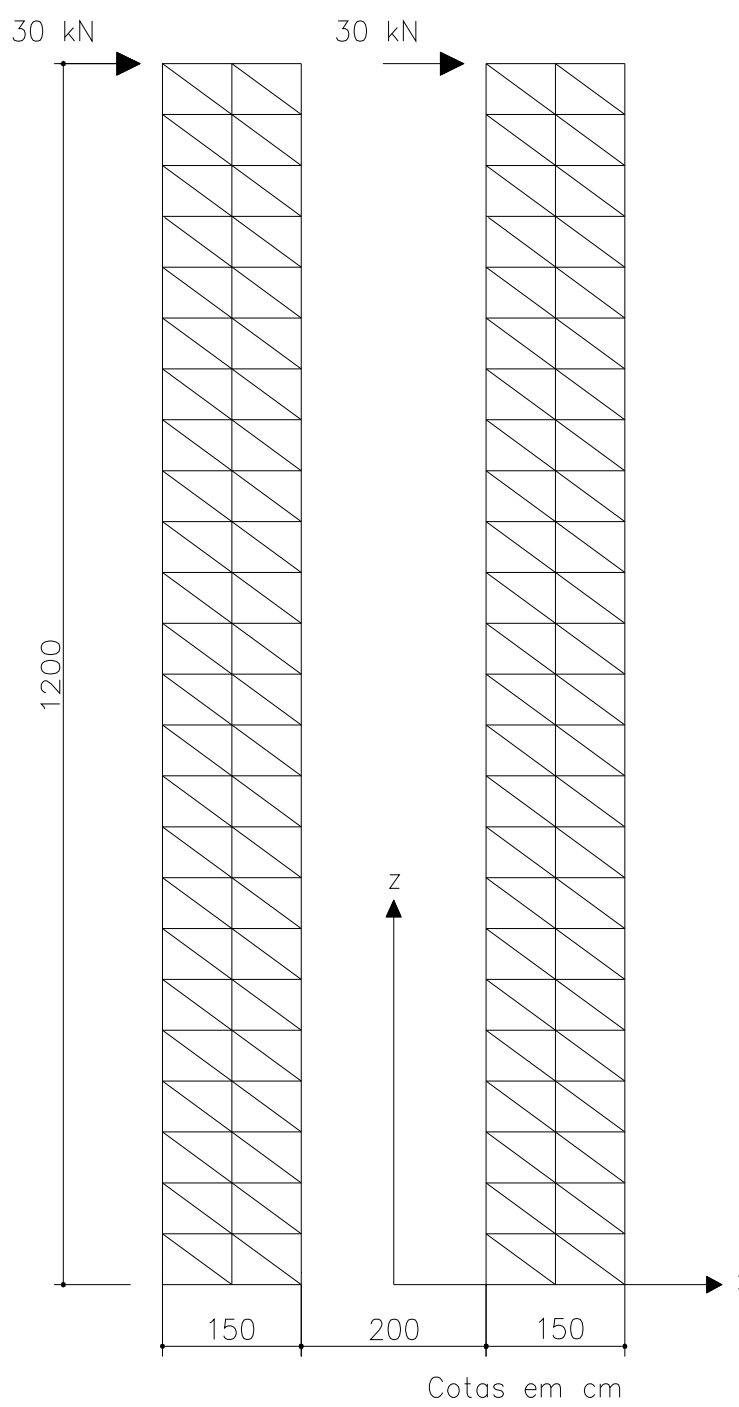

FIGURA 5.16 - Vista frontal das paredes quando isoladas

De acordo com a equação 5.1, obtém-se o deslocamento analítico de $0.1536 \mathrm{~m}$ no topo de cada uma das paredes. Utilizando-se o elemento desenvolvido obtém-se o valor de $0.1534 \mathrm{~m}$. 
Para se avaliar o acréscimo de rigidez do conjunto pela presença dos lintéis e verificar o desempenho da ligação dos elementos de membrana e barra fez-se dois tipos de discretização. No primeiro, figura 5.17, os lintéis são discretizados utilizando-se elementos de barra. No segundo, figura 5.18, os lintéis são discretizados com elementos de membrana. Importante ressaltar que os referidos lintéis são supostos de concreto armado com seção transversal de $20 \mathrm{~cm} \times 50 \mathrm{~cm}$.

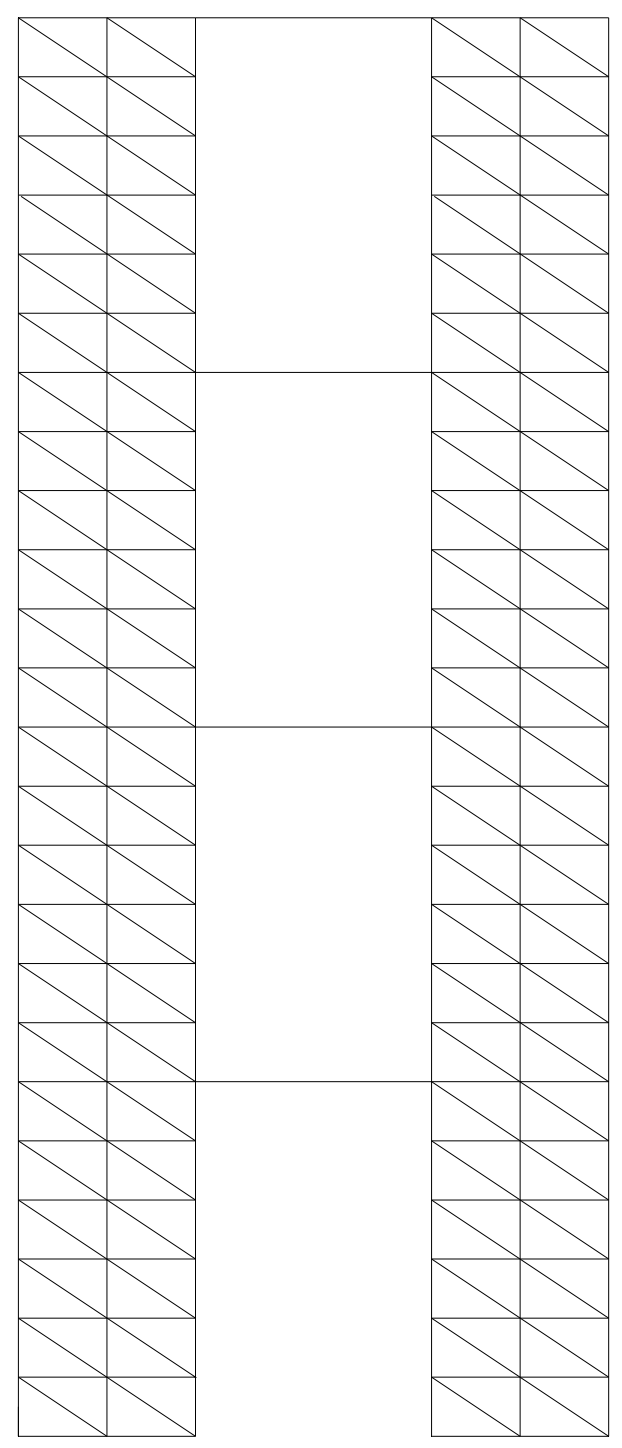

FIGURA 5.17 - Discretização do conjunto com elementos de barra 


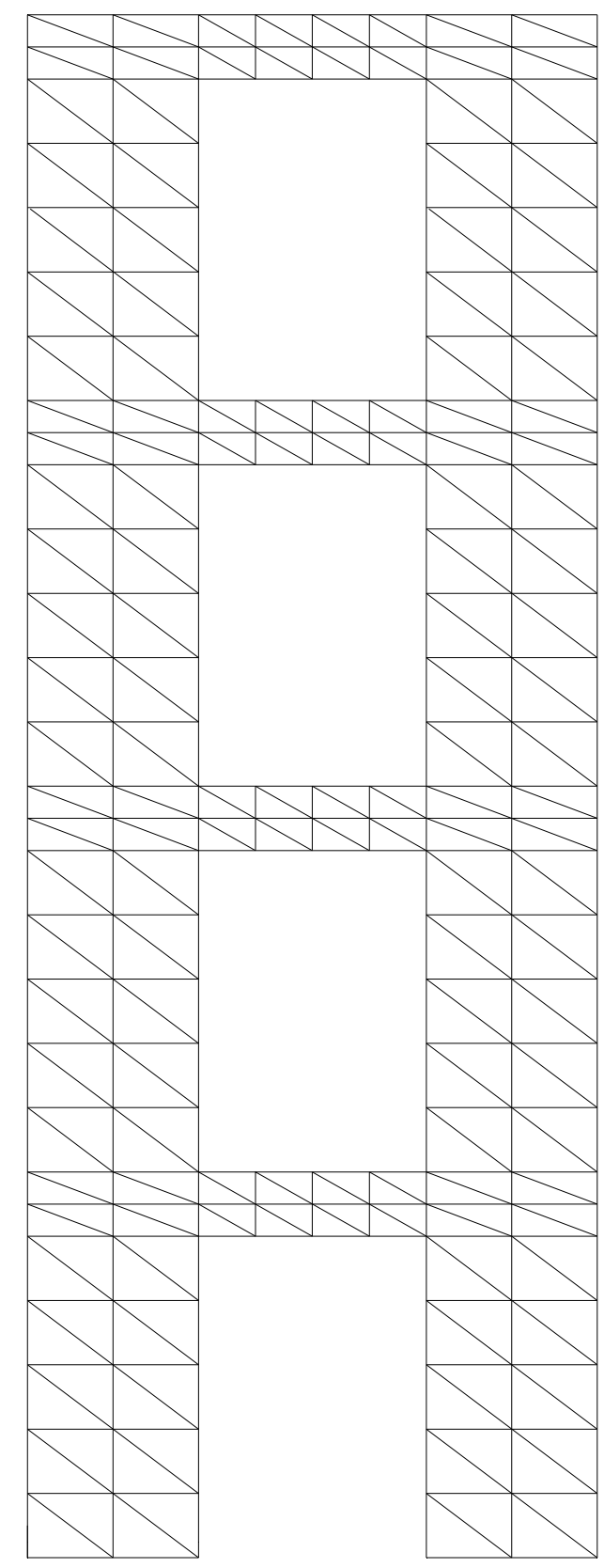

FIGURA 5.18 - Discretização do conjunto com elementos de membrana

$\mathrm{Na}$ tabela 5.9 apresentam-se os resultados para as duas discretizações realizadas.

TABELA 5.9 - Deslocamento no topo do conjunto. 


\begin{tabular}{|l|l|}
\hline \multicolumn{2}{|c|}{ Deslocamento no topo do conjunto ( m ) } \\
\hline Lintéis discretizados com elementos de barra & 0.0417 \\
\hline Lintéis discretizados com elementos de membrana & 0.0326 \\
\hline
\end{tabular}

Pela observação dos resultados da tabela 5.9, em comparação com o resultado obtido com as paredes isoladas, pode-se verificar um significativo aumento da rigidez do conjunto pela consideração dos lintéis. Esse enrijecimento era esperado e pode ser avaliado, com algumas aproximações, por expressões analíticas como as apresentadas em ALBIGES \& GOULET (1960).

Analisando-se, agora, exclusivamente os resultados obtidos para 0 conjunto paredes/lintéis, observa-se uma maior rigidez, quando a discretização é feita utilizando-se apenas elementos de membrana. Isso se deve à discretização adotada. A consideração de apenas dois elementos na altura de cada lintel provavelmente tornou o conjunto mais rígido. Com a discretização através das barras esse efeito foi minorado e o deslocamento resultou maior, o que indica que a ligação barra/membrana funcionou com boa acuidade.

Deve-se, por fim, ressaltar-se que se estivesse sendo utilizado um elemento membrana sem graus de liberdade rotacionais, a dificuldade de se modelar o referido conjunto seria muito maior. Nesse caso, seria necessário providenciar uma penetração do elemento barra nas paredes, para simular a ligação pretendida. Entretanto, essa solução, em qualquer hipótese, não apresenta resultados satisfatórios. 


\section{CAPÍTULO VI CONCLUSÕES}

A finalidade principal deste trabalho foi apresentar o desenvolvimento e a implementação, em um sistema computacional existente, de um novo elemento finito de membrana. Esse elemento possui, além das duas translações por nó em seu próprio plano, rotações em torno do eixo normal a esse plano.

Uma das vantagens do elemento desenvolvido é a aplicação na análise de cascas pelo método dos elementos finitos. É notória a complexidade da análise dessas estruturas, que em geral são analisadas utilizando-se métodos aproximados. Uma das maneiras de se fazer essa análise é a utilização de dois elementos planos, um de placa e um de membrana, que se complementam e acabam funcionando como um verdadeiro elemento de casca.

A dificuldade que surge em tais casos é exatamente a falta do grau de liberdade rotacional no elemento de membrana. A sua ausência dificulta a modelagem de maneira adequada do comportamento da estrutura e faz com que a matriz de rigidez global apresente singularidades no caso de elementos coplanares ou aproximadamente coplanares. A solução para esses casos é impedir o deslocamento ou eliminar esse grau de liberdade global. Entretanto, nem sempre essa é uma tarefa fácil, sobretudo nas cascas abatidas ou estruturas que não se desenvolvam segundo os planos formados pelos eixos do sistema de referência global. Para esses casos será necessária a colocação de coeficientes de molas, convenientemente 
adotados, de forma a eliminar a singularidade e não interferir nos resultados obtidos, o que nem sempre pode ser conseguido.

Entretanto, o elemento desenvolvido não apresenta esse inconveniente, já que ao ser acoplado a um elemento de placa têm-se rigidezes que contribuem para os seis graus de liberdade por nó de um sistema de análise de estruturas tridimensionais. Dessa forma, não existe a necessidade da colocação das referidas molas, sendo que a análise da casca pode ser realizada sem essas imperfeições de modelagem.

Outro ponto importante a respeito dos graus de liberdade rotacionais é que eles possibilitam a ligação com outros elementos de forma simples e respeitando-se condições mais verossímeis de vinculação. É o caso de se ligar elementos de barra aos elementos de membrana, obtendo-se uma estrutura plana que se encontra frequentemente quando se trata da modelagem de painéis de contraventamento de um edifício, no caso, paredes ligadas por lintéis.

Caso se utilize para essa modelagem elementos de membrana sem graus de liberdade rotacionais a ligação com a barra somente pode representar a transmissão de momentos fletores se forem adotados procedimentos de eficácia duvidosa. Entretanto, com a utilização do elemento aqui desenvolvido, pode-se realizar esse tipo de modelagem sem qualquer cuidado especial e os resultados serão obtidos com a representação mais coerente da vinculação mencionada.

O elemento foi desenvolvido utilizando-se a formulação livre, uma alternativa proposta por BERGAN \& NYGARD (1984). Uma vantagem dessa formulação é que através do uso de funções não-conforme de deslocamento se permite o desenvolvimento de elementos com convergência garantida e implementação simples e eficiente. Uma outra vantagem apresentada pela formulação é o fato de se garantir que o patch-test será satisfeito durante o 
próprio desenvolvimento do elemento, não sendo necessários testes posteriores para se verificar essa propriedade. O elemento possibilita atingir resultados suficientemente precisos, sob o ponto de vista prático, com discretizações relativamente pobres.

Os resultados numéricos apresentados no capítulo 5 comprovam o bom desempenho do elemento e mostram que a implementação ao sistema foi corretamente realizada. Com isso, obteve-se uma valiosa ferramenta que pode ser utilizada com segurança para a análise de estruturas submetidas a estado plano de tensão e para análise de cascas, desde que se acople o referido elemento a um elemento de placa também comprovadamente eficiente.

Analisando-se os exemplos 1 e 2 observa-se que tanto o elemento triangular quanto o elemento quadrilateral apresentam um bom desempenho quando submetidos a um carregamento predominante de flexão. Os valores ótimos dos parâmetros livres sugeridos por BERGAN \& FELIPPA (1985) realmente forneceram os melhores resultados, mesmo para redes pouco refinadas. O desempenho do elemento é notadamente superior ao elemento CST (Constant Strain Triangle), pois sua convergência é muito mais rápida e a precisão dos valores obtidos com redes pouco refinadas é muito superior.

Já o exemplo 3, além de confirmar os bons resultados obtidos anteriormente para estados de flexão predominante, assegura que a implementação ao sistema foi feita corretamente. Fica clara a possibilidade de o elemento estar em qualquer posição do espaço.

Com o exemplo 4 conclui-se que a ligação do elemento desenvolvido a um elemento de barra, com transmissão de momento fletor, pode ser realizada de forma simples e eficiente. Esse recurso, bastante importante para algumas modelagens de painéis de contraventamento, pode inclusive servir de ferramenta básica para estudos mais amplos a respeito do 
comportamento desses painéis. Pode-se, por exemplo, construir modelos de estruturas de contraventamento completas, representando-se as paredes através de elementos de membrana e os pilares e vigas através de elementos de barra.

Dessa forma, pode-se dizer que os objetivos principais deste trabalho foram plenamente atingidos, obtendo-se com esse desenvolvimento uma ferramenta adequada à solução dos problemas propostos. 


\section{CAPÍTULO VII REFERÊNCIAS BIBLIOGRÁFICAS}

ALBIGES, M.; GOULET, J. Contreventement des batiments. Annales I.T.B.T.P. n.149, p.473-500, 1960.

ALLMAN, D.J. A compatible triangular element including vertex rotations for plane elasticity analysis. Comput. Structures. v.19, n.1-2, p.1-8,1984.

ALLMAN, D.J. Evaluation of the constant strain triangle with drilling rotations. Int. j. numer. methods eng. v. 26, p.2645-2655, 1988.

ALMROTH, B.O.; BROGAN, F.A. Numerical procedures for analysis of structural shells. Thecnical rept. AFWAL-TR-80-3129, Lockheed Palo Alto Research Laboratory, Palo alto, CA, 1981

BATOZ, J.L.; TAHAR, M.B. Evaluation of a new quadrilateral thin plate bending element. Int. j. numer. methods eng. v. 18, p.1655-1677, 1982.

BERGAN, P.G. Triangular element with 6 parameters at each node. In: Plane stress analysis using the finite element method. Division of structural mechanics. The Norwegian institute of technology, Trondheim, Norway, 1967.

BERGAN, P.G. Finite elements based on energy orthogonal functions. Int. $j$. numer. methods eng. v. 15, p.1541-1555, 1980. 
BERGAN, P.G.; FELIPPA, C.A. A triangular membrane element with rotational degrees of freedom. Comp. Meths. Appl. Mech. Engrg., v.50, p.25-69,1985.

BERGAN, P.G.; FELIPPA, C.A. Efficient implementation of a triangular membrane element ith drilling freedoms. In: HUGHES, T.J.R.; HINTON, E. Finite element methods for plate and shell structures. 1.ed. Swansea,U.K.,1986. Cap.5, p.128-152.

BERGAN, P.G.; HANSSEN, L. A new approach for deriving 'good' element stiffness matrices. In: WHITEMAN J.R. The mathematics of finite elements and applications II. London, Academic Press, 1978. p.8396.

BERGAN, P.G.; NYGARD, M.K. Finite elements with increased freedom in choosing shape functions. Int. j. numer. methods eng. v.20, p.643663, 1984.

CARR, A.J. Refined finite element analysis of thin shell structures including dynamic loadings. Berkeley, 1967. Tese (Doutorado) - University of California.

CHEN, H.C. Evaluation of Allman triangular membrane element used in general shell analyses. Comput. Structures. v.43, n.5, p.881-887, 1992.

COOK, R.D. Improved two-dimensional finite element. J. Structural Div. ASCE. v.9, p.1851-1863, 1974.

COOK, R.D. Ways to improve the bending response of finite elements. Int. $j$. numer. methods eng. v. 11, p.1029-1039, 1977. 
COOK, R.D. A plane hybrid element with rotational D.O.F. and adjustable stiffness. Int. j. numer. methods eng. v. 24, p.1499-1508, 1987.

COOK, R.D.; MALKUS, D.S.; PLESHA, M.E. Concepts and applications of finite element analysis. 3.ed. Madison, John Wiley \& Sons,1989.

CORRÊA, M.R.S. Aperfeiçoamento de modelos usualmente empregados no projeto de sistemas estruturais de edifícios. São Carlos, 1991. 331p. Tese (Doutorado) - Escola de Engenharia de São Carlos, Universidade de São Paulo.

FELIPPA, C.A. Refined finite element analysis of linear and nonlinear twodimensional structures. Berkeley, 1966. Tese (Doutorado) University of California.

FELIPPA, C.A.; MILITELLO, C. Variational formulation of high-performance finite elements: parametrized variational principles. Comput. Structures. v.36, n.1,p.1-11,1990.

HUGHES, T.J.R.; MASUD, A.; HARARI, I. Numerical assessment of some membrane elements with drilling degrees of freedom. Comput. Structures. v.55, n.2, p.297-314,1995.

IBRAHIMBEGOVIC, A. A novel membrane finite element with an enhanced displacement interpolation. Finite elements analysis and design. v.7, p.167-179, 1990.

IRONS, B.; AHMAD, S. Techniques of finite elements. 2.ed. Chichester, John Wiley \& Sons, 1981. 
IRONS, B. et al. Triangular elements in plate bending - conforming and nonconforming solutions. Proc. conf. on matrix methods in structural mechanics. p.547-576,1965.

MORI, D.D. Os núcleos estruturais e a não-linearidade geométrica na análise de estruturas tridimensionais de edifícios altos. São Carlos, 1992. 195p. Tese (Doutorado) - Escola de Engenharia de São Carlos, Universidade de São Paulo.

NAVARRA, E.O.I. Calculo de estructuras por el metodo de elementos finitos. 1.ed. Barcelona, Artes Gráficas Torres, 1992.

RAMALHO, M.A. Sistema para análise de estruturas considerando interação com meio elástico. São Carlos, 1990. 389p. Tese (Doutorado) Escola de Engenharia de São Carlos, Universidade de São Paulo.

RAZZAQUE, A. The patch test for elements. Int. j. numer. methods eng. v. 22, p.63-71, 1986.

ROCKEY, K.C. et al. The finite element method. 2.ed. New york, Halsted Press, 1985.

SZE, K.Y.; WANJI, C.; CHEUNG, Y.K. An efficient quadrilateral plane element with drilling degrees of freedom using orthogonal stress model. Comput. Structures. v.42, n.5, p.695-705,1992.

TAIG I.C.; KERR R.I. Some problems in the discrete element representation of aircraft structures. In: FRAEIJS DE VEUBEKE, B.M. Matrix methods of structural analysis. London, Pergamon Press, 1964. 
TAYLOR, R.L.; BERESFORD, P.J.; WILSON, E.L. A non-conforming element for stress analysis. Int. j. numer. methods eng. v. 10, p.12111219, 1976.

TAYLOR, R.L.; SIMO, J.C. The patch test - a condition for assessing FEM convergence. Int. j. numer. methods eng. v. 22, p.39-62, 1986.

TIMOSHENKO, S.P.; GOODIER, J.N. Teoria da elasticidade. 3.ed. Rio de Janeiro, Guanabara Dois, 1990.

TOCHER, J.L.; HARTZ, B. Higher order finite element for plane stress. Proc. ASCE, J. Engrg. Mech. Div., v.93, p.149-174,1967.

TURNER, M.J. et al. Stiffness and deflection analysis of complex structures. J. Aero. Sci., v.23, n.9, p.805-823, 1956.

VALLIAPAN, S. Continuum mechanics. 1.ed. Rotterdam, A. A. Balkema, 1981.

VILLAÇA, S.F.; GARCIA, L.F.T. Introdução à teoria da elasticidade. 1.ed. Rio de Janeiro, COPPE/UFRJ, 1996.

WILLIAM, K.J. Finite element analysis of cellular structures. Berkeley, 1969. Tese (Doutorado) - University of California.

ZIENKIEWICZ,O.C. The finite element method. London, Mcgraw-Hill Book Company, 1985. 